\title{
Therapeutic Mechanisms of Herbal Medicines Against Insulin Resistance: A Review
}

\author{
Jun Li ${ }^{1,2}$, Litao Bai ${ }^{1}$, Fan Wei ${ }^{1}$, Jing Zhao ${ }^{1}$, Danwei Wang ${ }^{1}$, Yao Xiao ${ }^{1}$, Weitian Yan ${ }^{1}$ \\ and Junping Wei ${ }^{1 *}$
}

\footnotetext{
${ }^{1}$ Department of Endocrinology, Guang'anmen Hospital, China Academy of Chinese Medical Sciences, Beijing, China, ${ }^{2}$ Graduate School, Beijing University of Chinese Medicine, Beijing, China
}

\section{OPEN ACCESS}

Edited by:

Alejandro Urzua,

Universidad de Santiago de Chile,

Chile

Reviewed by:

Susan Semple,

University of South Australia,

Australia

Yun K. Tam,

Sinoveda Canada Inc., Canada

${ }^{*}$ Correspondence:

Junping Wei

weijunping@126.com

Specialty section: This article was submitted to

Ethnopharmacology,

a section of the journal

Frontiers in Pharmacology

Received: 17 December 2018 Accepted: 23 May 2019

Published: 14 June 2019

Citation:

Li J, Bai L, Wei F, Zhao J, Wang D, Xiao Y, Yan W and Wei J (2019)

Therapeutic Mechanisms of Herbal Medicines Against Insulin Resistance: A Review. Front. Pharmacol. 10:661. doi: 10.3389/fphar.2019.00661
Insulin resistance is a condition in which insulin sensitivity is reduced and the insulin signaling pathway is impaired. Although often expressed as an increase in insulin concentration, the disease is characterized by a decrease in insulin action. This increased workload of the pancreas and the consequent decompensation are not only the main mechanisms for the development of type 2 diabetes (T2D), but also exacerbate the damage of metabolic diseases, including obesity, nonalcoholic fatty liver disease, polycystic ovary syndrome, metabolic syndrome, and others. Many clinical trials have suggested the potential role of herbs in the treatment of insulin resistance, although most of the clinical trials included in this review have certain flaws and bias risks in their methodological design, including the generation of randomization, the concealment of allocation, blinding, and inadequate reporting of sample size estimates. These studies involve not only the single-flavored herbs, but also herbal formulas, extracts, and active ingredients. Numerous of in vitro and in vivo studies have pointed out that the role of herbal medicine in improving insulin resistance is related to interventions in various aspects of the insulin signaling pathway. The targets involved in these studies include insulin receptor substrate, phosphatidylinositol 3-kinase, glucose transporter, AMP-activated protein kinase, glycogen synthase kinase 3, mitogenactivated protein kinases, c-Jun-N-terminal kinase, nuclear factor-kappaB, protein tyrosine phosphatase 1B, nuclear factor-E2-related factor 2, and peroxisome proliferator-activated receptors. Improved insulin sensitivity upon treatment with herbal medicine provides considerable prospects for treating insulin resistance. This article reviews studies of the target mechanisms of herbal treatments for insulin resistance.

Keywords: herbal medicine, insulin resistance, signal transduction, pathway, mechanism

\section{INTRODUCTION}

Insulin resistance (IR) is a pathological condition in which target tissues (primarily skeletal muscle, liver, and adipose tissue) have an impaired biological response to insulin stimulation. During IR, the body's compensatory release of excess insulin to maintain blood sugar stability causes hyperinsulinemia that can progress to type 2 diabetes mellitus (T2D). Prospective studies have highlighted the importance of IR in the pathogenesis of T2D and suggest that IR is the best predictor of future T2D diagnosis (Lillioja et al., 1993). IR and obesity are connected with chronic inflammation in metabolic tissues such as adipose tissue and the liver (Winer et al., 2016). 
Some studies have pointed out that body mass index is positively associated with IR (Li W. et al., 2014) and inflammation in visceral adipose tissue is a main driver of IR (Lumeng et al., 2007). Closely linked to the epidemic of obesity (Ng et al., 2014), the number of adults with diabetes increased from 108 million in 1980 to 422 million in 2014 (Zhou et al., 2016), and this figure is projected to rise to 642 million people by 2040. There are many vascular and nerve-related complications in diabetes such as diabetes-induced dysregulation of cardiac function, instability of microvasculature of the heart, and increased risk for heart failure (Riehle and Abel, 2016; Levelt et al., 2016; Hinkel et al., 2017). The risk of dementia, Alzheimer's disease, and cognitive decline are elevated in people with IR (Biessels et al., 2006; Willette et al., 2015; Kullmann et al., 2016) and T2D; the global prevalence of diabetic foot pathologies is $6.3 \%$, and 12.9 to 49.0 million people worldwide have a history of foot ulceration (Armstrong et al., 2017; Zhang P. et al., 2017). These complications bring a tremendous medical and socioeconomic burden. IR is associated with increased risk for other associated disorders, including polycystic ovary syndrome (PCOS), hepatitis $\mathrm{C}$ virus, nonalcoholic fatty liver disease (NAFLD), and metabolic syndrome (Diamanti-Kandarakis and Dunaif, 2012; Meex and Watt, 2017; Aytug et al., 2003). Improving IR may provide a therapeutic strategy for controlling T2D, obesity, and many other diseases. Current interventions for IR include intensive lifestyle interventions, thiazolidinedione, DPP-4 inhibitors, and metformin. However, IR is not well controlled and poses a threat to modern society (Kahn et al., 2006). Some herbal medicines such as Coptis chinensis Franch (Zhen et al., 2011), Ganoderma lucidum, and Panax ginseng C. A. Mey result in enhanced insulin sensitivity through modulation of diverse physiological and cellular pathways (Chang et al., 2015; Martel et al., 2017; Bai et al., 2018). For centuries, natural herbs and herbal formulae derived from systemic traditional Chinese medicine theory and practice have been used to treat many kinds of ailments in China. At present, Chinese medicine has received strong support from the World Health Organization and will be included in Chapter 26 of the 11th edition of the Global Medical Program. Chinese medicine also provides treatments for obesity and T2D (D, 2018). In the third century BC, Huang Di Nei Jing, the most classic book of Chinese medicine, recorded similar diseases related to diabetes and obesity and provided treatment principles. Now, traditional Chinese medicine is widely used to clinically treat IR. In this review, we explored whether herbs and their formulations or monomers can improve IR and the mechanisms of herbal compounds that increase insulin sensitivity.

\section{METHODOLOGY}

According to the Pharmacopoeia of the People's Republic of China that was revised by the China Food and Drug Administration in 2015, herbal medicine is defined as therapy using herbs and materials derived from botanical herbal products and mineral and animal sources. Interventions that were used in this study include single-flavored herbs and their extracts, active ingredients, and herbal formulas. There were no geographical restrictions on the herbs included.

We reviewed literature (from PubMed) published between July 8, 2013 and July 6, 2018 on IR that had been treated with herbal medicine. The following combination of terms were used as search keywords: "herbal," "phytochemical," "phytomedicine," "natural product," and "insulin resistance" or "IR." The search did not exclude articles based on language or status of the publication.

The specified exclusion criteria include: a) case reports, case series, editorials, reviews; b) interventions containing ingredients other than herbs; and c) relevant indicators of IR, such as homeostatic model assessment of IR (HOMA-IR), and IR-index, not involved in the primary and secondary outcomes of clinical trials.

\section{RESULTS}

The Preferred Reporting Items for Systematic Reviews and Meta-Analyses (PRISMA) flow chart (Figure 1) of article processing shows that our search yielded 1,363 articles, and 1,007 articles were excluded based on the exclusion criteria. After excluding these 1,007 articles, we included 137 articles, including 36 clinical trials, 58 in vivo experiments, 20 in vitro experiments, and 23 that were a combination of both in vitro and in vivo experiments. Based on further reading of this literature, we divided 101 in vivo and in vitro experiments into three parts based on the interventional drug used: active ingredients (31 articles), natural products (38 articles), and herbal formulas (32 articles). The results suggest that most clinical trials (30 articles) indicate that herbal active ingredients, natural products, and herbal formulas, such as JTTZ formula, Jinlida, and Curcumin, have a therapeutic effects on IR. There were a few clinical trials (six articles) that did not support the above results, such as those that used marjoram tea, hydroalcoholic extract of Juglans regia (walnut) leaves, Fraxinus excelsior L. seeds/ fruit extract, garlic extract, bee propolis, red wine polyphenols. On the other hand, we concluded that the effects of herbal medicine on IR may be related to 11 important target molecules that affect insulin signaling, such as insulin receptor substrate, phosphatidylinositol 3-kinase, and glucose transporter.

\section{Clinical Trials to Improve Insulin Resistance}

In clinical trials, participants in the treatment group should be restricted to using herbs alone. If medication other than herbs are being used, then the medication must be administered to both the treatment group and the control group. Participants in the control group should receive hypoglycemic agents, placebo, or life interventions. There is no limit to the number of predetermined herbs, recipes, sample sizes, or duration of treatment.

IR can be accurately assessed by clinical examination. It is generally believed that hyperinsulinemic-euglycemic clamps are the "gold standard" for determining IR, but the complex nature and inherent potential hazards of this technique limit its routine use (Park et al., 2015). Commonly used alternatives are primarily HOMA-IR and quantitative insulin sensitivity check index 

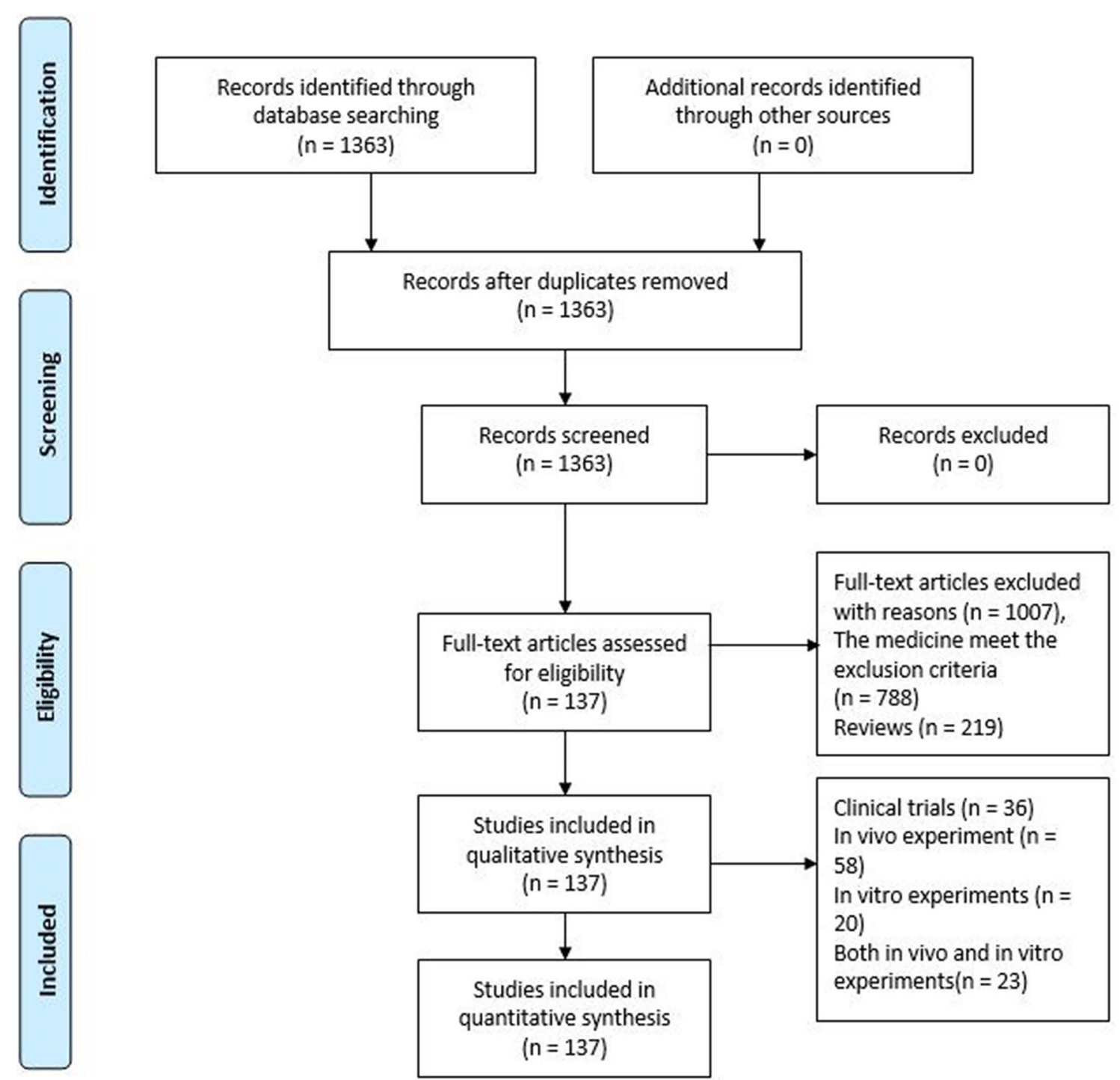

Full-text articles excluded

with reasons $(n=1007)$,

The medicine meet the

exclusion criteria

$(\mathrm{n}=788$ )

Reviews $(n=219$ )

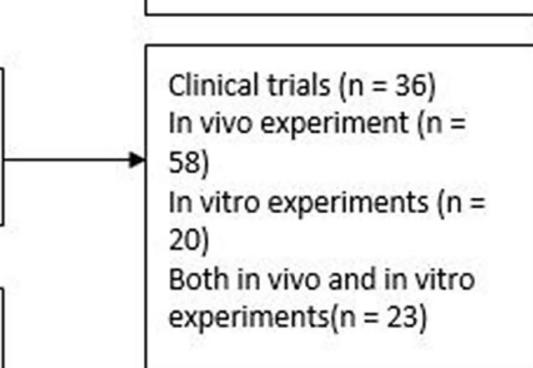

FIGURE 1 | PRISMA 2019 Flow Diagram.

(QUICKI), which use fasting insulin and glucose concentrations to assess IR and correlate with the results of the clamp study (Matthews et al., 1985). In the 36 clinical trials (Table 1) in the above table, most of the drugs examined were herbal formulas, including herbal extracts and active ingredients, and the diseases of concern included T2D, metabolic syndrome, obesity, impaired glucose tolerance, PCOS, and cirrhosis. Most studies have shown that herbal medicine can not only reduce IR but also improve blood sugar, blood lipids, glycosylated hemoglobin, and other biochemical indicators. Indicators of IR in these studies include HOMA-IR, QUICKI, area under the curve of insulin, and IR index. Among them, HOMA-IR was the indicator and was used in 29 studies $(29 / 36,80 \%)$. In order to objectively observe the therapeutic effect of herbs on IR, the changes in IR evaluation indicators before and after treatment in 36 clinical trials are listed in Table 2.
Two evaluators independently assessed the risk of bias in each study and provided the methodological quality of inclusion in clinical trials according to predetermined criteria in the Cochrane Handbook (Table 3). In general, the methodological quality was assessed to be poor. There are few reports of randomized sequence generation and allocation concealment. Fifteen studies $(30 / 36,83 \%)$ detailed how patients were randomized. Only six trials $(6 / 36,17 \%)$ in this study adequately reported the allocation of hidden methods. Twenty-five trials $(25 / 36$, $69 \%$ ) used blinding on their subjects and investigators. Five trials $(5 / 36,14 \%)$ used blinding on their subjects, investigators, and outcome evaluators. The following restrictions should be considered before accepting the conclusion. First, most of the clinical trials included in this review have certain flaws and bias risks in their methodological design, including the generation of randomization, the concealment of allocation, blinding, and 


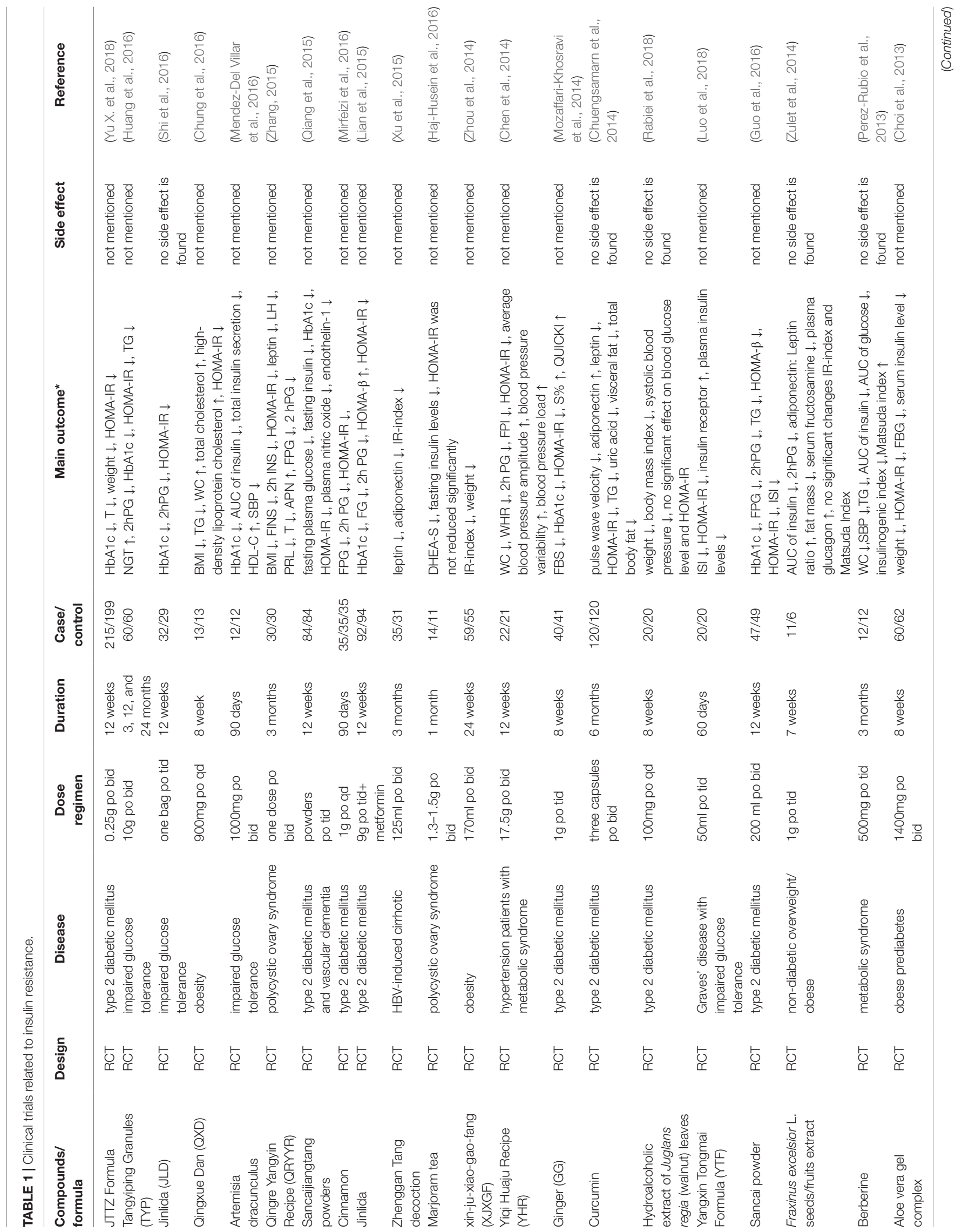




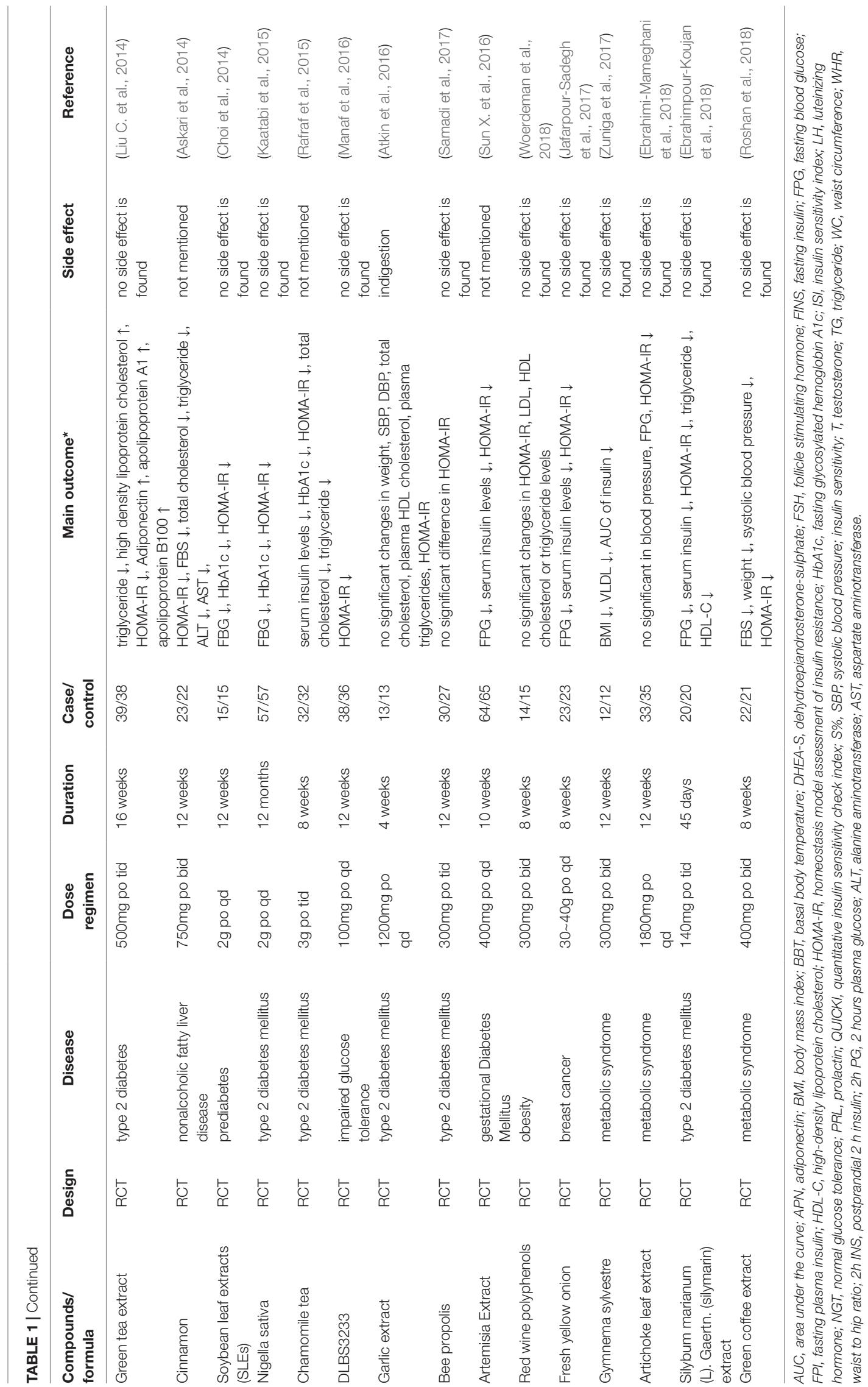


TABLE 2 | Changes in insulin resistance evaluation indicators before and after treatment in clinical trials.

\begin{tabular}{|c|c|c|c|c|}
\hline \multirow[t]{2}{*}{ Compounds/formula } & \multicolumn{3}{|c|}{ HOMA-IR ${ }^{1}$, AUC of insulin² ${ }^{2}$ IRS $^{3}$, QUICKI $^{4}$} & \multirow{2}{*}{$\begin{array}{l}\text { Baseline } \\
\text { difference }\end{array}$} \\
\hline & BT & AT & $p$ value ${ }^{\star *}$ & \\
\hline \multirow[t]{2}{*}{ JTTZ Formula ${ }^{1}$} & $\mathrm{~T}: 1.58 \pm 0.72$ & $\mathrm{~T}: 1.39 \pm 0.68$ & 0.01 & NSD \\
\hline & $\mathrm{C}: 1.5 \pm 0.75$ & C: $1.35 \pm 0.67$ & & \\
\hline \multirow[t]{2}{*}{ Tangyiping Granules (TYP) ${ }^{1}$} & $\mathrm{~T}: 4.02 \pm 0.46$ & T: $3.59 \pm 0.31$ & $<0.05$ & NSD \\
\hline & C: $3.87 \pm 0.36$ & C: $3.83 \pm 0.37$ & & \\
\hline \multirow[t]{2}{*}{ Jinlida (JLD) ${ }^{1}$} & $\mathrm{~T}: 2.4(2 \cdot 0,4.0)$ & $\mathrm{T}: 2.41(1.7,3.9)$ & 0.029 & NSD \\
\hline & C: $2.5(2.1,3.0)$ & C: $3.0(2.1,3.3)$ & & \\
\hline \multirow[t]{2}{*}{ Qingxue Dan (QXD)'1 } & $\mathrm{T:} 164 \pm 93$ & $\mathrm{T:} 150 \pm 92$ & $>0.05$ & NSD \\
\hline & C: $226 \pm 160$ & C: $205 \pm 184$ & & \\
\hline \multirow[t]{2}{*}{ Artemisia dracunculus² } & $\mathrm{T}: 56,136 \pm 27,426$ & $\mathrm{T:}$ 44,472 $\pm 23,370$ & $<0.05$ & NSD \\
\hline & C: $92,430 \pm 55,920$ & C: $94,278 \pm 43,230$ & & \\
\hline \multirow[t]{2}{*}{ Qingre Yangyin Recipe (QRYYR) ${ }^{1}$} & T: $3.48 \pm 2.03$ & $\mathrm{~T}: 2.83 \pm 1.52$ & $<0.05$ & $N R$ \\
\hline & $\mathrm{C}: 3.81 \pm 2.75$ & $\mathrm{C}: 2.69 \pm 1.16$ & & \\
\hline \multirow[t]{2}{*}{ Sancaijiangtang powders ${ }^{1}$} & $\mathrm{~T}: 6.0 \pm 0.8$ & $\mathrm{~T}: 4.6 \pm 1.3$ & $<0.05$ & NSD \\
\hline & C: $5.8 \pm 1.2$ & C: $3.5 \pm 0.8$ & & \\
\hline \multirow[t]{2}{*}{ Cinnamon ${ }^{1}$} & T: $8.82 \pm 6.59$ & T: $5.58 \pm 3.20$ & 0.013 & NSD \\
\hline & $\mathrm{C}: 7.06 \pm 5.65$ & C: $5.8 \pm 1.2$ & & \\
\hline \multirow[t]{2}{*}{ Jinlida ${ }^{1}$} & $\mathrm{~T}: 1.32 \pm 0.79$ & $\mathrm{~T}: 1.2 \pm 0.66$ & 0.824 & NSD \\
\hline & C: $1.41 \pm 0.79$ & C: $1.31 \pm 0.67$ & & \\
\hline \multirow[t]{2}{*}{ Zhenggan Tang decoction ${ }^{3}$} & $\mathrm{~T}: 1.68 \pm 0.21$ & $\mathrm{~T}: 0.92 \pm 0.18$ & $<0.05$ & NSD \\
\hline & $\mathrm{C:} 1.72 \pm 0.32$ & $\mathrm{C}: 1.69 \pm 0.44$ & & \\
\hline \multirow[t]{2}{*}{ Marjoram tea ${ }^{1}$} & $\mathrm{~T}: 1.53(0.18)$ & $\mathrm{T}: 1.14(0.14)$ & 0.06 & NSD \\
\hline & C: 1.5(0.25) & C: $1.68(0.28)$ & & \\
\hline \multirow[t]{2}{*}{ xin-ju-xiao-gao-fang (XJXGF)' } & $\mathrm{T}: 8.10 \pm 5.32$ & T: $5.48 \pm 1.05$ & 0.77 & NSD \\
\hline & C: $7.84 \pm 5.18$ & C: $9.57 \pm 1.45$ & & \\
\hline Yiqi Huaju Recipe $(Y H R)^{1}$ & $\mathrm{~T}: 6.01 \pm 4.05$ & $\mathrm{~T}: 4.07 \pm 2.80$ & $<0.05$ & NSD \\
\hline & $\mathrm{C}: 6.50 \pm 4.15$ & C: $6.63 \pm 4.02$ & & \\
\hline Ginger $(\mathrm{GG})^{4}$ & $\mathrm{~T}: 0.316 \pm 0.025$ & $\mathrm{~T}: 0.337 \pm 0.303$ & $<0.005$ & NSD \\
\hline & C: $0.324 \pm 0.031$ & C: $0.333 \pm 0.031$ & & \\
\hline Curcumin $^{1}$ & $\mathrm{~T}: 6.12(2-24.1)$ & $\mathrm{T:}$ 5.92(1.4-14.9) & $<0.01$ & NSD \\
\hline & C: $5.63(1.4-14.9)$ & C: $2.75(0.9-10.9)$ & & \\
\hline Hydroalcoholic extract of Juglans & $\mathrm{T}: 3.3 \pm 2.7$ & $\mathrm{~T}: 2.9 \pm 2.2$ & 0.186 & NSD \\
\hline regia (walnut) leaves ${ }^{1}$ & C: $3.0 \pm 1.7$ & C: $2.7 \pm 1.4$ & & \\
\hline Yangxin Tongmai Formula (YTF) ${ }^{1}$ & $\mathrm{~T}: 6.48 \pm 1.05$ & $\mathrm{~T}: 4.86 \pm 0.54$ & $<0.05$ & NR \\
\hline & $\mathrm{C}: 4.26 \pm 0.74$ & $\mathrm{C}: 4.86 \pm 0.69$ & & \\
\hline Sancai powder ${ }^{1}$ & $\mathrm{~T}: 3.2 \pm 0.6$ & $\mathrm{~T}: 0.8 \pm 0.5$ & $<0.05$ & NSD \\
\hline & C: $3.4 \pm 0.6$ & C: $0.7 \pm 0.5$ & & \\
\hline Fraxinus excelsior L. seeds/fruits & T: 5.65(2.68) & T: 6.86(5.17) & $>0.05$ & NSD \\
\hline extract $^{1}$ & C: $5.32(3.15)$ & C: 6.05(3.36) & & \\
\hline Berberine $^{2}$ & $\mathrm{~T}: 92,056 \pm 72,148$ & $\mathrm{~T}: 67,407 \pm 46,441$ & $<0.01$ & NSD \\
\hline & C: $67,605 \pm 18,730$ & C: $86,852 \pm 57,863$ & & \\
\hline Aloe vera gel complex ${ }^{1}$ & $\mathrm{~T}: 3.4 \pm 1.6$ & $\mathrm{~T}: 3.1 \pm 0.2$ & $<0.01$ & NSD \\
\hline & C: $3.3 \pm 1.2$ & C: $3.5 \pm 0.2$ & & \\
\hline Green tea extract ${ }^{1}$ & $\mathrm{~T}: 5.4 \pm 3.9$ & $\mathrm{~T}: 3.5 \pm 2.0$ & 0.004 & NSD \\
\hline & C: $5.9 \pm 4.5$ & C: $4.7 \pm 3.4$ & & \\
\hline Cinnamon ${ }^{1}$ & $\mathrm{~T}: 2.7 \pm 2.0$ & $\mathrm{~T}: 1.7 \pm 0.7$ & $<0.001$ & NSD \\
\hline & C: $3.0 \pm 1.2$ & C: $3.0 \pm 0.0$ & & \\
\hline Soybean leaf extracts (SLEs) ${ }^{1}$ & $\mathrm{~T}: 1.08 \pm 0.06$ & $\mathrm{~T}: 0.92 \pm 0.12$ & $<0.05$ & NSD \\
\hline & C: $1.07 \pm 0.08$ & C: $1.18 \pm 0.08$ & & \\
\hline Nigella sativa ${ }^{1}$ & $\mathrm{~T}: 3.0 \pm 0.24$ & $\mathrm{~T}: 2.5 \pm 0.18$ & 0.004 & NSD \\
\hline & C: $2.5 \pm 0.17$ & C: $2.51 \pm 0.15$ & & \\
\hline Chamomile tea $^{1}$ & $\mathrm{~T}: 7.05 \pm 2.34$ & $\mathrm{~T}: 4.24 \pm 1.95$ & $<0.001$ & NSD \\
\hline & C: $5.24 \pm 1.23$ & C: $5.55 \pm 1.12$ & & \\
\hline DLBS32331 & $\mathrm{T}: 3.00 \pm 1.76$ & $\mathrm{~T}: 2.16 \pm 1.17$ & 0.001 & NSD \\
\hline & C: $2.76 \pm 2.28$ & C: $2.28 \pm 1.24$ & & \\
\hline Garlic extract ${ }^{1}$ & $\mathrm{~T}: 1.89 \pm 1.1$ & $\mathrm{T:} 1.7 \pm 0.9$ & 0.05 & NSD \\
\hline & $\mathrm{C}: 2.5 \pm 2.0$ & $\mathrm{C}: 2.0 \pm 1.1$ & & \\
\hline Bee propolis ${ }^{4}$ & T: $0.37 \pm 0.03$ & $\mathrm{~T}: 0.34 \pm 0.03$ & $<0.001$ & NSD \\
\hline & C: $0.36 \pm 0.03$ & C: $0.03 \pm 0.33$ & & \\
\hline Artemisia Extract ${ }^{1}$ & $\mathrm{~T}: 2.7 \pm 1.8$ & $\mathrm{~T}: 1.7 \pm 2.4$ & 0.031 & NSD \\
\hline & C: $2.8 \pm 1.4$ & C: $4.0 \pm 1.5$ & & \\
\hline Red wine polyphenols ${ }^{1}$ & $\mathrm{~T}: 3.2(2.0,4.5)$ & $\mathrm{T}: 2.9(2.1,3.8)$ & 0.72 & NSD \\
\hline & C: $2.3(1.4,2.7)$ & C: $2.2(1.5,2.8)$ & & \\
\hline
\end{tabular}


TABLE 2 | Continued

\begin{tabular}{|c|c|c|c|c|}
\hline \multirow[t]{2}{*}{ Compounds/formula } & \multicolumn{3}{|c|}{ HOMA-IR ${ }^{1}$, AUC of insulin², IRS ${ }^{3}$, QUICKI $^{4}$} & \multirow{2}{*}{$\begin{array}{l}\text { Baseline } \\
\text { difference }\end{array}$} \\
\hline & BT & AT & $p$ value ${ }^{\star *}$ & \\
\hline Fresh yellow onion ${ }^{1}$ & $\begin{array}{l}\text { T: } 0.052 \pm 0.011 \\
\text { C: } 0.045 \pm 0.01\end{array}$ & $\begin{array}{l}\mathrm{T}: 0.046 \pm 0.006 \\
\mathrm{C}: 0.051 \pm 0.01\end{array}$ & 0.021 & NSD \\
\hline Gymnema sylvestre ${ }^{2}$ & $\begin{array}{l}T: 61,626 \pm 29,700 \\
\text { C: } 64,314 \pm 34,914\end{array}$ & $\begin{array}{l}\text { T: } 60,468 \pm 37,290 \\
\text { C: } 90,816 \pm 45,336\end{array}$ & 0.01 & NSD \\
\hline Artichoke leaf extract ${ }^{1}$ & $\begin{array}{l}\text { T: } 3.53(1.44) \\
\text { C: } 3.11(1.27)\end{array}$ & $\begin{array}{l}\text { T: } 3.30(1.47) \\
\text { C: } 3.63(1.55)\end{array}$ & $<0.05$ & NSD \\
\hline $\begin{array}{l}\text { Silybum marianum (L). Gaertn. } \\
\text { (silymarin) extract }^{1}\end{array}$ & $\begin{array}{l}\text { T: } 4.25 \pm 2.43 \\
\text { C: } 4.49 \pm 2.94\end{array}$ & $\begin{array}{l}\mathrm{T}: 2.75 \pm 1.19 \\
\mathrm{C}: 5.48 \pm 3.51\end{array}$ & 0.008 & NSD \\
\hline Green coffee extract ${ }^{1}$ & $\begin{array}{l}\mathrm{T}: 5.04 \pm 3.95 \\
\mathrm{C}: 4.71 \pm 2.55\end{array}$ & $\begin{array}{l}\text { T: } 3.62 \pm 1.83 \\
\text { C: } 5.94 \pm 5.16\end{array}$ & 0.024 & NSD \\
\hline
\end{tabular}

AT, after treatment; BT, before treatment; $C$, control group; NR, no reported; NSD, no significant difference; $T$, treatment group.

** $p$ value: differences in treatment group before and after treatment. "1", " 2 ", "3", "4" indicate that the indicators of insulin resistance in the experiment are "HOMA-IR", "AUC of insulin", "IRS" and "QUICKI".

inadequate reporting of sample size estimates. Secondly, the duration of 21 trials $(21 / 36,58 \%)$ was greater than or equal to 12 weeks, and 3 trials $(3 / 36,8 \%)$ lasted longer than 6 months. The impact of duration on the results of the study cannot be ignored. Finally, outcome measures for evaluation of major adverse clinical events, such long-term follow-up, were not considered in this review. Therefore, this review indicates that the evidence for both the benefits and harms of herbal treatment for IR is not strong, and it is necessary to rigorously design further trials with high methodological quality to confirm the conclusion.

It must be mentioned that six clinical trials (Juglans regia leaves, marjoram tea, Fraxinus excelsior L. seeds/fruit extract, garlic extract, bee propolis, and red wine polyphenols) have not confirmed the therapeutic effect of herbs on IR. Possible reasons may include that, firstly, all herbal medicines are not necessarily effective for treating IR while also improving the metabolic index and secondly, these two herbs were not studied using conventional methods of their consuming (they were obtained from extraction using ethanol and soaking in boiling water, respectively). This may have altered the concentration and composition of the drug solution. Despite this, the potential therapeutic effects of herbs on IR are worthy of attention.

\section{Insulin Signal Transduction}

The physiology of insulin involves a complex network of signaling pathways that is activated by the insulin receptor (Samuel and Shulman, 2016). Insulin binding to an insulin receptor on a cell triggers autophosphorylation followed by phosphorylation of intracellular receptor substrates 1 and 2 (IRS-1/IRS-2) (Cheng et al., 2013). Several upstream and downstream key signaling molecules in the insulin signaling pathway have been identified, including the phosphoinositide 3-kinase (PI3K)/Akt pathway that is known to be involved in the translocation of glucose transporter 4 (GLUT-4) from intracellular vesicles to cells and promote glucose uptake to adipose tissue and skeletal muscle, eventually decreasing blood glucose levels. Other related pathways include the mitogen-activated protein kinase (MAPK), adenosine monophosphate-activated protein kinase (AMPK), and stress-activated c-Jun-N-terminal kinase (JNK) pathways (Belwal et al., 2017), among others, and these key players in signal transduction processes are potential targets for drug interventions in IR. IR is characterized by multiple defects, with decreases in receptor concentration and kinase activity, PI3K activity (Anitha et al., 2006), the concentration and phosphorylation of IRS-1 and IRS-2 (Hoehn et al., 2008), and glucose transporter translocation (Bogan, 2012). Previous studies have found that abnormalities in insulin signaling pathways caused by lipid metabolism disorders, inflammatory responses, oxidative stress, endoplasmic reticulum stress, and mitochondrial dysfunction lead to IR (Guilherme et al., 2008; Szendroedi et al., 2011; Gurzov et al., 2014; Park E. et al., 2014; Siwicki et al., 2016). Metabolic disorder and inflammation cause IR and promote leukocytes to secrete proinflammatory cytokines, including IL-6 and tumor necrosis factor- $\alpha$ (TNF- $\alpha$ ) (Feve and Bastard, 2009; Wen et al., 2011; Wensveen et al., 2015), which provides a framework to understand how physiological stress, obesity, and diet promote IR. We have placed the experimental research on the treatment of IR by herbal medicine into three categories: active ingredients (Table 4), natural product (Table 5), and herbal formula (Table 6). The active ingredient is a relatively single component, and research has proven to play a major role in the therapeutic effects of herbal medicine. The active ingredients listed in Table 4 are berberine, ginsenoside, astragaloside, polydatin, baicalin, maslinic acid, paeoniflorin, Lycium barbarum polysaccharide, dihydromyricetin, atractylenolide, etc. Natural products are also extracted from herbs, but the ingredients are relatively complex. The herbs involved in the natural products in the table include mulberry leaves, Coptis chinensis, litchi seed, red ginseng, and Gastrodia elata Blume. There are many herbs involved in herbal formulas. Some of these herbs have been used frequently, such as C. chinensis, mulberry leaves, Pueraria montana lobata, Salvia miltiorrhiza, and Astragalus membranaceus. Therapeutic targets for these herbs include: insulin receptor substrate, phosphatidylinositol3-kinase, glucose transporter, AMP-activated protein kinase (AMPK), glycogen synthase kinase 3, MAPKs, JNK, 
TABLE 3 | Risk of bias of the clinical trials.

\begin{tabular}{|c|c|c|c|c|c|c|c|c|c|}
\hline Compounds/formula & $\mathbf{A}$ & B & C & D & $\mathbf{E}$ & $\mathbf{F}$ & G & $\mathbf{H}$ & Reference \\
\hline JTTZ Formula & $?$ & - & - & - & + & + & $?$ & $?$ & (Yu X. et al., 2018) \\
\hline Tangyiping Granules (TYP) & + & + & + & + & $?$ & + & $?$ & $?$ & (Huang et al., 2016) \\
\hline Jinlida (JLD) & + & - & - & - & $?$ & + & $?$ & $?$ & (Shi et al., 2016) \\
\hline Qingxue Dan (QXD) & + & $?$ & + & + & - & + & $?$ & $?$ & (Chung et al., 2016) \\
\hline Artemisia dracunculus & $?$ & - & + & + & - & + & $?$ & $?$ & (Mendez-Del Villar et al., 2016) \\
\hline Qingre Yangyin Recipe (QRYYR) & - & - & + & - & - & - & $?$ & $?$ & (Zhang, 2015) \\
\hline Sancaijiangtang powders & + & - & + & - & - & + & $?$ & $?$ & (Qiang et al., 2015) \\
\hline Cinnamon & + & $?$ & + & + & + & + & $?$ & $?$ & (Mirfeizi et al., 2016) \\
\hline Jinlida & + & + & + & + & + & + & - & $?$ & (Lian et al., 2015) \\
\hline Zhenggan Tang decoction & + & - & - & - & - & + & $?$ & $?$ & (Xu et al., 2015) \\
\hline Marjoram tea & + & - & + & + & + & + & $?$ & $?$ & (Haj-Husein et al., 2016) \\
\hline xin-ju-xiao-gao-fang (XJXGF) & + & - & + & + & - & + & $?$ & $?$ & (Zhou et al., 2014) \\
\hline Yiqi Huaju Recipe (YHR) & + & - & + & - & - & + & $?$ & $?$ & (Chen et al., 2014) \\
\hline Ginger (GG) & + & - & + & + & $?$ & + & $?$ & $?$ & (Mozaffari-Khosravi et al., 2014) \\
\hline Curcumin & + & + & + & + & - & + & $?$ & $?$ & (Chuengsamarn et al., 2014) \\
\hline $\begin{array}{l}\text { Hydroalcoholic extract of Juglans regia } \\
\text { (walnut) leaves }\end{array}$ & + & + & + & + & - & + & $?$ & $?$ & (Rabiei et al., 2018) \\
\hline Yangxin Tongmai Formula (YTF) ${ }^{1}$ & - & - & - & - & - & + & $?$ & $?$ & (Luo et al., 2018) \\
\hline Sancai powder & + & - & + & - & - & + & $?$ & $?$ & (Guo et al., 2016) \\
\hline Fraxinus excelsior L. seeds/fruits extract & $?$ & + & + & + & + & + & $?$ & $?$ & (Zulet et al., 2014) \\
\hline Berberine & + & $?$ & + & + & - & + & $?$ & $?$ & (Perez-Rubio et al., 2013) \\
\hline Aloe vera gel complex & + & - & + & + & - & + & $?$ & $?$ & (Choi et al., 2013) \\
\hline Green tea extract & + & $?$ & + & + & - & + & $?$ & $?$ & (Liu C. et al., 2014) \\
\hline Cinnamon & + & - & + & + & - & + & $?$ & $?$ & (Askari et al., 2014) \\
\hline Soybean leaf extracts (SLEs) & + & - & - & - & - & + & $?$ & $?$ & (Choi et al., 2014) \\
\hline Nigella sativa & + & - & + & - & - & + & $?$ & + & (Kaatabi et al., 2015) \\
\hline Chamomile tea & + & - & + & - & - & + & $?$ & $?$ & (Rafraf et al., 2015) \\
\hline DLBS3233 & $?$ & - & + & + & - & + & $?$ & $?$ & (Manaf et al., 2016) \\
\hline Garlic extract & $?$ & - & + & + & - & + & $?$ & $?$ & (Atkin et al., 2016) \\
\hline Bee propolis & $?$ & - & + & + & - & + & $?$ & $?$ & (Samadi et al., 2017) \\
\hline Artemisia Extract & + & - & + & + & - & + & $?$ & $?$ & (Sun X. et al., 2016) \\
\hline Red wine polyphenols & + & - & + & + & - & + & $?$ & $?$ & (Woerdeman et al., 2018) \\
\hline Fresh yellow onion & + & - & + & + & + & + & $?$ & $?$ & (Jafarpour-Sadegh et al., 2017) \\
\hline Gymnema sylvestre & + & - & + & + & - & + & $?$ & $?$ & (Zuniga et al., 2017) \\
\hline Artichoke leaf extract & + & - & + & + & - & + & $?$ & $?$ & (Ebrahimi-Mameghani et al., 2018) \\
\hline $\begin{array}{l}\text { Silybum marianum (L). Gaertn. } \\
\text { (silymarin) extract }\end{array}$ & + & - & + & + & - & + & $?$ & $?$ & (Ebrahimpour-Koujan et al., 2018) \\
\hline Green coffee extract & + & + & + & + & $?$ & + & $?$ & $?$ & (Roshan et al., 2018) \\
\hline
\end{tabular}

A, Adequate sequence generation; B, Concealment of allocation; C, Blinding (patient); D, Blinding (investigator); E, Blinding (assessor); F, Incomplete outcome data addressed (ITT analysis); G, Free of selective reporting; $\mathrm{H}$, Other potential threat to validity; +, Low risk; -, High risk; ?, Unclear.

nuclear factor-kappaB (NF- $\kappa \mathrm{B})$, protein tyrosine phosphatase $1 \mathrm{~B}$, nuclear factor-E2-related factor 2 , and peroxisome proliferatoractivated receptors. The results suggest that herbal interventions for IR are mostly multi-targeted, sometimes interfering with the same target through different pathways. Insulin receptor substrate signals transduction.

\section{Insulin Receptor Substrate Signal Transduction}

The insulin receptor belongs to the subfamily of receptor tyrosine kinases, including insulin-like growth factor 1 receptors and insulin receptor-related receptors (White, 2003). Most insulin signals promote or regulate phosphorylation of IRS-1 or its homolog IRS-2 via tyrosine (Haeusler and Accili, 2008), and IRS-1 is the major substrate of the insulin receptor. IRS mediates insulin action differently in different tissues, with IRS-1 playing a prominent role in skeletal muscle and IRS-2 in the liver
(Kido et al., 2000). Studies have shown that liver IRS-1 and IRS-2 have complementary effects in controlling liver metabolism; IRS-1 is more closely related to glucose homeostasis (Bouzakri et al., 2006), and IRS-2 is more closely related to lipid metabolism (Taniguchi et al., 2005). Insufficient expression of IRS-1 and IRS-2 can lead to IR (Tamemoto et al., 1994; Shimomura et al., 2000). Jinlida particles can raise insulin sensitivity in skeletal muscle in fat-induced insulin-resistant ApoE-/- mice by increasing the expression of IRS-1 mRNA and protein (Jin et al., 2015). Treating high insulin-induced HepG2 cells with FTZ in vitro upregulated the expression of IRS-1 protein while attenuating in vitro glucose levels (Hu et al., 2014). Abnormal phosphorylation of IRS is also an important mechanism of IR.

IRS1 and IRS2 appear to lack intrinsic catalytic activity but contain many serine and tyrosine phosphorylation sites (White, 2003). Serine/threonine phosphorylation of IRS-1 at the phosphorylation site Ser307 may inhibit insulin signaling (Rui et al., 2001) and attenuate tyrosine phosphorylation 
TABLE 4 | Active ingredients for improving insulin resistance.

\begin{tabular}{|c|c|c|c|c|c|c|}
\hline Type & Model & Monomer & Inducer & Animal/cell & Major findings & References \\
\hline In vivo and in vitro & Insulin resistance & Baicalin & Diet-induced & $\begin{array}{l}\text { Mice and 3T3-L1 } \\
\text { cell }\end{array}$ & $\begin{array}{l}\text { p38 MAPK, Akt, } \\
\text { GLUT4 }\end{array}$ & (Fang et al., 2018) \\
\hline In vivo & $\begin{array}{l}\text { Diabetic myocardial } \\
\text { hypertrophy }\end{array}$ & Polydatin & STZ & Mice & $N F-\kappa B, P P A R \beta$ & (Huang et al., 2015) \\
\hline In vivo and in vitro & $\begin{array}{l}\text { Diabetic and insulin } \\
\text { resistance }\end{array}$ & Polydatin & $\begin{array}{l}\text { High-fat and -sugar } \\
\text { diet and streptozocin, } \\
\text { palmitic acid }\end{array}$ & Rat and HepG2 cell & Akt, GSK-3 $\beta$, IRS & (Hao et al., 2014) \\
\hline In vivo and in vitro & Insulin resistance & $\begin{array}{l}\text { Lycium barbarum } \\
\text { polysaccharide (LBP) }\end{array}$ & High-fat diet & $\begin{array}{l}\text { HepG2 cells and } \\
\text { C57BL/6J mice }\end{array}$ & $\begin{array}{l}\text { PI3K/Akt, Nrf2, } \\
\text { GSK3 } \beta, \text { JNK }\end{array}$ & (Yang Y. et al., 2014) \\
\hline In vivo and in vitro & $\begin{array}{l}\text { Adiposity and } \\
\text { insulin resistance }\end{array}$ & Maslinic acid (MA) & High-fat diet & $\begin{array}{l}\text { C57BL/6J mice and } \\
\text { HepG2 cells }\end{array}$ & Akt, GSK3 $\beta$ & (Liu J. et al., 2014) \\
\hline In vivo & Insulin resistance & LBP-4a & - & OLETF rats & $\begin{array}{l}\text { PI3K, p38 MAPK, } \\
\text { GLUT4 }\end{array}$ & (Zhao R. et al., 2014) \\
\hline In vitro & Insulin resistance & Paeoniflorin & - & 3T3-L1 adipocytes & IRS-1, Akt & (Kong et al., 2013) \\
\hline In vivo & Obesity & Berberine & High-fat diet & Rats & IRS-1 & (Liu D. et al., 2018) \\
\hline In vivo & Obesity & Berberine & High-fat diet & Mice & AMPK & (Wang L. et al., 2018) \\
\hline In vivo & Natural aging & Berberine & - & Rats & p-AMPK & (Yu Y. et al., 2018) \\
\hline In vitro & Insulin resistance & Astragaloside IV & Glucose + insulin & HepG2 cells & AMPK & (Wang C. et al., 2018) \\
\hline In vitro & Insulin resistance & Astragaloside IV & Palmitate & C2C12 myotubes & IRS1, Akt & (Zhu et al., 2016) \\
\hline In vivo and in vitro & $\begin{array}{l}\text { Obesity/insulin } \\
\text { resistance }\end{array}$ & Ginsenoside Rb2 & High-fat diet/TNF- $\alpha$ & $\begin{array}{l}\text { Mice/3T3-L1 } \\
\text { adipocytes }\end{array}$ & $\begin{array}{l}\text { IRS-1, PI3K/Akt, } \\
\text { MAPK }\end{array}$ & (Dai et al., 2018) \\
\hline In vivo & Obesity & Ginsenoside Rg3 & High-fat diet & $\begin{array}{l}\text { C57BL/6 } \\
\text { mice/3T3-L1 pre- } \\
\text { adipocyte cell }\end{array}$ & PPAR & (Lee et al., 2017) \\
\hline In vivo & Insulin resistance & Ginsenoside Re & High-fat diet & C57BL/6 mice & JNK & (Kim et al., 2017) \\
\hline In vivo & Obesity & Ginsenoside Rg5 & High-fat diet & ICR mice & JNK & (Xiao et al., 2017) \\
\hline In vivo & Insulin resistance & $\begin{array}{l}\text { Dihydromyricetin } \\
\text { (DMY) }\end{array}$ & High-fat diet & $\begin{array}{l}\text { Male Sprague- } \\
\text { Dawley (SD) rats }\end{array}$ & GLUT1, AMPK & (Le et al., 2016) \\
\hline In vitro & Insulin resistance & $\begin{array}{l}\text { Atractylenolide I (AT-I) } \\
\text { and atractylenolide II } \\
\text { (AT-II) }\end{array}$ & LY294002 & $\begin{array}{l}\text { Mouse skeletal } \\
\text { muscle, C2C12 cells }\end{array}$ & $\begin{array}{l}\text { GLUT4, AMPK, } \\
\text { PI3K/Akt }\end{array}$ & (Chao et al., 2016) \\
\hline In vivo and in vitro & Insulin resistance & $\begin{array}{l}\text { Fudan-Yueyang } \\
\text { Ganoderma lucidum } \\
\text { (FYGL) }\end{array}$ & - & $\begin{array}{l}\text { ob/ob mice, L6 rat } \\
\text { skeletal muscle cells }\end{array}$ & $\begin{array}{l}\text { PTP1B, PI3K/ } \\
\text { Akt, GLUT4, } \\
\text { IRS-1, }\end{array}$ & (Yang et al., 2018) \\
\hline In vitro & Insulin resistance & $\begin{array}{l}\alpha \text {-Methyl } \\
\text { artoflavanocoumarin } \\
\text { (MAFC) }\end{array}$ & Insulin & HepG2 cells & $\begin{array}{l}\text { PTP1B, PI3K/ } \\
\text { Akt, IRS-1, }\end{array}$ & (Jung et al., 2017) \\
\hline In vitro & Insulin resistance & $\begin{array}{l}\text { Anthocyanins from } \\
\text { Purple Corn }\end{array}$ & DMEM & 3T3-L1 Adipocytes & $\begin{array}{l}\text { PPAR } \gamma, \text { IRS-1, } \\
\text { GLUT4, Akt }\end{array}$ & $\begin{array}{l}\text { (Luna-Vital et al., } \\
\text { 2017) }\end{array}$ \\
\hline In vitro & Insulin resistance & Geniposide & RPMI-1640 medium & HepG2 cells & NF-кB, GLUT-4 & (Jiang et al., 2017) \\
\hline In vivo & Insulin resistance & $\begin{array}{l}\text { Tartary buckwheat } \\
\text { flavonoid fraction (TBF) }\end{array}$ & High fructose & Mice & $\begin{array}{l}\text { Nrf2, GLUT-4, } \\
\text { IRS-1, }\end{array}$ & (Hu et al., 2017) \\
\hline In vitro and in vivo & Insulin resistance & $\begin{array}{l}\text { Pectic bee pollen } \\
\text { polysaccharide } \\
\text { (RBPP-P) }\end{array}$ & $\begin{array}{l}\text { High glucose and } \\
\text { fatty acids/high-fat } \\
\text { diet }\end{array}$ & HepG2 cells/mice & AMPK & (Li et al., 2017) \\
\hline In vitro & Insulin resistance & Fucosterol & - & HepG2 cells & PTP1B & (Jung et al., 2016) \\
\hline In vitro and in vivo & Insulin resistance & $\begin{array}{l}\text { Mulberry anthocyanin } \\
\text { extract (MAE) }\end{array}$ & $\begin{array}{l}\text { High glucose plus } \\
\text { palmitic acid }\end{array}$ & $\begin{array}{l}\text { HepG2 cells/db/db } \\
\text { mice }\end{array}$ & PI3K/Akt & (Yan et al., 2016) \\
\hline In vitro & Insulin resistance & $\begin{array}{l}\text { Tartary buckwheat } \\
\text { flavonoids (TBF) }\end{array}$ & High glucose & HepG2 cells & $\begin{array}{l}\text { MAPK, Nrf2, } \\
\text { IRS-1, }\end{array}$ & (Hu et al., 2016) \\
\hline In vivo & Insulin resistance & Corosolic acid & High-fat diet & C57BL/6 mice & $\begin{array}{l}\text { IRS-1, AMPK, } \\
\text { Akt }\end{array}$ & (Yang et al., 2016) \\
\hline In vivo & Insulin resistance & $\begin{array}{l}\text { 1-Deoxynojirimycin } \\
\text { (DNJ) }\end{array}$ & - & $\mathrm{db} / \mathrm{db}$ mice & $\begin{array}{l}\text { PI3K/AKt, } \\
\text { GLUT-4, IRS-1 }\end{array}$ & (Liu Q. et al., 2015) \\
\hline In vivo & Insulin resistance & Rutin & S961 & C57BL/6 mice & GLUT4 & (Hsu et al., 2014) \\
\hline In vitro & Insulin resistance & $\begin{array}{l}\text { Total phenolic fraction } \\
\text { of Anemarrhena } \\
\text { asphodeloides }\end{array}$ & $\begin{array}{l}\text { Macrophage-derived } \\
\text { conditioned medium }\end{array}$ & Adipocytes & AMPK & (Zhao W. et al., 2014) \\
\hline
\end{tabular}

levels (Saad et al., 1992). Salvia-Nelumbinis naturalis (SNN) improves hepatic insulin sensitivity in rats and increases IRS phosphorylation (Zhang et al., 2014). Tumor necrosis factor- $\alpha$ (TNF- $\alpha$ ) reduces insulin receptor substrate tyrosine phosphorylation and is an important mediator of IR in obesity and diabetes (Hotamisligil et al., 1996). Erchen decoction and Linguizhugan decoction reduce the level of TNF- $\alpha$ in dietinduced insulin-resistant rats to improve IR (Zhang H. et al., 2017), 
TABLE 5 | Natural product that improves insulin resistance.

\begin{tabular}{|c|c|c|c|c|c|c|}
\hline Type & Model & Natural product & Inducer & Animal/cell & Major findings & References \\
\hline In vitro & Insulin resistance & Oligonol & SF-MEM & HepG2 cells & $\begin{array}{l}\text { PTP1B, IRS-1, } \\
\text { PI3K/Akt, NF-кB }\end{array}$ & (Bhakta et al., 2017) \\
\hline In vivo & $\begin{array}{l}\text { Type } 2 \text { diabetic } \\
\text { mellitus }\end{array}$ & Sang-Tong-Jian (STJ) & High-fat diet & KKAy mice & $\begin{array}{l}\text { PI3K/Akt, GLUT2, } \\
\text { GLUT4, IRS1 }\end{array}$ & (Kuai et al., 2016) \\
\hline In vitro & Insulin resistance & Marein & High glucose & HepG2 cells & $\begin{array}{l}\text { IRS-1, Akt, GLUT1, } \\
\text { GSK-3 } \beta, \text { AMPK }\end{array}$ & (Jiang B. et al., 2016) \\
\hline In vivo & $\begin{array}{l}\text { Metabolic } \\
\text { syndrome }\end{array}$ & $\begin{array}{l}\text { The fermented Red ginseng } \\
\text { and Red ginseng extracts }\end{array}$ & High-fructose diet & Rats & IRS-1, GIUT4 & (Kho et al., 2016) \\
\hline In vivo & Insulin resistance & $\begin{array}{l}\text { Mulberry leaf extract and its } \\
\text { Formulation }\end{array}$ & $\begin{array}{l}\text { BW and high-energy } \\
\text { diet }\end{array}$ & $\mathrm{SD}$ rats & IRS-1, JNK & (Liu et al., 2016) \\
\hline In vivo & Insulin resistance & $\begin{array}{l}\text { Parkinsonia aculeata } \\
\text { (Caesalpineaceae) }\end{array}$ & High-fat diet & Mice & $\mathrm{AMPK} \alpha$ & (Araujo et al., 2016) \\
\hline In vivo & Insulin resistance & $\begin{array}{l}\text { The fruit of Acanthopanax } \\
\text { senticosus (Rupr. et Maxim). } \\
\text { Harms }\end{array}$ & High-fat diet & Mice & AMPK & (Saito et al., 2016) \\
\hline In vitro & $\begin{array}{l}\text { Type } 2 \text { diabetic } \\
\text { mellitus }\end{array}$ & $\begin{array}{l}\text { Nymphaea nouchali Burm. f. } \\
\text { (Family - Nymphaeaceae) }\end{array}$ & $\mathrm{MDI}$ & 3T3-L1 adipocytes & PPAR $\gamma$, GLUT4 & $\begin{array}{l}\text { (Parimala et al., } \\
\text { 2015) }\end{array}$ \\
\hline In vivo & $\begin{array}{l}\text { Type } 2 \text { diabetic } \\
\text { mellitus }\end{array}$ & $\begin{array}{l}\text { Cordyceps militaris number } 1 \\
\text { (CmNo1) }\end{array}$ & High-fat diet & Mice & IRS-1, Akt, GLUT4 & (Yu et al., 2015) \\
\hline In vitro & Insulin resistance e & $\begin{array}{l}\text { 6 } \alpha \text {-Hydroxylup-20(29)-en-3- } \\
\text { on-28-oic acid (1) }\end{array}$ & $\begin{array}{l}\text { Dexamethasone } \\
\text { (DXM) }\end{array}$ & 3T3-L1 adipocytes & PI3K/Akt, GLUT4 & (Qin et al., 2015) \\
\hline In vivo & $\begin{array}{l}\text { Insulin resistance } \\
\text { and hyperlipidemia }\end{array}$ & Ergostatrien-3 $\beta$-ol (EK100) & High-fat diet & C57BL/6J mouse & GLUT4, AMPK & (Kuo et al., 2015) \\
\hline In vitro & Insulin resistance & $\begin{array}{l}\text { Coptidis Rhizoma extracts } \\
\text { (CRE) }\end{array}$ & $\begin{array}{l}\text { Tumor necrosis } \\
\text { factor- } \alpha\end{array}$ & 3T3-L1 adipocytes & PPAR- $\gamma$, IRS- 1 & (Yuan et al., 2014) \\
\hline In vivo & $\begin{array}{l}\text { Metabolic } \\
\text { syndrome }\end{array}$ & Gastrodia elata Blume (EGB) & High-fructose diet & Rats & AMPK & (Kho et al., 2014) \\
\hline In vivo & $\begin{array}{l}\text { Adipose } \\
\text { dysfunction and } \\
\text { insulin resistance }\end{array}$ & $\begin{array}{l}\text { Cyclocarya paliurus leaves } \\
\text { extracts (CPE) }\end{array}$ & Mac-CM & Mice & IRS-1, Akt & (Jiang et al., 2014) \\
\hline $\begin{array}{l}\text { In vivo and } \\
\text { in vitro }\end{array}$ & Diabetic & Oroxylum indicum Vent. (OI) & STZ & $\begin{array}{l}\text { Rats and } 3 \text { T3-L1 } \\
\text { adipocytes }\end{array}$ & GLUT4 & $\begin{array}{l}\text { (Singh and Kakkar, } \\
\text { 2013) }\end{array}$ \\
\hline In vivo & Diabetic & $\begin{array}{l}\text { Citrus sinensis fruit peel } \\
\text { (CSMe) }\end{array}$ & $\begin{array}{l}\text { High-fat diet and } \\
\text { STZ }\end{array}$ & Rats & PPAR $\gamma$, GLUT4 & $\begin{array}{l}\text { (Sathiyabama et al., } \\
\text { 2018) }\end{array}$ \\
\hline In vivo & $\begin{array}{l}\text { Type } 2 \text { diabetic } \\
\text { mellitus }\end{array}$ & $\begin{array}{l}\text { Nardostachys jatamansi DC } \\
\text { extract (NJE) }\end{array}$ & $\begin{array}{l}\text { Pelletized } \\
\text { commercial chow } \\
\text { diet }\end{array}$ & $\begin{array}{l}\text { C57BL/KsJ-db/db } \\
\text { mice }\end{array}$ & AMPK & (You et al., 2018) \\
\hline $\begin{array}{l}\text { In vivo and } \\
\text { in vitro }\end{array}$ & $\begin{array}{l}\text { Type } 2 \text { diabetic } \\
\text { mellitus }\end{array}$ & Catalpol & $\begin{array}{l}\text { High-fat diet and } \\
\text { STZ/glucosamine } \\
\text { administration }\end{array}$ & $\begin{array}{l}\text { C57BL/6J mice/ } \\
\text { HepG2 cells }\end{array}$ & PI3K/Akt, AMPK & (Yan et al., 2018) \\
\hline In vivo & Insulin resistance & Ethyl acetate fraction (EAF) & $\begin{array}{l}\text { High-fat diet, } \\
\text { STZ,nicotinamide }\end{array}$ & Rats & IRS1, Akt & (Ooi et al., 2018) \\
\hline $\begin{array}{l}\text { In vivo and } \\
\text { in vitro }\end{array}$ & Obesity & $\begin{array}{l}\text { Epigallocatechin-3-Gallate- } \\
\text { Rich Green Tea Extract }\end{array}$ & High-fat diet & $\begin{array}{l}\text { Male c57BL/6 } \\
\text { mice/HepG2 cells }\end{array}$ & AMPK & (Bae et al., 2018) \\
\hline In vivo & $\begin{array}{l}\text { Type } 2 \text { diabetic } \\
\text { mellitus }\end{array}$ & $\begin{array}{l}\text { M. charantia ethanol extracts } \\
\text { (MCE) }\end{array}$ & $\begin{array}{l}\text { High-fat diet, } \\
\text { streptozotocin (STZ) }\end{array}$ & Rats & JNK, GLUT4 & (Ma et al., 2017) \\
\hline $\begin{array}{l}\text { In vivo and } \\
\text { in vitro }\end{array}$ & Insulin resistance & $\begin{array}{l}\text { Caffeic acid phenethyl ester } \\
\text { (CAPE) }\end{array}$ & - & $\begin{array}{l}\text { Mice and HepG2 } \\
\text { Cell }\end{array}$ & $\mathrm{JNK}, \mathrm{NF}-\kappa \mathrm{B}, \mathrm{IRS} 1$ & $\begin{array}{l}\text { (Nie and Chang, } \\
\text { 2017) }\end{array}$ \\
\hline In vivo & $\begin{array}{l}\text { Type } 2 \text { diabetic } \\
\text { mellitus }\end{array}$ & Aged garlic extract (AGE) & - & $\begin{array}{l}\text { Tsumura Suzuki } \\
\text { mice }\end{array}$ & AMPK & (Miki et al., 2017) \\
\hline $\begin{array}{l}\text { In vivo and } \\
\text { in vitro }\end{array}$ & $\begin{array}{l}\text { Insulin resistance/ } \\
\text { type } 2 \text { diabetic } \\
\text { mellitus }\end{array}$ & $\begin{array}{l}\text { Sea buckthorn fruit oil is rich } \\
\text { in palmitoleic acid (POA) }\end{array}$ & - & $\begin{array}{l}\text { HepG2 cells/SD } \\
\text { rats }\end{array}$ & PI3K/Akt, GSK-3 $\beta$ & (Gao et al., 2017) \\
\hline In vitro & Insulin resistance & $\begin{array}{l}\text { Opuntia ficus-indica var. } \\
\text { saboten (OFS) }\end{array}$ & DMEM & L6 muscle cells & $\begin{array}{l}\text { AMPK, p38 MAPK, } \\
\text { GLUT4 }\end{array}$ & (Leem et al., 2016) \\
\hline In vivo & Obesity & $\begin{array}{l}\text { P. grandiflorus root ethanol } \\
\text { extract (PGE) }\end{array}$ & High-fat diet & C57BL/6J mice & PPAR $\alpha$, PPAR $\gamma$ & (Kim et al., 2016) \\
\hline In vivo & Obesity & $\begin{array}{l}\text { Parkinsonia aculeata (HEPa/ } \\
\text { EtOAc) }\end{array}$ & High-fat diet & C57BL/6J mice & AMPK & (Araujo et al., 2016) \\
\hline $\begin{array}{l}\text { In vivo and } \\
\text { in vitro }\end{array}$ & Insulin resistance & $\begin{array}{l}\text { Rhizoma Anemarrhenae } \\
\text { extract (TFA) }\end{array}$ & STZ & $\begin{array}{l}\text { Mice/3T3-L1 and } \\
\text { Hela cells }\end{array}$ & AMPK & (Han et al., 2015) \\
\hline $\begin{array}{l}\text { In vivo and } \\
\text { in vitro }\end{array}$ & Insulin resistance & Toona Sinensis leaf (TSL) & High-fat diet/AS160 & $\begin{array}{l}\text { Mice/C2C12 } \\
\text { myotubes }\end{array}$ & AMPK, PPAR $\gamma$ & (Liu H. et al., 2015) \\
\hline
\end{tabular}


TABLE 5 | Continued

\begin{tabular}{|c|c|c|c|c|c|c|}
\hline Type & Model & Natural product & Inducer & Animal/cell & Major findings & References \\
\hline $\begin{array}{l}\text { In vitro and } \\
\text { in vivo }\end{array}$ & $\begin{array}{l}\text { Type } 2 \text { diabetes } \\
\text { mellitus }\end{array}$ & Fumosorinone (FU) & - & $\begin{array}{l}\text { HepG2 cells/KKAy } \\
\text { mice }\end{array}$ & $\begin{array}{l}\text { IRS2, Akt, GSK3 } \beta \text {, } \\
\text { PTP1B }\end{array}$ & (Liu Z. et al., 2015) \\
\hline $\begin{array}{l}\text { In vitro and } \\
\text { in vivo }\end{array}$ & Insulin resistance & Ginseng berry extract (GBD) & DMEM & $\begin{array}{l}\text { C57BL/6 mice/ } \\
\text { C2C12 cell }\end{array}$ & PPAR $\gamma$. IRS1, Akt & (Yang et al., 2015) \\
\hline In vivo & $\begin{array}{l}\text { Type } 2 \text { diabetes } \\
\text { mellitus }\end{array}$ & $\begin{array}{l}\text { Bitter melon (BM; Momordica } \\
\text { charantia) }\end{array}$ & High-fat diet & OLETF rats & $N F-\kappa B, J N K$ & (Seo et al., 2015) \\
\hline In vivo & Obesity & Ginkgo biloba extract (GbE) & High-fat diet & Rats & IRS1, PTP1B & (Banin et al., 2014) \\
\hline In vivo & $\begin{array}{l}\text { Metabolic } \\
\text { syndrome }\end{array}$ & Zingiber officinale & $\begin{array}{l}\text { High-fat high- } \\
\text { carbohydrate diet }\end{array}$ & $\begin{array}{l}\text { Rats/L6 skeletal } \\
\text { muscle cells }\end{array}$ & AMPK & (Li Y. et al., 2014) \\
\hline $\begin{array}{l}\text { In vitro and } \\
\text { in vivo }\end{array}$ & Insulin resistance & M. koenigii (MK) & High-fat diet & $\begin{array}{l}\text { Mice/L6 skeletal } \\
\text { muscle cells }\end{array}$ & GLUT4, Akt & (Pandey et al., 2014) \\
\hline In vivo & Obesity & $\begin{array}{l}\text { Artemisia scoparia (SCO) and } \\
\text { Artemisia santolinifolia (SAN) }\end{array}$ & High-fat diet & C57BL/6J mice & PPAR $\gamma$ & (Richard et al., 2014) \\
\hline In vitro & Insulin resistance & Cinnamon extract (CE) & - & $\begin{array}{l}\text { 3T3-L1 adipocytes } \\
\text { and C2C12 } \\
\text { myocytes }\end{array}$ & AMPK & (Shen et al., 2014) \\
\hline In vivo & Obesity & $\begin{array}{l}\text { Extracts of Artemisia } \\
\text { santolinaefolia (SANT) and } \\
\text { Artemisia scoparia (SCO) }\end{array}$ & High-fat diet & C57/B6J mice & AMPK & (Wang et al., 2013) \\
\hline
\end{tabular}

similar to the pharmacological action of thiazolidinedione (Peraldi et al., 1997). In addition, degenerative neuropathies such as Alzheimer's disease (Talbot and Wang, 2014) and multiple system atrophy (Bassil et al., 2017) are also closely related to brain IR caused by blocked IRS signaling. Defects in IRS-1 may cause vascular damage and accelerate the progression of atherosclerosis (Abe et al., 1998), while IRS-2 delays neointimal formation under IR (Kubota et al., 2003). Gal-geun-dang-gwitang attenuates endothelial dysfunction by promoting nitric oxide (NO)-cyclic guanosine monophosphate (cGMP) signaling and improves insulin sensitivity in individuals with diabetic atherosclerosis. Gal-geun-dang-gwi-tang was also shown to be associated with restored expression of IRS-1 in the thoracic aorta and skeletal muscle (Lee et al., 2014).

\section{PI3K/Akt Signaling Pathway Signal Transduction}

Glucose is mainly metabolized in insulin-sensitive tissues by two pathways: the classical phosphatidylinositol 3-kinase (PI3K) pathway and the 5'-AMP activating kinase (AMPK) signal transduction pathway (Jeong et al., 2017). Tyrosine phosphorylation of the insulin receptor substrate activates PI3K, and activated PI3K catalyzes 4,5-2 phosphatidylinositol (PIP2) and produces PIP3, which acts as a second messenger that activates Akt (White, 2003). Activated Akt promotes downstream molecules that regulate metabolism. Liuwei Dihaung decoction can be used to treat IR by regulating the PI3K/Akt signaling pathway in the liver of rats with T2D, accompanied by phosphorylation and upregulation of PI3K/Akt pathway-associated proteins (Dai et al., 2016). PI3K is composed of a regulatory subunit p 85 and a catalytic subunit p110 (Geering et al., 2007) and has dual activities of phosphatidylinositol kinase and serine/threonine (Ser/Thr) protein kinase. Heterozygous mutations in the PI3Kp85 regulatory subunit gene often result in metabolic disorders such as IR associated with decreased ability to activate PI3K in muscle and adipose tissue (Winnay et al., 2016). Significant damage to PI3K signaling in muscle often results in muscle IR and systemic glucose intolerance (Luo et al., 2006). Central glucagon-like peptide 2 can enhance hepatic insulin sensitivity by activating G3-2R-p85a interactions in PI3K signaling in proopiomelanocortin neurons (Shi et al., 2013). Different proportions of Jiaotai Pill enhance PI3K pathway insulin signaling by upregulating the expression of the PI3K p85 subunit in skeletal muscle, attenuating the development of diabetes in a rat model of T2D (Dong et al., 2013). Akt has three isoforms, of which Akt1 and Akt2 are highly expressed in skeletal muscle and have unique and overlapping functions (Matheny et al., 2018). Overexpression of Aktl is associated with increased beta cell size and total islet mass (Tuttle et al., 2001), and Akt2 is more important for insulin-stimulated glucose metabolism (Bouzakri et al., 2006). Defects in signaling pathways caused by mutations in the protein kinase $A k t 2 / P K B$ gene often impair the ability of insulin to lower blood glucose in the liver and skeletal muscle (George et al., 2004). Paeoniflorin improves TNF- $\alpha$-induced IR in adipocytes and is associated with insulin-stimulated Akt phosphorylation recovery in adipocytes (Kong et al., 2013). Akt2 is involved in glucose uptake by insulin-regulated muscle and adipocytes by promoting the transport of GLUT-4 to the cell surface (Ng et al., 2008), as is metformin, which also increases liver Akt phosphorylation and promotes GLUT- 4 translocation (Garabadu and Krishnamurthy, 2017). Jiangzhi capsule improved fructose-induced IR and repaired the damaged muscle fiber membrane GLUT- 4 cycle by regulating the ratio of phosphorylated Akt to total Akt in the gastrocnemius muscle (Jiang L. et al., 2016). Akt2 is required for hepatic lipid accumulation in obese and insulin-resistant states induced by leptin deficiency or high-fat diet (HFD) (Leavens et al., 2009). Modified lingguizhugan decoction improves liver fat accumulation and IR in rats with metabolic syndrome by inhibiting abnormal increases in leptin and PKB in the liver (Yao et al., 2017). 
TABLE 6 | Herbal formula that improves insulin resistance.

\begin{tabular}{|c|c|c|c|c|c|c|}
\hline Type & Model & Herbal formula & Inducer & Animal/cell & Major findings & References \\
\hline In vivo & $\begin{array}{l}\text { Type } 2 \text { diabetic } \\
\text { mellitus }\end{array}$ & SGY preparation & High-fat diet and STZ & $\mathrm{db} / \mathrm{db}$ mice & $\begin{array}{l}\text { PI3K/Akt, IRS-1, } \\
\text { GLUT4 }\end{array}$ & $\begin{array}{l}\text { (Xing and Chen, } \\
\text { 2018) }\end{array}$ \\
\hline In vivo & $\begin{array}{l}\text { Type } 2 \text { diabetic } \\
\text { mellitus }\end{array}$ & Dai-Zong-Fang & - & $\mathrm{db} / \mathrm{db}$ mice & $\begin{array}{l}\text { Akt, IRS-1, AMPK, } \\
\text { GLUT4 }\end{array}$ & (Zhu et al., 2018) \\
\hline In vitro & Insulin resistance & Zengye Decoction (ZYD) & Insulin-induced & HepG2 cells & AMPK & (Liu Z. et al., 2018) \\
\hline In vivo & Diabetic & $\begin{array}{l}\text { Jia-Wei-Jiao-Tai-Wan } \\
\text { (JWJTW) }\end{array}$ & $\begin{array}{l}\text { STZ and a high-sucrose- } \\
\text { high-fat diet }\end{array}$ & Rats & IRS, PI3K, GLUT4 & (Chen et al., 2017) \\
\hline In vivo & $\begin{array}{l}\text { Insulin resistance } \\
\text { and nonalcoholic } \\
\text { fatty liver disease }\end{array}$ & Seyoeum (SYE) & High-fat diet & C57BL/6 mice & IRS-1, IRS-2 & (Na et al., 2017) \\
\hline In vitro & Insulin resistance & Wu-Mei-Wan & Palmitate & HepG2 cells & $\begin{array}{l}\text { PI3K/Akt, GLUT4, } \\
\text { IRS }\end{array}$ & (Yang et al., 2017) \\
\hline $\begin{array}{l}\text { In vivo and } \\
\text { in vitro }\end{array}$ & $\begin{array}{l}\text { Type } 2 \text { diabetic } \\
\text { mellitus }\end{array}$ & Preparation JQ-R & Palmitic acid & $\begin{array}{l}\text { KKAy mice and } \\
\text { cells }\end{array}$ & $\begin{array}{l}\text { NF-кB, PI3K/AKt, } \\
\text { JNK, MAPK }\end{array}$ & (Liu et al., 2017) \\
\hline In vivo & $\begin{array}{l}\text { Type } 2 \text { diabetic } \\
\text { mellitus }\end{array}$ & $\begin{array}{l}\text { Fenugreek seed and } \\
\text { mulberry leaf }\end{array}$ & High-fat diet and alloxan & Rats & GLUT4 & (Kan et al., 2017) \\
\hline $\begin{array}{l}\text { In vivo and } \\
\text { in vitro }\end{array}$ & Insulin resistance & $\begin{array}{l}\text { Erchen Decoction and } \\
\text { Linguizhugan Decoction }\end{array}$ & High-fat diet & Rats & $N F-\kappa B, I R S-1$ & (Zhang H. et al., 2017) \\
\hline In vivo & $\begin{array}{l}\text { Chronic partial } \\
\text { sleep deprivation, } \\
\text { obesity-resistant }\end{array}$ & Jiao-Tai-Wan (JTW) & $\begin{array}{l}\text { High-fat, high-energy } \\
\text { diet, environmental noise }\end{array}$ & SD rats & NF-кB & (Zou et al., 2017) \\
\hline In vivo & $\begin{array}{l}\text { Metabolic } \\
\text { syndrome }\end{array}$ & $\begin{array}{l}\text { Modified lingguizhugan } \\
\text { decoction }\end{array}$ & High-fat diet & Rat & Akt & (Yao et al., 2017) \\
\hline In vivo & $\begin{array}{l}\text { Type } 2 \text { diabetic } \\
\text { mellitus }\end{array}$ & $\begin{array}{l}\text { Jiang Tang Xiao Ke } \\
\text { (JTXK) granule }\end{array}$ & High-fat diet and STZ & KKAy mice & $\begin{array}{l}\text { PI3K/Akt, IRS-1, } \\
\text { GLUT4, GSK3 } \beta\end{array}$ & (Yu et al., 2017) \\
\hline In vivo & Insulin resistance & Jiangzhi Capsule & Liquid fructose & Rats & GLUT4, Akt & (Jiang L. et al., 2016) \\
\hline In vivo & $\begin{array}{l}\text { Type } 2 \text { diabetes } \\
\text { mellitus }\end{array}$ & Liuwei Dihuang decoction & High-fat diets and STZ & SD rats & PI3K/Akt, IRS2 & (Dai et al., 2016) \\
\hline In vivo & $\begin{array}{l}\text { Type } 2 \text { diabetic } \\
\text { mellitus }\end{array}$ & $\begin{array}{l}\text { ZiBu PiYin Recipe } \\
\text { (ZBPYR) }\end{array}$ & High-fat diets and STZ & Rat & GSK3 $\beta$ & (Sun Z. et al., 2016) \\
\hline In vivo & Insulin resistance & Jinlida & High-fat diet & Mice & IRS-1 & (Jin et al., 2015) \\
\hline In vivo & $\begin{array}{l}\text { Polycystic ovary } \\
\text { syndrome }\end{array}$ & $\begin{array}{l}\text { Shouwu Jiangqi } \\
\text { Decoction (SJD) }\end{array}$ & $\begin{array}{l}\text { Sodium sulfate } \\
\text { prasterone, high-fat diet }\end{array}$ & SD rats & IRS-1, PI3K & (Wang et al., 2016) \\
\hline In vivo & Pre-diabetic & Tang-Nai-Kang (TNK) & & Rats & AMPK, PPAR $\gamma$ & (Li et al., 2015) \\
\hline In vivo & Insulin resistance & Jinlida (JLD) & High-fat diet & Rats & JNK, p38MAPK & (Liu Y. et al., 2015) \\
\hline In vitro & Insulin resistance & $\begin{array}{l}\text { Modified Si-Miao-San } \\
\text { (mSMS) }\end{array}$ & $\begin{array}{l}\text { Conditioned medium } \\
\text { derived from activated } \\
\text { macrophages }\end{array}$ & 3T3-L1 adipocytes & $\begin{array}{l}\text { NF-кB, AMPK, PI3K, } \\
\text { IRS-1 }\end{array}$ & (Yang J. et al., 2014) \\
\hline In vivo & $\begin{array}{l}\text { Diabetic } \\
\text { atherosclerosis }\end{array}$ & $\begin{array}{l}\text { Gal-geun-dang-gwi-tang } \\
\text { (GGDGT) }\end{array}$ & Western diet & (ApoE-/-) mice & IRS-1 & (Lee et al., 2014) \\
\hline $\begin{array}{l}\text { In vivo and } \\
\text { in vitro }\end{array}$ & Insulin resistance & $\begin{array}{l}\text { Gyeongshingangjeehwan } \\
18 \text { (GGEx18) }\end{array}$ & High-fat diet & $\begin{array}{l}\text { C57BL/6J mice } \\
\text { and 3T3-L1 } \\
\text { adipocytes }\end{array}$ & AMPK, PPAR $\alpha$ & (Oh et al., 2015) \\
\hline $\begin{array}{l}\text { In vivo and } \\
\text { in vitro }\end{array}$ & Insulin resistance & $\begin{array}{l}\text { Salvia-Nelumbinis } \\
\text { naturalis (SNN) }\end{array}$ & $\mathrm{HC}$ diet & $\begin{array}{l}\text { HepG2 cells and } \\
\text { rats }\end{array}$ & Akt, IRS & (Zhang et al., 2014) \\
\hline In vivo & Insulin resistance & $\begin{array}{l}\text { Kangen-karyu and } \\
\text { Salviae Miltiorrhizae Radix }\end{array}$ & - & Rats & $\begin{array}{l}\text { PI3K/Akt, p38MAPK, } \\
\text { NF-кB }\end{array}$ & (Park C. et al., 2014) \\
\hline In vivo & $\begin{array}{l}\text { Polycystic ovarian } \\
\text { syndrome }\end{array}$ & $\begin{array}{l}\text { Bushen Huatan Recipe } \\
\text { (BHR) }\end{array}$ & Dehydroeplandrosterone & Rats & $\begin{array}{l}\text { Akt, GSK-3 } \beta \text {, GLUT4, } \\
\text { IRS- } 1 \text {, PPAR- } \gamma\end{array}$ & (Hong and Wu, 2014) \\
\hline $\begin{array}{l}\text { In vivo and } \\
\text { in vitro }\end{array}$ & $\begin{array}{l}\text { Metabolic } \\
\text { syndrome }\end{array}$ & $\begin{array}{l}\text { Fu Fang Zhen Zhu Tiao } \\
\text { Zhi formula (FTZ) }\end{array}$ & $\begin{array}{l}\text { High insulin and high-fat } \\
\text { diet }\end{array}$ & $\begin{array}{l}\text { HepG2 cells and } \\
\text { rats }\end{array}$ & PI3K, IRS-1 & (Hu et al., 2014) \\
\hline In vivo & $\begin{array}{l}\text { Type } 2 \text { diabetic } \\
\text { mellitus }\end{array}$ & $\begin{array}{l}\text { Fructus Mume formula } \\
\text { and its separated } \\
\text { prescription }\end{array}$ & High-fat diet and STZ & Rats & IRS-1, GIUT-4 & (Li et al., 2013) \\
\hline In vivo & Insulin resistance & Refined-JQ (JQ-R) & High-fat diet & C57BL/6J mice & AMPK & (Gao et al., 2014) \\
\hline In vivo & $\begin{array}{l}\text { Type } 2 \text { diabetes } \\
\text { mellitus }\end{array}$ & $\mathrm{TZQ}-\mathrm{F}$ & High-fat diet & $\mathrm{KKA}(\mathrm{y})$ mice & $\begin{array}{l}\text { PPAR } \gamma, \text { IRS-1, IRS-2, } \\
\text { GLUT1, PI3K }\end{array}$ & (Nan Xia et al., 2013) \\
\hline In vivo & $\begin{array}{l}\text { Type } 2 \text { diabetes } \\
\text { mellitus }\end{array}$ & Jiaotai Pill (JTP) & STZ and high fat diet & Rats & PI3K, IRS-1, GLUT4 & (Dong et al., 2013) \\
\hline In vivo & $\begin{array}{l}\text { Polycystic ovary } \\
\text { syndrome }\end{array}$ & Heqi San & Dehydroepiandrosterone & Female SD rats & PI3K/Akt, GLTU4 & (Zhao et al., 2017) \\
\hline In vivo & $\begin{array}{l}\text { Type } 2 \text { diabetes } \\
\text { mellitus }\end{array}$ & Fructus Mume formula & High-fat diet and STZ & Rats & IRS-1, GLUT4 & (Li et al., 2013) \\
\hline
\end{tabular}




\section{Glucose Transporters Signal Transduction}

There are currently 13 known sugar transporter proteins (GLUT112 and HMIT) encoded in the human genome (Joost and Thorens, 2001). Based on sequence similarity and characteristic elements, the extended GLUT family can be divided into three subfamilies, of which class I contains the glucose transporters GLUT1-4, which all show tissue/cell specific expression (Wood and Trayhurn, 2003). GLUT-4 is highly expressed in adipose tissue and skeletal muscle (Bogan, 2012). The main cellular mechanism for handling exogenous glucose load is insulin-stimulated glucose transport into skeletal muscle, and the primary glucose transporter that mediates this uptake is GLUT-4 (Huang and Czech, 2007). Oxidative stress caused by overnutrition often induces GLUT- 4 inactivation by carbonylation and oxidation (Boden et al., 2015), and related gene variants (Stenbit et al., 1997) often lead to GLUT-4 deficiency and downregulation in skeletal muscle and adipose tissue (Zisman et al., 2000; Abel et al., 2001). Exercise and caloric restriction can upregulate GLUT- 4 gene expression and increase insulininduced GLUT-4 transport to the plasma membrane (Richter and Hargreaves 2013; Zanquetta et al., 2003). A novel botanical formula containing standardized extracts of mulberry leaf, fenugreek seed, and American ginseng can attenuate the decrease in GL UT-4 expression induced by an HFD and alloxan (Kan et al., 2017). A key step in the physiological role of GLUT-4 is translocation (Bai et al., 2007), in which GLUT-4 is redistributed from the intracellular pool to the plasma membrane under the regulation of the Akt substrate AS160 rab GTPaseactivating protein (Sano et al., 2007). Studies have shown that cold exposure therapy can significantly increase GLUT-4 translocation in basal skeletal muscle and may be a potential treatment for diabetes (Hanssen et al., 2015). Oroxylum indicum stem bark extract significantly enhanced insulin sensitivity in mature 3T3-L1 adipocytes, as evidenced by increased skeletal muscle GLUT-4 translocation (Singh and Kakkar, 2013). GLUT-2 is mainly found in the liver, intestine, kidney, and pancreatic beta cells (Wood and Trayhurn, 2003), and it plays an important role in glucose transport and energy metabolism because it promotes glucose uptake or liver efflux (Thorens et al., 1992). Sang-TongJian, a new formulation of flavonoids and alkaloids from mulberry leaves, improves IR in KKAy mice, which is associated with upregulation of GLUT-2 (liver) gene, and protein expression (Kuai et al., 2016). GLUT-1 is expressed at the highest level in the endothelial tissues of barrier tissues such as blood vessels and blood-brain barriers, and moderate levels of expression are also observed in adipose tissue, muscle, and liver, which play an important role in supplying glucose to organs such as the brain (Deng et al., 2014; Tang et al., 2017). Chinese herbal formula TZQ-F treatment upregulates the expression of related proteins such as GLUT-1, which regulates the potency of insulin action and is beneficial for reducing hyperinsulinemia (Nan Xia et al., 2013).

\section{AMP-Activated Protein Kinase Signal Transduction}

AMPK is a conserved, ubiquitously expressed heterotrimeric serine/threonine protein kinase (Kahn et al., 2005) that plays a key role in regulating cellular energy metabolism (Lage et al., 2008). AMPK integrates nutrient and hormonal signals in peripheral tissues and the hypothalamus and is regulated by multiple hormones such as leptin, adiponectin, ciliary neurotrophic factor, and ghrelin (Minokoshi et al., 2002; Watt et al., 2006; Zhao L. et al., 2015). AMPK plays an important role in regulating food intake, body weight, glucose, and lipid metabolism (Minokoshi et al., 2004). In addition, AMPK can also be activated in response to cellular stress, exercise (Cantó et al., 2010), and drugs (Sasaki et al., 2009). Based on traditional Chinese medicine, Dai-ZongFang improves insulin sensitivity in $\mathrm{db} / \mathrm{db}$ diabetic mice by inhibiting liver lipids and enhancing energy metabolism in skeletal muscle by inhibiting AMPK activation (Zhu et al., 2018). Under physiological conditions, AMPK is mainly present in an inactive form complexed with Mg-ATP, which is more abundant than AMP (Xiao et al., 2011). An increase in AMP concentration activates AMPK, and by phosphorylating the activation loop within the kinase domain (Li et al., 2011), AMPK transitions from an inactive form to a catalytic form: binding of AMP to the c-regulatory domain promotes phosphorylation of the upstream kinase and causes allosteric activation, and inhibition of the dephosphorylation of Thr172 in the kinase domain activation loop regulates AMPK phosphorylation levels (Xiao et al., 2007). Goka fruit supplements improve IR and liver lipid accumulation in mice with HFD-induced obesity by increasing AMPK phosphorylation in the liver. AMPK in adipocytes is critical for maintaining mitochondrial integrity, responding to pharmacological agents and heat stress, and protecting against nutrient overload-induced NAFLD and IR (Kishton et al., 2016; Mottillo et al., 2016). Modified Si-Miao-San positively regulates AMPK phosphorylation to promote basal glucose uptake by 3T3-L1 adipocytes and beneficially improves insulin signaling by inhibiting inflammation in adipocytes (Yang J. et al., 2014). Adiponectin is a major insulinsensitized adipokine (Kadowaki and Yamauchi, 2011). It has been shown that adiponectin and its receptors AdipoR1 and AdipoR2 enhance glucose and fatty acid metabolism by activating AMPK in peripheral tissues (Kubota et al., 2007). The herbal composition GGEx18 can treat visceral obesity and visceral obesity-related IR by upregulating visceral fat expression of fatty acid oxidation genes. The results show that the expression of fatty acid oxidation genes, including genes encoding adiponectin, AMPK, and others, is significantly increased in mesenteric adipose tissue of 3T3-L1 adipocytes and obese mice (Oh et al., 2015).

\section{Glycogen Synthase Kinase 3 Signal Transduction}

GSK-3 is a ubiquitous cytosolic serine/threonine protein kinase expressed in mammalian tissues as two closely related isoforms: GSK-3 $\alpha$ and GSK-3 $\beta$ (Dajani et al., 2001). GSK-3 is constitutively active under resting conditions and regulates human metabolism through phosphorylation of glycogen synthase and other substrates (Kaidanovich and Eldar-Finkelman, 2002). Inhibition of GSK-3 is required for insulin-stimulated glycogen and protein synthesis, and its inhibition is critical for the normal functioning of insulin-activated signaling pathways (Ali et al., 2001). The skeletal muscle GSK-3 activity and its expression level were significantly increased in patients with T2D (Saltiel and Kahn, 2001), and abnormally excessively elevated GSK-3 resulted in 
further inhibition of glycogen synthase activity. A large body of evidence indicates that GSK-3 inhibitors have therapeutic uses in neurodegenerative diseases, cancer, and T2D (Patel and Woodgett, 2008; Hur and Zhou, 2010; Martinez et al., 2002). Jiangtangxiaoke granules are an effective drug for T2D, since this treatment can regulate the expression of glycogen synthase kinase $3 \beta$ (GSK3 $\beta$ ) by regulating the PI3K/Akt signaling pathway in skeletal muscle of mice with T2D (Yu et al., 2017). Insulin-induced GSK-3 inhibition is mediated through its downstream target protein kinase B (PKB), which phosphorylates and inactivates GSK-3 at Ser9/21 (Cross et al., 1995; Frame et al., 2001). ZiBu PiYin recipe treatment alters insulin signaling in T2DM rats in association with inhibited GSK3 $\beta$ overexpression resulting from increased p-GSK3 $\beta$ levels in the pre-frontal cortex and hippocampus (Sun Z. et al., 2016). Abnormal overactivity of GSK-3 may also limit IR-mediated signaling through phosphorylation of IRS-1. Polydatin significantly increased phosphorylated GSK-3 $\beta$ and increased protein levels of phosphorylated IRS in liver and insulin-resistant HepG2 cells of diabetic rats (Hao et al., 2014). Therefore, GSK-3 inhibitors can be a promising new drug for diabetic IR.

\section{P38 Mitogen-Activated Protein Kinase Signal Transduction}

MAPKs and their downstream targets are important signaling modules for cellular responses to changes in the physical and chemical properties of the environment (Cuenda et al., 2017). It is known that MAPK has at least four subfamilies in mammalian cells: p38 kinase (p38 $, \beta, \gamma$, and $\delta$ ), extracellular signal-regulated kinase (ERK1/2), ERK5, and Jun amino terminal kinase (JNK1-3) (Gehart et al., 2010). Insulin activates the PI3K/Akt pathway, which is responsible for glucose uptake, and the MAPK pathway, which is critical for IR (Saltiel and Kahn, 2001). MAPK is involved in a variety of processes that control hepatic metabolism (Lawan and Bennett, 2017). Obesity and inflammationrelated stress responses in insulin-responsive tissues activate liver MAPKs, which are thought to impair insulin action and lipid metabolism (Hotamisligil and Davis, 2016). MAPK phosphatases (MKPs) can dephosphorylate MAPK to catalyze the inactivation of MAPK (Gehart et al., 2010). Baicalin plays an important role in reversing HFD-induced glucose intolerance and IR in diet-induced obese mice, and its mechanism is associated with downregulation of p-p38 MAPK levels (Fang et al., 2018). Reactive oxygen species (ROS)-mediated activation of p38MAPK stress response signaling has been recognized as one of the causes of insulin signaling damage and hepatic IR (Al-Lahham et al., 2016). Jinlida, a compound preparation based on traditional Chinese medicine, can attenuate oxidative stress and reduce phosphorylation of p38MAPK and JNK in high-fat fed rats, showing antioxidant effects and upregulation of insulin signaling (Liu Y. et al., 2015).

\section{C-Jun-N-Terminal Kinase Signal Transduction}

The JNK is a member of the MAPK family, and three JNK isoforms exist in mammals: JNK1, JNK2, and JNK3 (Lawan and
Bennett, 2017). JNK1 and JNK2 are expressed in almost all celRls, including liver parenchymal cells, while JNK3 is mainly expressed in the brain, heart, and testis (Seki et al., 2012). Cytokines, ROS, endoplasmic reticulum stress, and free fatty acids activate JNK (Ozcan et al., 2004; Holzer et al., 2011; Zhao H. et al., 2015) and play a key role in metabolic disorders such as obesity, IR, and T2D (Vallerie and Hotamisligil, 2010). Lycium barbarum polysaccharide treatment effectively inhibits phospho-JNK levels in HFD-fed mice and reduces ROS levels via the PI3K/AKT/Nrf2 axis, acting as a novel anti-hyperlipideinduced IR oxidizer (Yang Y. et al., 2014). Stress factors such as non-esterified fatty acids are generally thought to induce inhibitory serine phosphorylation of IRS-1 through the JNK pathway and impair insulin signaling (Hirosumi et al., 2002; Gao et al., 2018). Studies have also confirmed that hepatocyte-specific deletion of JNK1 enhances IR (Sabio et al., 2009). Therefore, JNK may positively regulate hepatic insulin signaling, and in other insulin-sensitive organs, JNK negatively regulates insulin action, especially under stress conditions. This is the potential protective effect of mulberry leaf extract (MLE) and a formula consisting of MLE, fenugreek seed extract, and cinnamon cassia extract (MLEF) on hyperglycemia induced by high-energy diet and toxic chemicals in rats and recovery of insulin sensitivity, the most likely mechanism is the upregulation of phosphorylation of JNK and other related proteins in the liver to promote IRS-1 phosphorylation (Liu et al., 2016).

\section{Nuclear Factor-kappaB Signal Transduction}

$\mathrm{NF}-\kappa \mathrm{B}$ is a sequence-specific transcription factor that is a major regulator of inflammatory responses, including responses to inflammation and oxidative stress (Chiang et al., 2009). In the quiescent state, NF- $\kappa \mathrm{B}$ binds to the inhibitor subunit $\mathrm{I} \kappa \mathrm{B}$ in an inactive form in the cytoplasm. IKK- $\beta$ is required for activation during acute inflammation. Phosphorylation-activated IKK $\beta$ induces phosphorylation of IкB kinase a (Arkan et al., 2005) and $I \kappa B a$ phosphorylates I $\mathrm{\kappa} B$ and leads to proteolysis of I $\mathrm{KB}$, which exposes nuclear recognition sites for NF- $\kappa B$. NF- $\kappa B$ is translocated into the nucleus, resulting in the expression of related target genes such as inflammatory cytokines (Cai et al., 2005). Thus, blocking NF- $\kappa B$ signaling improves IR and prevents the development of diabetes (Wang et al., 2014). Jiao-TaiWan, composed of Rhizome Coptidis and Cortex Cinnamomi, reversibly increases markers of systemic inflammation and IR caused by sleep loss in Sprague-Dawley rats, and these changes are related to downregulation of NF- $\kappa \mathrm{B}$ mRNA expression in peripheral blood mononuclear cells (Zou et al., 2017). NF- $\mathrm{B}$ may represent an attractive therapeutic target for obesity, IR, diabetes, and other complications associated with these diseases.

\section{Protein Tyrosine Phosphatase 1B Signal Transduction}

Protein tyrosine phosphatase $1 \mathrm{~B}$ belongs to the protein tyrosine phosphatase (PTP) family (Tiganis, 2013) and has a catalytic domain characterized by an 11 amino acid sequence motif containing cysteine (Cys215) and arginine (Arg221) (Haque et al., 2011). These residues are critical to the catalytic activity 
of the enzyme. As a negative regulator of the insulin signaling cascade, PTP1B overexpression inhibits tyrosine phosphorylation of IR and IRS-1, enhances serine phosphorylation, thereby terminating insulin signaling (Johnson et al., 2002). Oligonol, a low molecular weight polyphenol mixture derived from lychee fruit, can significantly reduce $\mathrm{PTP} 1 \mathrm{~B}$ expression and reduce serine phosphorylation of IRS-1, improving insulin sensitivity in insulin-resistant HepG2 cells (Bhakta et al., 2017). In general, PTP1B inhibitors are a promising class of insulin sensitizers.

\section{Nuclear Factor-E2-Related Factor 2 Signal Transduction}

Nuclear factor erythrocyte 2-related factor 2 (Nrf2) is a key regulator of antioxidant signaling and plays a crucial role in maintaining redox homeostasis (Seo and Lee, 2013). Under physiological conditions, Nrf2 remains in the cytoplasm by binding to the endogenous inhibitor Keap1, which mediates rapid activation of the proteasome and subsequent degradation of Nrf2 (Zhang et al., 2015). Under exogenous and endogenous oxidative stress, Nrf2 becomes stable and released from the Keap1/Nrf2 complex, Nrf2 degradation is inhibited, and Nrf2 accumulates in the nucleus, synergistically enhancing the expression of various genes encoding antioxidant enzymes (Bhakkiyalakshmi et al., 2015). Many studies have shown that increased Nrf2 signaling can inhibit oxidative stress and improve insulin and leptin resistance (Yagishita et al., 2017). L. barbarum polysaccharide, an antioxidant from wolfberry, increases Nrf2 phosphorylation in livers of HFD-fed mice and HepG2 cells by inducing PI3K/AKT signaling and induces Nrf2/ARE signaling to reduce oxidative stress and maintain peripheral insulin sensitivity (Yang Y. et al., 2014).

\section{Peroxisome Proliferator-Activated Receptor Signal Transduction}

Peroxisome proliferator-activated receptors (PPARs) are nuclear receptors involved in the transcriptional control of genes encoding proteins involved in adipocyte differentiation, lipid and carbohydrate metabolism, and adipokine synthesis, including three isoforms encoded by different genes (Eldor et al., 2013). PPARa is highly expressed in liver, kidney, and skeletal muscle. PPAR $\gamma$ is also highly expressed in various cell types and organs, including fat cells, muscle cells, liver, and kidneys, and is considered to be a major regulator of glucose homeostasis (Haluzík and Haluzík, 2006). Studies have suggested that the production of future PPARa and $\gamma$ double agonists will simultaneously bring about favorable changes in PPARa lipid mass spectrometry and blood glucose benefits of PPAR $\gamma$ agonists (Massaro et al., 2016). The existing insulinsensitizing drug thiazolidinedione is a potent agonist of nuclear PPAR- $\gamma$ (Hevener et al., 2003). Based on the traditional anti-diabetic formula, TZQ-F can improve IR in KKA(y) mice through its efficacy in regulating adipocyte differentiation and insulin action, and the results indicate that its therapeutic effect is related to the upregulation of PPAR $\gamma$ expression in liver tissue (Nan Xia et al., 2013) and PPAR $\gamma$ coactivator 1a (PGC1a), which is a PPAR-mediated transcriptional coactivator of fatty acid oxidation (Koo et al., 2004). TangNai-Kang is a mixture of five herbal plant extracts that has been shown to improve glucose metabolism abnormalities in patients with pre-diabetes. Tang-Nai-Kang treatment can deacetylate PGC1a to activate it and synergize with PPAR expression to enhance fatty acid oxidation and improve insulin levels in rats (Li et al., 2015).

\section{CONCLUSIONS AND PERSPECTIVES}

IR is a pathological condition common to many metabolic diseases; the most well known of which is T2D. Some surveys show that China is one of the countries with the highest incidence of T2D in the world, and the number of people with diabetes in the adult population have exceeded 113.9 million in 2010 (Zheng et al., 2018). The global trend of other metabolic diseases associated with IR is also not optimistic. From 2003 to 2012, the overall prevalence of metabolic syndrome in the United States was 33\% (Aguilar et al., 2015). It is estimated that nearly 100 million people in the United States have NAFLD (Rinella, 2015). Global Burden of Disease studies have shown that the prevalence of obesity has doubled in 73 countries between 1980 and 2015 (Inoue et al., 2018). In addition, based on the 1990 National Institutes of Health standard, PCOS affects 6-10\% of women worldwide (Goodarzi et al., 2011), and studies have indicated that $56.3 \%$ of Han women in China with PCOS have IR ( $\mathrm{Li}$ et al., 2018). Therefore, in the face of such a large potential patient population, the harm caused by IR cannot be ignored. Herbs have been used in China for more than 2,000 years and are still considered effective drugs to prevent and treat various diseases. The discovery and application of artemisinin, a compound derived from Artemisia annua, is a good example. In recent years, research on Chinese medicine has gradually been standardized and systematized. China's latest guidelines for preventing and treating T2D are also the first to include Chinese medicine treatment.

The information presented in this review shows that herbal formulas, active ingredients, and natural products can be effective to improve IR. Targets of herbal compounds that affect insulin signaling include insulin receptor substrate, phosphatidylinositol 3-kinase, glucose transporter, AMPK, glycogen synthase kinase 3, MAPKs, JNK, NF- $\kappa \mathrm{B}$, protein tyrosine phosphatase $1 \mathrm{~B}$, nuclear factor-E2-related factor 2, and peroxisome proliferatoractivated receptors.

In Table 7, we have listed the composition of the above herbal formula in detail. In addition, we have found that certain herbs have a good application prospect in the treatment of IR. Such single botanicals include Coptis, Pueraria, Mulberry, Salvia, and others. Effective extracts of herbal medicines include berberine and mulberry leaves. There are also effective active ingredients such as berberine, ginsenoside, astragaloside, and resveratrol. The effects of these drugs are not only limited to enhancing insulin sensitivity, but also can be beneficial for improving 
TABLE 7 | Composition of herbal formula.

JTTZ formula

Tangyiping granules (TYP)

Jinlida (JLD)

Qingxue Dan (QXD)

Qingre Yangyin Recipe (QRYYR)

Sancaijiangtang powders Jinlida

Zhenggan Tang decoction

xin-ju-xiao-gao-fang (XJXGF)

Yiqi Huaju Recipe (YHR)

Yangxin Tongmai Formula (YTF)

Sancai powder

SGY preparation

Dai-Zong-Fang

Zengye Decoction (ZYD)

Jia-Wei-Jiao-Tai-Wan (JWJTW)

Seyoeum (SYE)

Wu-Mei-Wan

Preparation JQ-R

Fenugreek seed and mulberry leaf

Erchen Decoction and Linguizhugan

Decoction

Jiao-Tai-Wan (JTW)

Modified lingguizhugan decoction

Jiang Tang Xiao Ke (JTXK) granule Jiangzhi Capsule

Liuwei Dihuang decoction

ZiBu PiYin Recipe (ZBPYR)

Jinlida

Shouwu Jiangqi Decoction (SJD)

Tang-Nai-Kang (TNK)

Jinlida (JLD)

Modified Si-Miao-San (mSMS)

Gal-geun-dang-gwi-tang (GGDGT)
Aloe vera, Coptis chinensis, Rhizoma Anemarrhenae, red yeast rice, Momordica charantia, Salvia miltiorrhiza, Schisandra chinensis, Zingiber oj-jicinale Rosc.

Astragalus mongholicus $30 \mathrm{~g}$, Paeoniae Radix Alba 12 g, Coptis chinensis 15 g, Salvia miltiorrhiza 12 g, Pinellia ternate 9 g,

Pueraria lobata $30 \mathrm{~g}$.

Panax ginseng C. A. Mey., puerarin, pale white atractylodes rhizome, Coptis chinensis, poria cocos, radix polygonati

officinalis, and so on

Scutellaria baicalensis Georgi, Coptis chinensis Franch., Platycladus orientalis (Linn). Franco, Gardenia jasminoides Ellis,

Rhizoma of Rheum palmatum Linne

Cortex Lycii, Rehmannia glutinosa Libosch, Ophiopogon japonicus (Linn. f). Ker-Gawl., Cynanchum otophyllum, Salvia miltiorrhiza, Poria cocos(Schw). Wolf, Acorus tatarinowii, Alisma plantago-aquatica Linn., Lycium barbarum L., Cuscuta chinensis Lam., Epimedium sagittatum, Rubus idaeus L.

Panax Ginseng,Asparagus Racemosus, Radix, Rehmanniae, dark plum fruit, Cortex, Cinnamomi, Rhizoma Coptidis,

Panax ginseng C. A. Mey., Fallopia multiflora (Thunb). Harald, Atractylodes lancea (Thunb). DC, Sophora flavescens, Ophiopogon japonicus (Linn. f). Ker-Gawl., Rehmannia glutinosa Libosch, Fallopia multiflora (Thunb). Harald, Cornus officinalis Sieb. et Zucc., Poria cocos (Schw). Wolf, Eupatorium fortunei Turcz., Coptis chinensis Franch., Anemarrhena asphodeloides Bunge, Epimedii Folium, Salvia miltiorrhiza Bge., Pueraria thomsonii Benth, Litchi chinensis Sonn., Cortex Lycii

Pseudostellaria heterophylla (Miq). Pax ex Pax et Hoffm., Atractylodes macrocephala Koidz., Astragalus mongholicus Bunge, Poria cocos (Schw). Wolf, Angelica sinensis (Oliv). Diels, Salvia miltiorrhiza Bge., Trionyx sinensis Wiegmann, Radix Bupleuri, Cynanchum otophyllum

Rheum palmatum L., Coptis chinensis Franch., Cassia tora Linn., Citrus aurantium L.

Astragali Radix 10 g, Coptis chinensis Franch. 3 g, Typha angustifolia L. 10 g, Artemisia capillaris Thunb 10 g, Alisma plantago-aquatica Linn. $10 \mathrm{~g}$

Radix Ginseng 10 g, Radix Salviae Miltiorrhizae 15 g, Ramulus Cinnamomi 6 g, Fructus Aurantii Immaturus 10 g, Rhizoma

Alismatis $10 \mathrm{~g}$

Radix Ginseng, Radix Asparagi, Cochinchinensis, Radix Rehmanniae, Rhizoma Coptidis, Cortex Cinnamomi Cassiae, Fructus Mume

Morus alba L., Pueraria thomsonii Benth (Leguminous), Dioscoreae rhizoma (Dioscoreaceae), Momordica charantia L.

Rhizoma Coptidis, Fructus Aurantii Immaturus

Radix Scrophulariae, Radix Rehmanniae, Radix Ophiopogonis

Cinnamomum cassia, Rhizoma coptidis, Astragalus membranaceus, Herba Gynostemmatis, Radix Puerariae Lobatae, Folium Mori, Semen Trigonellae

Coix lacryma-jobi, Oryza sativa, Sesamum indicum, Glycine max, Liriope platyphylla, Dioscorea batatas

Lycium barbarumL., Angelica dahurica (Fisch. ex Hoffm.)Benth. et Hook. f. ex Franch. et Sav, Zingiber oj-jicinale

Rosc., Rhizoma coptidis, Angelica sinensis (Oliv). Diels, Ziziphus jujuba Mill., Zanthoxylum bungeanum Maxim., Cinnamomum cassia, Panax ginseng C. A. Mey., Platycladus orientalis (Linn). Franco

Rhizoma Coptidis, Astragalus membranaceus, Lonicera japonica

Morus alba L., Trigonella foenum-graecum L., Panax quinquefolius $L$.

Pinellia ternata, Pericarpium Citri Reticulatae, Poria cocos (Schw). Wolf, Glycyrrhiza uralensis Fisch./Poria cocos, cassia twig, Rhizoma Atractylodis Macrocephalae, and licorice

Rhizome Coptidis, Cortex Cinnamomi

Poria cocos (Schw). Wolf, Cinnamomum cassia Presl, Atractylodes lancea (Thunb). DC., Glycyrrhiza uralensis Fisch.,

Codonopsis pilosula (Franch). Nannf., d Rheum palmatum L

Radix rehmanniae, Fructuscorni, Radix salviae miltiorrhizae, Rhizoma coptidis, Radix Puerariae Lobatae, etc.

Radix Astragali, Poria cocos (Schw). Wolf, Folium Nelumbinis, Rhizoma Alisma, Fructus Crataeg, Fructus Chaenomelis, Radix et Rhizoma Salviae Miltiorrhizae, Radix et Rhizoma Notoginseng, Pollen Typhae, Rhizoma et Radix Polygoni cuspidate, Herba Taraxaci, Radix Polygoni multiflori, Fructus Ligustri Lucidi

Rehmannia glutinosa Libosch, Cornus officinalis Sieb, Dioscorea opposite Thunb, Alisma orientale Juz, Poria cocos Wolf, Paeonia suffruticosa Andrews

Red Ginseng, Common Yam Rhizome, Poria cocos (Schw). Wolf, Cynanchum otophyllum, Salvia miltiorrhiza Bge., Dolicho Lablab L., Nelumbo nucifera Gaertn., Acorus tatarinowii, Polygala tenuifolia Willd., Santalum album linn, Pericarpium Citri Reticulatae, Glycyrrhiza uralensis Fisch.

Panax ginseng C. A. Mey., puerarin, pale white atractylodes rhizome, Coptis chinensis, poria cocos, radix polygonati officinalis, etc.

Fallopia multiflora (Thunb)., Harald, Astragalus membranaceus (Fisch)., Bunge., roasted Bombyx Batryticatus, Common Yam Rhizome, Euonymus alatus (Thunb). Sieb., Cyperus rotundus L., etc.

Fructus Ligustri Lucidi, Prunella vulgaris L., Saururus chinensis (Lour). Baill, Psidium guajava Linn., Panax ginseng C. A. Mey. Panax ginseng C. A. Mey., Polygonatum sibiricum, Atractylodes Lancea (Thunb). DC., Sophora flavescens, Ophiopogon japonicus (Linn. f). Ker-Gawl., Rehmannia glutinosa Libosch, Fallopia multiflora (Thunb). Harald, Cornus officinalis Sieb. et Zucc., Poria cocos (Schw). Wolf., Eupatorium fortunei Turcz., Coptis chinensis Franch., Anemarrhena asphodeloides Bunge, Epimedium brevicornu Maxim., Salvia miltiorrhiza Bge., Pueraria thomsonii Benth, Litchi chinensis Sonn., Cortex Lycii Coptis chinensis Franch., Phellodendron amurense Rupr., Semen Coicis, Atractylodes Lancea (Thunb). DC.

Pueraria thomsonii Benth, Glycyrrhiza uralensis Fisch., Angelica sinensis (Oliv). Diels, Ophiopogon japonicus (Linn. f). Ker-Gawl., Cynanchum otophyllum, Cornus officinalis Sieb. et Zucc., Chaenomeles sinensis (Thouin) Koehne, Rehmannia glutinosa Libosch, Nelumbo nucifera Gaertn, Dark Plum Fruit, Schisandra chinensis, Anemarrhena asphodeloides Bunge, Ligusticum chuanxiong Hort., Asparagus cochinchinensis (Lour.) Merr., Trichosanthes kirilowii Maxim, Cyperus rotundus L. 
TABLE 7 | Continued

Gyeongshingangjeehwan 18

(GGEx18)

Salvia-Nelumbinis naturalis (SNN)

Kangen-karyu and Salviae

Miltiorrhizae Radix

Bushen Huatan Recipe (BHR)

Fu Fang Zhen Zhu Tiao Zhi formula (FTZ)

Fructus Mume formula and its separated prescription

Refined-JQ (JQ-R)

TZQ-F

Jiaotai Pill (JTP)

Heqi San

Fructus Mume formula
Laminaria japonica, Rheum palmatum L., Ephedra sinica Stapf

Salvia miltiorrhiza Bge., Nehlmbo nucifera, Reynoutria japonica Houtt., Artemisia capillaris Thunb Cynanchum otophyllum, Ligusticum chuanxiong Hort., Carthamus tinctorius L., Cyperus rotundus L. Radix Aucklandiae, Salvia miltiorrhiza Bge./Salvia miltiorrhiza Bge.

Epimedii Folium, Curculigo orchioides Gaertn, Atractylodes Lancea (Thunb). DC., Pinellia ternata (Thunb). Breit., Pericarpium Citri Reticulatae, Acorus calamus L., Cyperus rotundus L., Ligusticum chuanxiong Hort., Alisma plantago-aquatica Linn., Cervus nippon Temminc, Arisaema heterophyllum Blume, Amomum villosum Lour., etc.

Fructus Ligustri Lucidi, Atractylodes macrocephala Koidz., Salvia miltiorrhiza Bge., Coptis chinensis Franch., Panax notoginseng (Burk). F.H. Chen, Eucommia ulmoides, Cirsium japonicum Fisch. ex DC, Citrus medica L. var. sarcodactylis Swingle

Prunus mume (Sieb). Sieb. et Zucc., Asarum heterotropoides, Zingiberis officinale Rosc, Coptidis chinensis Franch, Aconitum carmichaelii Debx., Angelicas Sinensis (Oliv). Diels, Zanthoxylum bungeanum Maxim., Cinnamomum cassia Presl, Panax ginseng C. A. Mey., Phellodendrom chinense Schneid

Rhizoma Coptidis, Astragalus membranaceus, Lonicera japonica

Morus alba L., Lotus Leaf, Salvia miltiorrhiza Bge., Grataegus pinnati fida Bge., Radix paeoniae rubra

Coptis chinensis Franch., Cinnamomum cassia Presl

Schisandra chinensis (Turcz). Baill., Cynanchum otophyllum C. K. Schneid., Hordeum vulgare L

Prunus mume (Sieb).Sieb. et Zucc., Asarum heterotropoides Fr. Schmidt var. mandshuricum, Zingiberis officinale Rosc,

Coptidis chinensis Franch, Aconitum carmichaelii Debx., Angelicas Sinensis (Oliv). Diels, Zanthoxylum bungeanum Maxim.,

Cinnamomum cassia Presl, Panax ginseng C. A. Mey., Phellodendrom chinense Schneid systemic metabolism, such as reducing fasting blood glucose and postprandial blood glucose, improving blood lipid metabolism, reducing body weight, lowering blood pressure, and regulating female hormone secretion. Therefore, the role of herbal medicine in the treatment of IR is not only beneficial for treating T2D, but also provides new ideas for treating obesity, metabolic syndrome, PCOS, and NAFLD.

However, there were some shortcomings in our research. First, most of the interventions studied were herbal formulas and extracts. The diversity of ingredients in the herbal formulas and extracts results in complex potential therapeutic mechanisms. Not only does it make understanding the role of drugs difficult, but it also makes in-depth research impossible. However, the existing research also has the same shortcomings as our research. In addition, there are studies questioning the role of herbal medicine in the treatment of IR. The beneficial effects of ginsenosides on IR are listed in Table 4, but clinical trials have shown that oral ginseng or ginsenosides do not improve insulin sensitivity in glucose-tolerant or obese/overweight subjects who are newly diagnosed with diabetes (Reeds et al., 2011). However, the clinical trial lasted only 8 weeks, and in most in vitro and in vivo tests, ginsenosides were administered by intraperitoneal injection. In clinical trials, the systemic utilization and metabolic processes have to be considered only after oral administration. Studies have indicated that ginsenoside is a precursor. The pharmacological action of ginsenoside is to activate intestinal deglycosylation and fatty acid esterification (Hasegawa, 2004). Therefore, the in vitro and in vivo levels of ginsenosides should not be the only focus of the trial.

In response to these shortcomings, we can make some improvements in future studies. For example, regarding the bioavailability of herbal medicines, we can use targeted drug delivery systems (TDDSs) to improve the way in which the active ingredients of herbal medicines are administered. Research on targeted preparations related to TDDSs has become a popular topic, especially for applications in the field of anti-cancer research. Targeted administration can be divided into liposomes, granules, nanoparticles, emulsions, and other similar preparations (Li et al., 2009). The combination of drugs and specific target carriers can play a synergistic and attenuating role. At present, research on herbal drug delivery systems is still in the exploration stage, and the design, synthesis, and quality evaluation of TDDS are more suitable for single herbal ingredients. Therefore, separating the active ingredients of herbs is particularly important, including those known or unknown. We can select safe and effective single herbs from the many herbal formulas obtained from the literature and experimental research and separate the active ingredients, such as monomers, by pharmacological methods. Then, based on the active ingredients of the herbal medicine, the effective target mechanism of the drug can be studied. Finally, the active ingredient, target, and TDDS are combined. This not only makes the research on herbal medicine more targeted and efficient, but also provides a good prospect for the development and application of anti-insulin drugs.

\section{AUTHOR CONTRIBUTIONS}

JL and LB designed the work of review. JL, LB, and FW reviewed the literature available on this topic and wrote the paper. JZ, DW, YX, and WY contributed in the scientific writing of the manuscript. JL, LB, and JW revised the manuscript. All authors approved the paper for publication. JL, LB, FW, JZ, DW, YX, and WY contributed equally to this work. JL and LB contributed equally to this study and share first authorship.

\section{FUNDING}

This paper was supported by Central Health Research Project W2017BJ43. 


\section{REFERENCES}

Abe, H., Yamada, N., Kamata, K., Kuwaki, T., Shimada, M., Osuga, J., et al. (1998). Hypertension, hypertriglyceridemia, and impaired endothelium-dependent vascular relaxation in mice lacking insulin receptor substrate-1. J. Clin. Invest. 101 (8), 1784-1788. doi: 10.1172/JCI1594

Abel, E., Peroni, O., Kim, J., Kim, Y., Boss, O., Hadro, E., et al. (2001). Adiposeselective targeting of the GLUT4 gene impairs insulin action in muscle and liver. Nature 409 (6821), 729-733. doi: 10.1038/35055575

Aguilar, M., Bhuket, T., Torres, S., Liu, B., and Wong, R. J. (2015). Prevalence of the metabolic syndrome in the United States, 2003-2012. JAMA 313 (19), 19731974. doi: $10.1001 /$ jama.2015.4260

Ali, A., Hoeflich, K., and Woodgett, J. (2001). Glycogen synthase kinase-3: properties, functions, and regulation. Chem. Rev. 101 (8), 2527-2540. doi: $10.1021 / \mathrm{cr} 000110 \mathrm{o}$

Al-Lahham, R., Deford, J. H., and Papaconstantinou, J. (2016). Mitochondrialgenerated ROS down regulates insulin signaling via activation of the p38MAPK stress response pathway. Mol. Cell Endocrinol. 419, 1-11. doi: 10.1016/j. mce.2015.09.013

Anitha, M., Gondha, C., Sutliff, R., Parsadanian, A., Mwangi, S., Sitaraman, S. V., et al. (2006). GDNF rescues hyperglycemia-induced diabetic enteric neuropathy through activation of the PI3K/Akt pathway. J. Clin. Invest. 116 (2), 344-356. doi: 10.1172/JCI26295

Araujo, T. G., de Oliveira, A. G., Vecina, J. F., Marin, R. M., Franco, E. S., Abdalla Saad, M. J., et al. (2016). Parkinsonia aculeata (Caesalpineaceae) improves high-fat diet-induced insulin resistance in mice through the enhancement of insulin signaling and mitochondrial biogenesis. J. Ethnopharmacol. 183, 95-102. doi: 10.1016/j.jep.2016.02.048

Arkan, M., Hevener, A., Greten, F., Maeda, S., Li, Z., Long, J., et al. (2005). IKKbeta links inflammation to obesity-induced insulin resistance. Nat. Med. 11 (2), 191-198. doi: 10.1038/nm1185

Armstrong, D. G., Boulton, A. J. M., and Bus, S. A. (2017). Diabetic foot ulcers and their recurrence. N. Engl. J. Med. 376 (24), 2367-2375. doi: 10.1056/ NEJMra1615439

Askari, F., Rashidkhani, B., and Hekmatdoost, A. (2014). Cinnamon may have therapeutic benefits on lipid profile, liver enzymes, insulin resistance, and highsensitivity C-reactive protein in nonalcoholic fatty liver disease patients. Nutr. Res. 34 (2), 143-148. doi: 10.1016/j.nutres.2013.11.005

Atkin, M., Laight, D., and Cummings, M. H. (2016). The effects of garlic extract upon endothelial function, vascular inflammation, oxidative stress and insulin resistance in adults with type 2 diabetes at high cardiovascular risk. A pilot double blind randomized placebo controlled trial. J. Diabetes Complications. 30 (4), 723-727. doi: 10.1016/j.jdiacomp.2016.01.003

Aytug, S., Reich, D., Sapiro, L. E., Bernstein, D., and Begum, N. (2003). Impaired IRS-1/PI3-kinase signaling in patients with HCV: a mechanism for increased prevalence of type 2 diabetes. Hepatology 38 (6), 1384-1392. doi: 10.1016/j. hep.2003.09.012

Bae, U. J., Park, J., Park, I. W., Chae, B. M., Oh, M. R., Jung, S. J., et al. (2018). Epigallocatechin-3-gallate-rich green tea extract ameliorates fatty liver and weight gain in mice fed a high fat diet by activating the sirtuin 1 and AMP activating protein kinase pathway. Am. J. Chin. Med. 46 (3), 617-632. doi: 10.1142/S0192415X18500325

Bai, L., Gao, J., Wei, F., Zhao, J., Wang, D., and Wei, J. (2018). Therapeutic potential of ginsenosides as an adjuvant treatment for diabetes. Front. Pharmacol. 9, 423. doi: 10.3389/fphar.2018.00423

Bai, L., Wang, Y., Fan, J., Chen, Y., Ji, W., Qu, A., et al. (2007). Dissecting multiple steps of GLUT4 trafficking and identifying the sites of insulin action. Cell Metab. 5 (1), 47-57. doi: 10.1016/j.cmet.2006.11.013

Banin, R. M., Hirata, B. K., Andrade, I. S., Zemdegs, J. C., Clemente, A. P., Dornellas, A. P., et al. (2014). Beneficial effects of Ginkgo biloba extract on insulin signaling cascade, dyslipidemia, and body adiposity of diet-induced obese rats. Braz. J. Med. Biol. Res. 47 (9), 780-788. doi: 10.1590/1414-431X20142983

Bassil, F., Canron, M. H., Vital, A., Bezard, E., Li, Y., Greig, N. H., et al. (2017). Insulin resistance and exendin-4 treatment for multiple system atrophy. Brain 140 (5), 1420-1436. doi: 10.1093/brain/awx044

Belwal, T., Nabavi, S. F., Nabavi, S. M., and Habtemariam, S. (2017). Dietary anthocyanins and insulin resistance: when food becomes a medicine. Nutrients 9 (10), 1-22. doi: $10.3390 /$ nu9101111
Bhakkiyalakshmi, E., Sireesh, D., Rajaguru, P., Paulmurugan, R., and Ramkumar, K. M. (2015). The emerging role of redox-sensitive Nrf2-Keap1 pathway in diabetes. Pharmacol. Res. 91, 104-114. doi: 10.1016/j.phrs.2014.10.004

Bhakta, H. K., Paudel, P., Fujii, H., Sato, A., Park, C. H., Yokozawa, T., et al. (2017). Oligonol promotes glucose uptake by modulating the insulin signaling pathway in insulin-resistant HepG2 cells via inhibiting protein tyrosine phosphatase 1B. Arch. Pharm. Res. 40 (11), 1314-1327. doi: 10.1007/s12272-017-0970-6

Biessels, G. J., Staekenborg, S., Brunner, E., Brayne, C., and Scheltens, P. (2006). Risk of dementia in diabetes mellitus: a systematic review. Lancet Neurol. 5 (1), 64-74. doi: 10.1016/S1474-4422(05)70284-2

Boden, G., Homko, C., Barrero, C., Stein, T., Chen, X., Cheung, P., et al. (2015). Excessive caloric intake acutely causes oxidative stress, GLUT4 carbonylation, and insulin resistance in healthy men. Sci. Transl. Med. 7 (304), 304re307. doi: 10.1126/scitranslmed.aac4765

Bogan, J. S. (2012). Regulation of glucose transporter translocation in health and diabetes. Аnnu. Rev. Biochem. 81, 507-532. doi: 10.1146/annurev-biochem060109-094246

Bouzakri, K., Zachrisson, A., Al-Khalili, L., Zhang, B. B., Koistinen, H. A., Krook, A., et al. (2006). siRNA-based gene silencing reveals specialized roles of IRS-1/ Akt2 and IRS-2/Akt1 in glucose and lipid metabolism in human skeletal muscle. Cell Metab. 4 (1), 89-96. doi: 10.1016/j.cmet.2006.04.008

Cai, D., Yuan, M., Frantz, D., Melendez, P., Hansen, L., Lee, J., et al. (2005). Local and systemic insulin resistance resulting from hepatic activation of IKK-beta and NF-kappaB. Nat. Med. 11 (2), 183-190. doi: 10.1038/nm1166

Cantó, C., Jiang, L., Deshmukh, A., Mataki, C., Coste, A., Lagouge, M., et al. (2010). Interdependence of AMPK and SIRT1 for metabolic adaptation to fasting and exercise in skeletal muscle. Cell Metab. 11 (3), 213-219. doi: 10.1016/j. cmet.2010.02.006

Chang, C. J., Lin, C. S., Lu, C. C., Martel, J., Ko, Y. F., Ojcius, D. M., et al. (2015). Ganoderma lucidum reduces obesity in mice by modulating the composition of the gut microbiota. Nat. Commun. 6, 7489. doi: 10.1038/ncomms8489

Chao, C. L., Huang, H. C., Lin, H. C., Chang, T. C., and Chang, W. L. (2016). Sesquiterpenes from Baizhu stimulate glucose uptake by activating AMPK and PI3K. Am. J. Chin. Med. 44 (5), 963-979. doi: 10.1142/S0192415X16500531

Chen, G., Yang, X., Yang, X., Li, L., Luo, J., Dong, H., et al. (2017). Jia-Wei-Jiao-TaiWan ameliorates type 2 diabetes by improving beta cell function and reducing insulin resistance in diabetic rats. BMC Complement. Altern. Med. 17 (1), 507. doi: 10.1186/s12906-017-2016-5

Chen, Y., Fu, D. Y., Fu, X. D., He, Y. M., and Wang, W. J. (2014). Effect of yiqi huaju recipe combined with routine therapy in treating hypertension patients with metabolic syndrome: a clinical study. Zhongguo Zhong Xi Yi Jie He Za Zhi. 34 (6), 680-687.

Cheng, K. C., Asakawa, A., Li, Y. X., Liu, I. M., Amitani, H., Cheng, J. T., et al. (2013). Opioid mu-receptors as new target for insulin resistance. Pharmacol. Ther. 139 (3), 334-340. doi: 10.1016/j.pharmthera.2013.05.002

Chiang, S. H., Bazuine, M., Lumeng, C. N., Geletka, L. M., Mowers, J., White, N. M., et al. (2009). The protein kinase IKKepsilon regulates energy balance in obese mice. Cell 138 (5), 961-975. doi: 10.1016/j.cell.2009.06.046

Choi, H. C., Kim, S. J., Son, K. Y., Oh, B. J., and Cho, B. L. (2013). Metabolic effects of aloe vera gel complex in obese prediabetes and early non-treated diabetic patients: randomized controlled trial. Nutrition 29 (9), 1110-1114. doi: 10.1016/j.nut.2013.02.015

Choi, M. S., Ryu, R., Seo, Y. R., Jeong, T. S., Shin, D. H., Park, Y. B., et al. (2014). The beneficial effect of soybean (Glycine max (L). Merr). leaf extracts in adults with prediabetes: a randomized placebo controlled trial. Food Funct. 5 (7), 1621-1630. doi: 10.1039/c4fo00199k

Chuengsamarn, S., Rattanamongkolgul, S., Phonrat, B., Tungtrongchitr, R., and Jirawatnotai, S. (2014). Reduction of atherogenic risk in patients with type 2 diabetes by curcuminoid extract: a randomized controlled trial. J. Nutr. Biochem. 25 (2), 144-150. doi: 10.1016/j.jnutbio.2013.09.013

Chung, W., Ryu, J., Chung, S., and Kim, S. (2016). [Effect of Qingxue Dan on obesity and metabolic biomarker: a double-blind randomized-controlled pilot study]. J. Tradit. Chin. Med. 36 (3), 291-298. doi: 10.1016/S0254-6272(16)30040-1

Cross, D., Alessi, D., Cohen, P., Andjelkovich, M., and Hemmings, B. (1995). Inhibition of glycogen synthase kinase- 3 by insulin mediated by protein kinase B. Nature 378 (6559), 785-789. doi: 10.1038/378785a0

Cuenda, A., Lizcano, J. M., and Lozano, J. (2017). Editorial: mitogen activated protein kinases. Front Cell Dev. Biol. 5, 80. doi: 10.3389/fcell.2017.00080 
D, C. (2018). Why Chinese medicine is heading for clinics around the world. Nature 561, 448-450. doi: 10.1038/d41586-018-06782-7

Dai, B., Wu, Q., Zeng, C., Zhang, J., Cao, L., Xiao, Z., et al. (2016). The effect of Liuwei Dihuang decoction on PI3K/Akt signaling pathway in liver of type 2 diabetes mellitus (T2DM) rats with insulin resistance. J. Ethnopharmacol. 192, 382-389. doi: 10.1016/j.jep.2016.07.024

Dai, S., Hong, Y., Xu, J., Lin, Y., Si, Q., and Gu, X. (2018). Ginsenoside Rb2 promotes glucose metabolism and attenuates fat accumulation via AKTdependent mechanisms. Biomed. Pharmacother. 100, 93-100. doi: 10.1016/j. biopha.2018.01.111

Dajani, R., Fraser, E., Roe, S., Young, N., Good, V., Dale, T., et al. (2001). Crystal structure of glycogen synthase kinase 3 beta: structural basis for phosphateprimed substrate specificity and autoinhibition. Cell 105 (6), 721-732. doi: 10.1016/S0092-8674(01)00374-9

Deng, D., Xu, C., Sun, P., Wu, J., Yan, C., Hu, M., et al. (2014). Crystal structure of the human glucose transporter GLUT1. Nature 510 (7503), 121-125. doi: 10.1038/nature13306

Diamanti-Kandarakis, E., and Dunaif, A. (2012). Insulin resistance and the polycystic ovary syndrome revisited: an update on mechanisms and implications. Endocr. Rev. 33 (6), 981-1030. doi: 10.1210/er.2011-1034

Dong, H., Wang, J. H., Lu, F. E., Xu, L. J., Gong, Y. L., and Zou, X. (2013). Jiaotai Pill enhances insulin signaling through phosphatidylinositol 3-kinase pathway in skeletal muscle of diabetic rats. Chin. J. Integr. Med. 19 (9), 668-674. doi: 10.1007/s11655-013-1560-1

Ebrahimi-Mameghani, M., Asghari-Jafarabadi, M., and Rezazadeh, K. (2018). TCF7L2-rs7903146 polymorphism modulates the effect of artichoke leaf extract supplementation on insulin resistance in metabolic syndrome: a randomized, double-blind, placebo-controlled trial. J. Integr. Med. 16 (5), 329334. doi: 10.1016/j.joim.2018.05.006

Ebrahimpour-Koujan, S., Gargari, B. P., Mobasseri, M., Valizadeh, H., and AsghariJafarabadi, M. (2018). Lower glycemic indices and lipid profile among type 2 diabetes mellitus patients who received novel dose of Silybum marianum (L). Gaertn. (silymarin) extract supplement: a triple-blinded randomized controlled clinical trial. Phytomedicine 44, 39-44. doi: 10.1016/j.phymed.2018.03.050

Eldor, R., DeFronzo, R. A., and Abdul-Ghani, M. (2013). In vivo actions of peroxisome proliferator-activated receptors: glycemic control, insulin sensitivity, and insulin secretion. Diabetes Care 36 Suppl 2, S162-174. doi: $10.2337 / \mathrm{dcS} 13-2003$

Fang, P., Yu, M., Min, W., Han, S., Shi, M., Zhang, Z., et al. (2018). Beneficial effect of baicalin on insulin sensitivity in adipocytes of diet-induced obese mice. Diabetes Res. Clin. Pract. 139, 262-271. doi: 10.1016/j.diabres.2018.03.007

Feve, B., and Bastard, J. P. (2009). The role of interleukins in insulin resistance and type 2 diabetes mellitus. Nat. Rev. Endocrinol. 5 (6), 305-311. doi: 10.1038/ nrendo.2009.62

Frame, S., Cohen, P., and Biondi, R. (2001). A common phosphate binding site explains the unique substrate specificity of GSK3 and its inactivation by phosphorylation. Mol. Cell 7 (6), 1321-1327. doi: 10.1016/S1097-2765(01) 00253-2

Gao, L. H., Liu, Q., Liu, S. N., Chen, Z. Y., Li, C. N., Lei, L., et al. (2014). A refinedJinQi-JiangTang tablet ameliorates prediabetes by reducing insulin resistance and improving beta cell function in mice. J. Ethnopharmacol. 151 (1), 675-685. doi: 10.1016/j.jep.2013.11.024

Gao, S., Guo, Q., Qin, C., Shang, R., and Zhang, Z. (2017). Sea buckthorn fruit oil extract alleviates insulin resistance through the PI3K/Akt signaling pathway in type 2 diabetes mellitus cells and rats. J. Agric. Food Chem. 65 (7), 1328-1336. doi: 10.1021/acs.jafc.6b04682

Gao, W., Du, X., Lei, L., Wang, H., Zhang, M., Wang, Z., et al. (2018). NEFAinduced ROS impaired insulin signalling through the JNK and p38MAPK pathways in non-alcoholic steatohepatitis. J. Cell Mol. Med. 22 (7), 3408-3422. doi: $10.1111 /$ jcmm. 13617

Garabadu, D., and Krishnamurthy, S. (2017). Metformin attenuates hepatic insulin resistance in type-2 diabetic rats through PI3K/Akt/GLUT-4 signalling independent to bicuculline-sensitive GABAA receptor stimulation. Pharm. Biol. 55 (1), 722-728. doi: 10.1080/13880209.2016.1268635

Geering, B., Cutillas, P., Nock, G., Gharbi, S., and Vanhaesebroeck, B. (2007). Class IA phosphoinositide 3-kinases are obligate p85-p110 heterodimers. Proc. Natl. Acad. Sci. U.S.A. 104 (19), 7809-7814. doi: 10.1073/pnas. 0700373104
Gehart, H., Kumpf, S., Ittner, A., and Ricci, R. (2010). MAPK signalling in cellular metabolism: stress or wellness? EMBO Rep. 11 (11), 834-840. doi: 10.1038/ embor. 2010.160

George, S., Rochford, J., Wolfrum, C., Gray, S., Schinner, S., Wilson, J., et al. (2004). A family with severe insulin resistance and diabetes due to a mutation in AKT2. Science 304 (5675), 1325-1328. doi: 10.1126/science. 1096706

Goodarzi, M. O., Dumesic, D. A., Chazenbalk, G., and Azziz, R. (2011). Polycystic ovary syndrome: etiology, pathogenesis and diagnosis. Nat. Rev. Endocrinol. 7 (4), 219-231. doi: 10.1038/nrendo.2010.217

Guilherme, A., Virbasius, J. V., Puri, V., and Czech, M. P. (2008). Adipocyte dysfunctions linking obesity to insulin resistance and type 2 diabetes. Nat. Rev. Mol. Cell Biol. 9 (5), 367-377. doi: 10.1038/nrm2391

Guo, Q., Zhang, H., Li, M., Zhao, Z., Luo, Y., Luo, Y., et al. (2016). Efficacy and safety of Sancai powder in patients with type 2 diabetes mellitus: a randomized controlled trial. J. Tradit. Chin. Med. 36 (5), 640-648. doi: 10.1016/ S0254-6272(16)30084-X

Gurzov, E. N., Tran, M., Fernandez-Rojo, M. A., Merry, T. L., Zhang, X., Xu, Y., et al. (2014). Hepatic oxidative stress promotes insulin-STAT-5 signaling and obesity by inactivating protein tyrosine phosphatase N2. Cell Metab. 20 (1), 85-102. doi: 10.1016/j.cmet.2014.05.011

Haeusler, R. A., and Accili, D. (2008). The double life of Irs. Cell Metab. 8 (1), 7-9. doi: 10.1016/j.cmet.2008.06.010

Haj-Husein, I., Tukan, S., and Alkazaleh, F. (2016). The effect of marjoram (Origanum majorana) tea on the hormonal profile of women with polycystic ovary syndrome: a randomised controlled pilot study. J. Hum. Nutr. Diet 29 (1), 105-111. doi: 10.1111/jhn.12290

Haluzík, M., and Haluzík, M. (2006). Peroxisome proliferator activated receptors (PPAR) and insulin sensitivity: experimental studies. Cesk Fysiol. 55 (4), 163-168.

Han, J., Yang, N., Zhang, F., Zhang, C., Liang, F., Xie, W., et al. (2015). Rhizoma Anemarrhenae extract ameliorates hyperglycemia and insulin resistance via activation of AMP-activated protein kinase in diabetic rodents. J. Ethnopharmacol. 172, 368-376. doi: 10.1016/j.jep.2015.05.016

Hanssen, M. J., Hoeks, J., Brans, B., van der Lans, A. A., Schaart, G., van den Driessche, J. J., et al. (2015). Short-term cold acclimation improves insulin sensitivity in patients with type 2 diabetes mellitus. Nat. Med. 21 (8), 863-865. doi: 10.1038/nm.3891

Hao, J., Chen, C., Huang, K., Huang, J., Li, J., Liu, P., et al. (2014). Polydatin improves glucose and lipid metabolism in experimental diabetes through activating the Akt signaling pathway. Eur. J. Pharmacol. 745, 152-165. doi: 10.1016/j.ejphar.2014.09.047

Haque, A., Andersen, J. N., Salmeen, A., Barford, D., and Tonks, N. K. (2011), Conformation-sensing antibodies stabilize the oxidized form of PTP1B and inhibit its phosphatase activity. Cell 147 (1), 185-198. doi: 10.1016/j. cell.2011.08.036

Hasegawa, H. (2004). Proof of the mysterious efficacy of ginseng: basic and clinical trials: metabolic activation of ginsenoside: deglycosylation by intestinal bacteria and esterification with fatty acid. J. Pharmacol. Sci. 95 (2), 153-157. doi: 10.1254/jphs.FMJ04001X4

Hevener, A., He, W., Barak, Y., Le, J., Bandyopadhyay, G., Olson, P., et al. (2003). Muscle-specific Pparg deletion causes insulin resistance. Nat. Med. 9 (12), 1491-1497. doi: 10.1038/nm956

Hinkel, R., Howe, A., Renner, S., Ng, J., Lee, S., Klett, K., et al. (2017). Diabetes Mellitus-Induced Microvascular Destabilization in the Myocardium. J. Am. Coll. Cardiol. 69 (2), 131-143. doi: 10.1016/j.jacc.2016.10.058

Hirosumi, J., Tuncman, G., Chang, L., Gorgun, C. Z., Uysal, K. T., Maeda, K., et al. (2002). A central role for JNK in obesity and insulin resistance. Nature 420 (6913), 333-336. doi: 10.1038/nature01137

Hoehn, K. L., Hohnen-Behrens, C., Cederberg, A., Wu, L. E., Turner, N., Yuasa, T., et al. (2008). IRS1-independent defects define major nodes of insulin resistance. Cell Metab. 7 (5), 421-433. doi: 10.1016/j.cmet.2008.04.005

Holzer, R. G., Park, E. J., Li, N., Tran, H., Chen, M., Choi, C., et al. (2011). Saturated fatty acids induce $\mathrm{c}$-Src clustering within membrane subdomains, leading to JNK activation. Cell 147 (1), 173-184. doi: 10.1016/j.cell.2011.08.034

Hong, Y. L., and Wu, F. (2014). Effect of Bushen Huatan Recipe on the Akt signal pathway in polycystic ovarian syndrome model rats with insulin resistance: an experimental research. Zhongguo Zhong Xi Yi Jie He Za Zhi. 34 (2), $230-234$. 
Hotamisligil, G. S., and Davis, R. J. (2016). Cell signaling and stress responses. Cold Spring Harb. Perspect. Biol. 8 (10), 1-20. doi: 10.1101/cshperspect. a006072

Hotamisligil, G., Peraldi, P., Budavari, A., Ellis, R., White, M., and Spiegelman, B. (1996). IRS-1-mediated inhibition of insulin receptor tyrosine kinase activity in TNF-alpha- and obesity-induced insulin resistance. Science 271 (5249), 665668. doi: $10.1126 /$ science.271.5249.665

Hsu, C. Y., Shih, H. Y., Chia, Y. C., Lee, C. H., Ashida, H., Lai, Y. K., et al. (2014). Rutin potentiates insulin receptor kinase to enhance insulin-dependent glucose transporter 4 translocation. Mol. Nutr. Food Res. 58 (6), 1168-1176. doi: 10.1002/mnfr.201300691

Hu, X., Wang, M., Bei, W., Han, Z., and Guo, J. (2014). The Chinese herbal medicine FTZ attenuates insulin resistance via IRS1 and PI3K in vitro and in rats with metabolic syndrome. J. Transl. Med. 12 (1479-5876 (Electronic)), 47-56. doi: 10.1186/1479-5876-12-47

Hu, Y., Hou, Z., Liu, D., and Yang, X. (2016). Tartary buckwheat flavonoids protect hepatic cells against high glucose-induced oxidative stress and insulin resistance via MAPK signaling pathways. Food Funct. 7 (3), 1523-1536. doi: 10.1039/C5FO01467K

Hu, Y., Hou, Z., Yi, R., Wang, Z., Sun, P., Li, G., et al. (2017). Tartary buckwheat flavonoids ameliorate high fructose-induced insulin resistance and oxidative stress associated with the insulin signaling and $\mathrm{Nrf2} / \mathrm{HO}-1$ pathways in mice. Food Funct. 8 (8), 2803-2816. doi: 10.1039/C7FO00359E

Huang, B., Xue, L., Wu, Y., and Jiang, Q. S. (2015). Effect and mechanism of polydatin on diabetic myocardial hypertrophy in mice. Zhongguo Zhong Yao Za Zhi. 40 (21), 4256-4261.

Huang, S., and Czech, M. P. (2007). The GLUT4 glucose transporter. Cell Metab. 5 (4), 237-252. doi: 10.1016/j.cmet.2007.03.006

Huang, Y. Q., Yang, Q. F., Wang, H., Xu, Y. S., Peng, W., and Jiang, Y. H. (2016). Long-term clinical effect of Tangyiping Granules () on patients with impaired glucose tolerance. Chin. J. Integr. Med. 22 (9), 653-659. doi: 10.1007/ s11655-016-2512-3

Hur, E. M., and Zhou, F. Q. (2010). GSK3 signalling in neural development. Nat. Rev. Neurosci. 11 (8), 539-551. doi: 10.1038/nrn2870

Inoue, Y., Qin, B., Poti, J., Sokol, R., and Gordon-Larsen, P. (2018). Epidemiology of obesity in adults: latest trends. Curr. Obes. Rep. 7 (4), 276-288. doi: 10.1007/ s13679-018-0317-8

Jafarpour-Sadegh, F., Montazeri, V., Adili, A., Esfehani, A., Rashidi, M. R., and Pirouzpanah, S. (2017). Consumption of fresh yellow onion ameliorates hyperglycemia and insulin resistance in breast cancer patients during doxorubicin-based chemotherapy: a randomized controlled clinical trial. Integr. Cancer Ther. 16 (3), 276-289. doi: 10.1177/1534735416656915

Jeong, M., Park, J., Youn, D., Jung, Y., Kang, J., Lim, S., et al. (2017). Albiflorin ameliorates obesity by inducing thermogenic genes via AMPK and PI3K/AKT in vivo and in vitro. Metab. Clin. Exp. 73, 85-99. doi: 10.1016/j.metabol.2017.05. 009

Jiang, B., Le, L., Zhai, W., Wan, W., Hu, K., Yong, P., et al. (2016). Protective effects of marein on high glucose-induced glucose metabolic disorder in HepG2 cells. Phytomedicine 23 (9), 891-900. doi: 10.1016/j.phymed.2016.05.004

Jiang, C., Yao, N., Wang, Q., Zhang, J., Sun, Y., Xiao, N., et al. (2014). Cyclocarya paliurus extract modulates adipokine expression and improves insulin sensitivity by inhibition of inflammation in mice. J. Ethnopharmacol. 153 (2), 344-351. doi: 10.1016/j.jep.2014.02.003

Jiang, H., Ma, Y., Yan, J., Liu, J., and Li, L. (2017). Geniposide promotes autophagy to inhibit insulin resistance in HepG2 cells via P62/NFkappaB/GLUT4. Mol. Med. Rep. 16 (5), 7237-7244. doi: 10.3892/mmr.2017.7503

Jiang, L., Yao, L., Yang, Y., Ke, D., Batey, R., Wang, J., et al. (2016). Jiangzhi capsule improves fructose-induced insulin resistance in rats: association with repair of the impaired sarcolemmal glucose transporter-4 recycling. J. Ethnopharmacol. 194, 288-298. doi: 10.1016/j.jep.2016.09.009

Jin, X., Zhang, H. X., and Cui, W. W. (2015). Effect of Jinlida on DGAT1 in skeletal muscle in fat-induced insulin resistance ApoE -/- mice. Zhong Yao Cai. 38 (6), 1237-1241.

Johnson, T. O., Ermolieff, J., and Jirousek, M. R. (2002). Protein tyrosine phosphatase 1B inhibitors for diabetes. Nat. Rev. Drug Discov. 1 (9), 696-709. doi: $10.1038 / \mathrm{nrd} 895$

Joost, H., and Thorens, B. (2001). The extended GLUT-family of sugar/polyol transport facilitators: nomenclature, sequence characteristics, and potential function of its novel members (review). Mol. Membr. Biol. 18 (4), 247-256. doi: $10.1080 / 09687680110090456$

Jung, H. A., Bhakta, H. K., Min, B. S., and Choi, J. S. (2016). Fucosterol activates the insulin signaling pathway in insulin resistant HepG2 cells via inhibiting PTP1B. Arch. Pharm. Res. 39 (10), 1454-1464. doi: 10.1007/s12272-016-0819-4

Jung, H. J., Seong, S. H., Ali, M. Y., Min, B. S., Jung, H. A., and Choi, J. S. (2017). Alpha-Methyl artoflavanocoumarin from Juniperus chinensis exerts antidiabetic effects by inhibiting PTP1B and activating the PI3K/Akt signaling pathway in insulin-resistant HepG2 cells. Arch. Pharm. Res. 40 (12), 14031413. doi: 10.1007/s12272-017-0992-0

Kaatabi, H., Bamosa, A. O., Badar, A., Al-Elq, A., Abou-Hozaifa, B., Lebda, F., et al. (2015). Nigella sativa improves glycemic control and ameliorates oxidative stress in patients with type 2 diabetes mellitus: placebo controlled participant blinded clinical trial. PLoS One 10 (2), e0113486. doi: 10.1371/journal.pone. 0113486

Kadowaki, T., and Yamauchi, T. (2011). Adiponectin receptor signaling: a new layer to the current model. Cell Metab. 13 (2), 123-124. doi: 10.1016/j. cmet.2011.01.012

Kahn, B. B., Alquier, T., Carling, D., and Hardie, D. G. (2005). AMP-activated protein kinase: ancient energy gauge provides clues to modern understanding of metabolism. Cell Metab. 1 (1), 15-25. doi: 10.1016/j.cmet.2004.12.003

Kahn, S. E., Hull, R. L., and Utzschneider, K. M. (2006). Mechanisms linking obesity to insulin resistance and type 2 diabetes. Nature 444 (7121), 840-846. doi: 10.1038/nature05482

Kaidanovich, O., and Eldar-Finkelman, H. (2002). The role of glycogen synthase kinase-3 in insulin resistance and type 2 diabetes. Expert Opin. Ther.Targets. 6 (5), 555-561. doi: 10.1517/14728222.6.5.555

Kan, J., Velliquette, R. A., Grann, K., Burns, C. R., Scholten, J., Tian, F., et al. (2017). A novel botanical formula prevents diabetes by improving insulin resistance. BMC Complement. Altern. Med. 17 (1), 352. doi: 10.1186/s12906-017-1848-3

Kho, M. C., Lee, Y. J., Cha, J. D., Choi, K. M., Kang, D. G., and Lee, H. S. (2014). Gastrodia elata ameliorates high-fructose diet-induced lipid metabolism and endothelial dysfunction. Evid. Based Complement. Alternat. Med. 2014, 101624. doi: $10.1155 / 2014 / 101624$

Kho, M. C., Lee, Y. J., Park, J. H., Kim, H. Y., Yoon, J. J., Ahn, Y. M., et al. (2016). Fermented red ginseng potentiates improvement of metabolic dysfunction in metabolic syndrome rat models. Nutrients 8 (6), 1-15. doi: 10.3390/nu8060369

Kido, Y., Burks, D., Withers, D., Bruning, J., Kahn, C., White, M., et al. (2000). Tissue-specific insulin resistance in mice with mutations in the insulin receptor, IRS-1, and IRS-2. J. Clin. Invest. 105 (2), 199-205. doi: 10.1172/JCI7917

Kim, J. M., Park, C. H., Park, S. K., Seung, T. W., Kang, J. Y., Ha, J. S., et al. (2017). Ginsenoside Re ameliorates brain insulin resistance and cognitive dysfunction in high fat diet-induced C57BL/6 mice. J. Agric. Food Chem. 65 (13), 27192729. doi: $10.1021 /$ acs.jafc.7b00297

Kim, Y. J., Choi, J. Y., Ryu, R., Lee, J., Cho, S. J., Kwon, E. Y., et al. (2016). Platycodon grandiflorus root extract attenuates body fat mass, hepatic steatosis and insulin resistance through the interplay between the liver and adipose tissue. Nutrients 8 (9), 1-10. doi: 10.3390/nu8090532

Kishton, R., Barnes, C., Nichols, A., Cohen, S., Gerriets, V., Siska, P., et al. (2016). AMPK is essential to balance glycolysis and mitochondrial metabolism to control T-ALL cell stress and survival. Cell Metab. 23 (4), 649-662. doi: 10.1016/j.cmet.2016.03.008

Kong, P., Chi, R., Zhang, L., Wang, N., and Lu, Y. (2013). Effects of paeoniflorin on tumor necrosis factor-alpha-induced insulin resistance and changes of adipokines in 3T3-L1 adipocytes. Fitoterapia. 91, 44-50. doi: 10.1016/j. fitote.2013.08.010

Koo, S. H., Satoh, H., Herzig, S., Lee, C. H., Hedrick, S., Kulkarni, R., et al. (2004). PGC-1 promotes insulin resistance in liver through PPAR-alpha-dependent induction of TRB-3. Nat. Med. 10 (5), 530-534. doi: 10.1038/nm1044

Kuai, M., Li, Y., Sun, X., Ma, Z., Lin, C., Jing, Y., et al. (2016). A novel formula Sang-Tong-Jian improves glycometabolism and ameliorates insulin resistance by activating PI3K/AKT pathway in type 2 diabetic KKAy mice. Biomed. Pharmacother. 84, 1585-1594. doi: 10.1016/j.biopha.2016.10.101

Kubota, N., Yano, W., Kubota, T., Yamauchi, T., Itoh, S., Kumagai, H., et al. (2007). Adiponectin stimulates AMP-activated protein kinase in the hypothalamus and increases food intake. Cell Metab. 6 (1), 55-68. doi: 10.1016/j.cmet.2007.06.003

Kubota, T., Kubota, N., Moroi, M., Terauchi, Y., Kobayashi, T., Kamata, K., et al. (2003). Lack of insulin receptor substrate-2 causes progressive neointima 
formation in response to vessel injury. Circulation 107 (24), 3073-3080. doi: 10.1161/01.CIR.0000070937.52035.25

Kullmann, S., Heni, M., Hallschmid, M., Fritsche, A., Preissl, H., and Haring, H. U. (2016). Brain insulin resistance at the crossroads of metabolic and cognitive disorders in humans. Physiol. Rev. 96 (4), 1169-1209. doi: 10.1152/ physrev.00032.2015

Kuo, Y. H., Lin, C. H., and Shih, C. C. (2015). Ergostatrien-3beta-ol from Antrodia camphorata inhibits diabetes and hyperlipidemia in high-fat-diet treated mice via regulation of hepatic related genes, glucose transporter 4, and AMPactivated protein kinase phosphorylation. J. Agric. Food Chem. 63 (9), 24792489. doi: 10.1021 /acs.jafc.5b00073

Lage, R., Dieguez, C., Vidal-Puig, A., and Lopez, M. (2008). AMPK: a metabolic gauge regulating whole-body energy homeostasis. Trends Mol. Med. 14 (12), 539-549. doi: 10.1016/j.molmed.2008.09.007

Lawan, A., and Bennett, A. M. (2017). Mitogen-activated protein kinase regulation in hepatic metabolism. Trends Endocrinol. Metab. 28 (12), 868-878. doi: 10.1016/j.tem.2017.10.007

Le, L., Jiang, B., Wan, W., Zhai, W., Xu, L., Hu, K., et al. (2016). Metabolomics reveals the protective of Dihydromyricetin on glucose homeostasis by enhancing insulin sensitivity. Sci. Rep. 6, 36184. doi: 10.1038/srep36184

Leavens, K. F., Easton, R. M., Shulman, G. I., Previs, S. F., and Birnbaum, M. J. (2009). Akt2 is required for hepatic lipid accumulation in models of insulin resistance. Cell Metab. 10 (5), 405-418. doi: 10.1016/j.cmet.2009.10.004

Lee, J. B., Yoon, S. J., Lee, S. H., Lee, M. S., Jung, H., Kim, T. D., et al. (2017). Ginsenoside Rg3 ameliorated HFD-induced hepatic steatosis through downregulation of STAT5-PPARgamma. J. Endocrinol. 235 (3), 223-235. doi: 10.1530/JOE-17-0233

Lee, S. M., Lee, Y. J., Choi, J. H., Kho, M. C., Yoon, J. J., Shin, S. H., et al. (2014). Gal-geun-dang-gwi-tang improves diabetic vascular complication in apolipoprotein E KO mice fed a western diet. BMC Complement. Altern. Med. 14, 453. doi: 10.1186/1472-6882-14-453

Leem, K. H., Kim, M. G., Hahm, Y. T., and Kim, H. K. (2016). Hypoglycemic effect of Opuntia ficus-indica var. saboten is due to enhanced peripheral glucose uptake through activation of AMPK/p38 MAPK pathway. Nutrients 8 (12), 1-15. doi: $10.3390 /$ nu8120800

Levelt, E., Rodgers, C. T., Clarke, W. T., Mahmod, M., Ariga, R., Francis, J. M., et al. (2016). Cardiac energetics, oxygenation, and perfusion during increased workload in patients with type 2 diabetes mellitus. Eur. Heart J. 37 (46), 34613469. doi: 10.1093/eurheartj/ehv442

Li, D. C., Zhong, X. K., Zeng, Z. P., Jiang, J. G., Li, L., Zhao, M. M., et al. (2009). Application of targeted drug delivery system in Chinese medicine. J. Control Release 138 (2), 103-112. doi: 10.1016/j.jconrel.2009.05.008

Li, J. B., Xu, L. J., Dong, H., Huang, Z. Y., Zhao, Y., Chen, G., et al. (2013). Effects of Chinese Fructus Mume formula and its separated prescription extract on insulin resistance in type 2 diabetic rats. J. Huazhong Univ. Sci. Technol. Med. Sci. 33 (6), 877-885. doi: 10.1007/s11596-013-1215-7

Li, L., Yoshitomi, H., Wei, Y., Qin, L., Zhou, J., Xu, T., et al. (2015). Tang-Nai-Kang alleviates pre-diabetes and metabolic disorders and induces a gene expression switch toward fatty acid oxidation in SHR.Cg-Leprcp/NDmcr rats. PLoS One 10 (4), e0122024. doi: 10.1371/journal.pone.0122024

Li, W., Chen, Q., Xie, Y., Hu, J., Yang, S., and Lin, M. (2018). Prevalence and degree of insulin resistance in Chinese Han women with PCOS: Results from euglycemic-hyperinsulinemic clamps. Clin. Endocrinol. (Oxf). 90 (1), 138-144. doi: $10.1111 /$ cen. 13860

Li, X., Gong, H., Yang, S., Yang, L., Fan, Y., and Zhou, Y. (2017). Pectic bee pollen polysaccharide from Rosa rugosa alleviates diet-induced hepatic steatosis and insulin resistance via induction of AMPK/mTOR-mediated autophagy. Molecules 22 (5), 1-13. doi: 10.3390/molecules22050699

Li, Y., Tran, V. H., Kota, B. P., Nammi, S., Duke, C. C., and Roufogalis, B. D. (2014). Preventative effect of Zingiber officinale on insulin resistance in a high-fat high-carbohydrate diet-fed rat model and its mechanism of action. Basic Clin. Pharmacol. Toxicol. 115 (2), 209-215. doi: 10.1111/bcpt.12196

Li, Y., Xu, S., Mihaylova, M. M., Zheng, B., Hou, X., Jiang, B., et al. (2011). AMPK phosphorylates and inhibits SREBP activity to attenuate hepatic steatosis and atherosclerosis in diet-induced insulin-resistant mice. Cell Metab. 13 (4), 376388. doi: 10.1016/j.cmet.2011.03.009

Li, W., Zhang., S., Liu., H., Wang., L., Zhang., C., Leng., J., et al. (2014). Different associations of diabetes with $\beta$-cell dysfunction and insulin resistance among obese and nonobese chinese women with prior gestational diabetes mellitus. Diabetes Care 37 (9), 2533-2539. doi: 10.2337/dc14-0573

Lian, F., Tian, J., Chen, X., Li, Z., Piao, C., Guo, J., et al. (2015). The efficacy and safety of Chinese herbal medicine Jinlida as add-on medication in type 2 diabetes patients ineffectively managed by metformin monotherapy: a doubleblind, randomized, placebo-controlled, multicenter trial. PLoS One 10 (6), e0130550. doi: 10.1371/journal.pone.0130550

Lillioja, S., Mott, D. M., Spraul, M., Ferraro, R., Foley, J. E., Ravussin, E., et al. (1993). Insulin resistance and insulin secretory dysfunction as precursors of non-insulin-dependent diabetes mellitus. Prospective studies of Pima Indians.\%A Lillioja S. N. Engl. J. Med. 329 (27), 1988-1992. doi: 10.1056/ NEJM199312303292703

Liu, C. Y., Huang, C. J., Huang, L. H., Chen, I. J., Chiu, J. P., and Hsu, C. H. (2014). Effects of green tea extract on insulin resistance and glucagon-like peptide 1 in patients with type 2 diabetes and lipid abnormalities: a randomized, doubleblinded, and placebo-controlled trial. PLoS One 9 (3), e91163. doi: 10.1371/ journal.pone.0091163

Liu, D., Zhang, Y., Liu, Y., Hou, L., Li, S., Tian, H., et al. (2018). Berberine modulates gut microbiota and reduces insulin resistance via the TLR4 signaling pathway. Exp. Clin. Endocrinol. Diabetes 126 (8), 513-520. doi: 10.1055/s-0043-125066

Liu, H. W., Huang, W. C., Yu, W. J., and Chang, S. J. (2015). Toona Sinensis ameliorates insulin resistance via AMPK and PPARgamma pathways. Food Funct. 6 (6), 1855-1864. doi: 10.3390/molecules201219794

Liu, J., Wang, X., Chen, Y.-P., Mao, L.-F., Shang, J., Sun, H.-B., et al. (2014), Maslinic acid modulates glycogen metabolism by enhancing the insulin signaling pathway and inhibiting glycogen phosphorylase. Chin. J. Nat. Med. 12 (4), 259-265. doi: 10.1016/S1875-5364(14)60052-2

Liu, Q., Li, X., Li, C., Zheng, Y., and Peng, G. (2015). 1-Deoxynojirimycin alleviates insulin resistance via activation of insulin signaling PI3K/AKT pathway in skeletal muscle of db/db mice. Molecules 20 (12), 21700-21714. doi: 10.1039/ C5FO00056D

Liu, Q., Liu, S., Gao, L., Sun, S., Huan, Y., Li, C., et al. (2017). Anti-diabetic effects and mechanisms of action of a Chinese herbal medicine preparation JQ-R in vitro and in diabetic KK(Ay) mice. Acta. Pharm. Sin B. 7 (4), 461-469. doi: 10.1016/j.apsb.2017.04.010

Liu, Y., Li, X., Xie, C., Luo, X., Bao, Y., Wu, B., et al. (2016). Prevention effects and possible molecular mechanism of mulberry leaf extract and its formulation on rats with insulin-insensitivity. PLoS One 11 (4), e0152728. doi: 10.1371/journal. pone. 0152728

Liu, Y., Song, A., Zang, S., Wang, C., Song, G., Li, X., et al. (2015). Jinlida reduces insulin resistance and ameliorates liver oxidative stress in high-fat fed rats. J. Ethnopharmacol. 162, 244-252. doi: 10.1016/j.jep.2014.12.040

Liu, Z. Q., Liu, T., Chen, C., Li, M. Y., Wang, Z. Y., Chen, R. S., et al. (2015). Fumosorinone, a novel PTP1B inhibitor, activates insulin signaling in insulin-resistance HepG2 cells and shows anti-diabetic effect in diabetic KKAy mice. Toxicol. Appl. Pharmacol. 285 (1), 61-70. doi: 10.1016/j.taap. 2015.03.011

Liu, Z., Kuang, W., Xu, X., Li, D., Zhu, W., Lan, Z., et al. (2018). Putative identification of components in Zengye decoction and their effects on glucose consumption and lipogenesis in insulin-induced insulin-resistant HepG2 cells. J. Chromatogr. B Analyt. Technol. Biomed. Life Sci. 1073, 145-153. doi: 10.1016/j.jchromb.2017.12.019

Lumeng, C. N., Bodzin, J. L., and Saltiel, A. R. (2007). Obesity induces a phenotypic switch in adipose tissue macrophage polarization. J. Clin. Invest. 117 (1), 175184. doi: 10.1172/JCI29881

Luna-Vital, D., Weiss, M., and Gonzalez de Mejia, E. (2017). Anthocyanins from purple corn ameliorated tumor necrosis factor-alpha-induced inflammation and insulin resistance in 3T3-L1 adipocytes via activation of insulin signaling and enhanced GLUT4 translocation. Mol. Nutr. Food Res. 61 (12), 1-41. doi: 10.1002/mnfr.201700362

Luo, J., Sobkiw, C. L., Hirshman, M. F., Logsdon, M. N., Li, T. Q., Goodyear, L. J., et al. (2006). Loss of class IA PI3K signaling in muscle leads to impaired muscle growth, insulin response, and hyperlipidemia. Cell Metab. 3 (5), 355-366. doi: 10.1016/j.cmet.2006.04.003

Luo, Y. H., Zhu, M., Wang, D. G., Yang, Y. S., Tan, T., Zhu, H., et al. (2018). Yangxin Tongmai formula ameliorates impaired glucose tolerance in children with Graves' disease through upregulation of the insulin receptor levels. Acta. Pharmacol. Sin. 39 (6), 923-929. doi: 10.1038/aps.2017.94 
Ma, C., Yu, H., Xiao, Y., and Wang, H. (2017). Momordica charantia extracts ameliorate insulin resistance by regulating the expression of SOCS-3 and JNK in type 2 diabetes mellitus rats. Pharm. Biol. 55 (1), 2170-2177. doi: 10.1080/13880209.2017.1396350

Manaf, A., Tjandrawinata, R. R., and Malinda, D. (2016). Insulin sensitizer in prediabetes: a clinical study with DLBS3233, a combined bioactive fraction of Cinnamomum burmanii and Lagerstroemia speciosa. Drug Des. Devel. Ther. 10, 1279-1289. doi: 10.2147/DDDT.S97568

Martel, J., Ojcius, D. M., Chang, C. J., Lin, C. S., Lu, C. C., Ko, Y. F., et al. (2017). Anti-obesogenic and antidiabetic effects of plants and mushrooms. Nat. Rev. Endocrinol. 13 (3), 149-160. doi: 10.1038/nrendo.2016.142

Martinez, A., Castro, A., Dorronsoro, I., and Alonso, M. (2002). Glycogen synthase kinase 3 (GSK-3) inhibitors as new promising drugs for diabetes, neurodegeneration, cancer, and inflammation. Med. Res. Rev. 22 (4), 373-384. doi: $10.1002 / \operatorname{med} .10011$

Massaro, M., Scoditti, E., Pellegrino, M., Carluccio, M. A., Calabriso, N., Wabitsch, M., et al. (2016). Therapeutic potential of the dual peroxisome proliferator activated receptor (PPAR)alpha/gamma agonist aleglitazar in attenuating TNFalpha-mediated inflammation and insulin resistance in human adipocytes. Pharmacol. Res. 107, 125-136. doi: 10.1016/j.phrs.2016.02.027

Matheny, R. W., Jr., Geddis, A. V., Abdalla, M. N., Leandry, L. A., Ford, M., McClung, H. L., et al. (2018). AKT2 is the predominant AKT isoform expressed in human skeletal muscle. Physiol. Rep. 6 (6), e13652. doi: 10.14814/phy2.13652

Matthews, D. R., Hosker, J. P., Rudenski, A. S., Naylor, B. A., Treacher, D. F., and Turner, R. C. (1985). Homeostasis model assessment: insulin resistance and beta-cell function from fasting plasma glucose and insulin concentrations in man. Diabetologia 28 (7), 412-419. doi: 10.1007/BF00280883

Meex, R. C. R., and Watt, M. J. (2017). Hepatokines: linking nonalcoholic fatty liver disease and insulin resistance. Nat. Rev. Endocrinol. 13 (9), 509-520. doi: 10.1038/nrendo.2017.56

Mendez-Del Villar, M., Puebla-Perez, A. M., Sanchez-Pena, M. J., Gonzalez-Ortiz, L. J., Martinez-Abundis, E., and Gonzalez-Ortiz, M. (2016). Effect of Artemisia dracunculus administration on glycemic control, insulin sensitivity, and insulin secretion in patients with impaired glucose tolerance. J. Med. Food. 19 (5), 481-485. doi: 10.1089/jmf.2016.0005

Miki, S., Inokuma, K. I., Takashima, M., Nishida, M., Sasaki, Y., Ushijima, M., et al. (2017). Aged garlic extract suppresses the increase of plasma glycated albumin level and enhances the AMP-activated protein kinase in adipose tissue in TSOD mice. Mol. Nutr. Food Res. 61 (5), 1-22. doi: 10.1002/mnfr.201600797

Minokoshi, Y., Alquier, T., Furukawa, N., Kim, Y., Lee, A., Xue, B., et al. (2004). AMP-kinase regulates food intake by responding to hormonal and nutrient signals in the hypothalamus. Nature 428 (6982), 569-574. doi: 10.1038/ nature 02440

Minokoshi, Y., Kim, Y., Peroni, O., Fryer, L., Müller, C., Carling, D., et al. (2002). Leptin stimulates fatty-acid oxidation by activating AMP-activated protein kinase. Nature 415 (6869), 339-343. doi: 10.1038/415339a

Mirfeizi, M., Mehdizadeh Tourzani, Z., Mirfeizi, S. Z., Asghari Jafarabadi, M., Rezvani, H. R., and Afzali, M. (2016). Controlling type 2 diabetes mellitus with herbal medicines: a triple-blind randomized clinical trial of efficacy and safety. J. Diabetes 8 (5), 647-656. doi: 10.1111/1753-0407.12342

Mottillo, E. P., Desjardins, E. M., Crane, J. D., Smith, B. K., Green, A. E., Ducommun, S., et al. (2016). Lack of adipocyte AMPK exacerbates insulin resistance and hepatic steatosis through brown and beige adipose tissue function. Cell Metab. 24 (1), 118-129. doi: 10.1016/j.cmet.2016.06.006

Mozaffari-Khosravi, H., Talaei, B., Jalali, B. A., Najarzadeh, A., and Mozayan, M. R. (2014). The effect of ginger powder supplementation on insulin resistance and glycemic indices in patients with type 2 diabetes: a randomized, double-blind, placebo-controlled trial. Complement. Ther. Med. 22 (1), 9-16. doi: 10.1016/j. ctim.2013.12.017

Na, H. Y., Seol, M. H., Kim, M., and Lee, B. C. (2017). Effect of seyoeum on obesity, insulin resistance, and nonalcoholic fatty liver disease of high-fat diet-fed C57BL/6 Mice. Evid. Based Complement. Alternat. Med. 2017, 4658543. doi: $10.1155 / 2017 / 4658543$

Nan Xia, J., Qin Zhang, D., Du, J., and Wen, J. (2013). Regulation effects of TZQ-F on adipocyte differentiation and insulin action. J. Ethnopharmacol. 150 (2), 692-699. doi: 10.1016/j.jep.2013.09.038

Ng, M., Fleming, T., Robinson, M., Thomson, B., Graetz, N., Margono, C., et al. (2014). Global, regional, and national prevalence of overweight and obesity in children and adults during 1980-2013: a systematic analysis for the Global Burden of Disease Study 2013. Lancet 384 (9945), 766-781. doi: 10.1016/ S0140-6736(14)60460-8

Ng, Y., Ramm, G., Lopez, J. A., and James, D. E. (2008). Rapid activation of Akt2 is sufficient to stimulate GLUT4 translocation in 3T3-L1 adipocytes. Cell Metab. 7 (4), 348-356. doi: 10.1016/j.cmet.2008.02.008

Nie, J., and Chang, Y. (2017). Caffeic acid phenethyl ester (propolis extract) ameliorates insulin resistance by inhibiting JNK and NF-kappaB inflammatory pathways in diabetic mice and HepG2 cell models. J. Agric. Food Chem. 65 (41), 9041-9053. doi: 10.1021/acs.jafc.7b02880

Oh, J., Lee, H., Lim, H., Woo, S., Shin, S. S., and Yoon, M. (2015). The herbal composition GGEx18 from Laminaria japonica, Rheum palmatum, and Ephedra sinica inhibits visceral obesity and insulin resistance by upregulating visceral adipose genes involved in fatty acid oxidation. Pharm. Biol. 53 (2), 301-312. doi: 10.3109/13880209.2014.917328

Ooi, J., Adamu, H. A., Imam, M. U., Ithnin, H., and Ismail, M. (2018). Polyphenolrich ethyl acetate fraction isolated from Molineria latifolia ameliorates insulin resistance in experimental diabetic rats via IRS1/AKT activation. Biomed. Pharmacother. 98, 125-133. doi: 10.1016/j.biopha.2017.12.002

Ozcan, U., Cao, Q., Yilmaz, E., Lee, A., Iwakoshi, N., Ozdelen, E., et al. (2004). Endoplasmic reticulum stress links obesity, insulin action, and type 2 diabetes. Science 306 (5695), 457-461. doi: 10.1126/science.1103160

Pandey, J., Maurya, R., Raykhera, R., Srivastava, M. N., Yadav, P. P., and Tamrakar, A. K. (2014). Murraya koenigii (L). Spreng. ameliorates insulin resistance in dexamethasone-treated mice by enhancing peripheral insulin sensitivity. J. Sci. Food Agric. 94 (11), 2282-2288. doi: 10.1002/jsfa.6555

Parimala, M., Debjani, M., Vasanthi, H. R., and Shoba, F. G. (2015). Nymphaea nouchali Burm. f. hydroalcoholic seed extract increases glucose consumption in 3T3-L1 adipocytes through activation of peroxisome proliferator-activated receptor gamma and insulin sensitization. J. Adv. Pharm. Technol. Res. 6 (4), 183-189. doi: 10.4103/2231-4040.165013

Park, C. H., Kim, D. H., Park, M. H., Kim, M. K., Kim, N. D., Kim, C. M., et al. (2014). Chinese prescription Kangen-karyu and Salviae Miltiorrhizae Radix improve age-related oxidative stress and inflammatory response through the PI3K/Akt or MAPK pathways. Am. J. Chin. Med. 42 (4), 987-1005. doi: 10.1142/S0192415X14500621

Park, E. C., Kim, S. I., Hong, Y., Hwang, J. W., Cho, G. S., Cha, H. N., et al. (2014). Inhibition of CYP4A reduces hepatic endoplasmic reticulum stress and features of diabetes in mice. Gastroenterology 147 (4), 860-869. doi: 10.1053/j. gastro.2014.06.039

Park, S. E., Park, C. Y., and Sweeney, G. (2015). Biomarkers of insulin sensitivity and insulin resistance: Past, present and future. Crit. Rev. Clin. Lab. Sci: 52 (4), 180-190. doi: 10.3109/10408363.2015.1023429

Patel, S., and Woodgett, J. (2008). Glycogen synthase kinase-3 and cancer: good cop, bad cop? Cancer Cell. 14 (5), 351-353. doi: 10.1016/j.ccr.2008.10.013

Peraldi, P., Xu, M., and Spiegelman, B. (1997). Thiazolidinediones block tumor necrosis factor-alpha-induced inhibition of insulin signaling. J. Clin. Invest. 100 (7), 1863-1869. doi: 10.1172/JCI119715

Perez-Rubio, K. G., Gonzalez-Ortiz, M., Martinez-Abundis, E., Robles-Cervantes, J. A., and Espinel-Bermudez, M. C. (2013). Effect of berberine administration on metabolic syndrome, insulin sensitivity, and insulin secretion. Metab. Syndr. Relat. Disord. 11 (5), 366-369. doi: 10.1089/met.2012.0183

Qiang, G., Wenzhai, C., Huan, Z., Yuxia, Z., Dongdong, Y., Sen, Z., et al. (2015). Effect of Sancaijiangtang on plasma nitric oxide and endothelin-1 levels in patients with type 2 diabetes mellitus and vascular dementia: a single-blind randomized controlled trial. J. Tradit. Chin. Med. 35 (4), 375-380. doi: 10.1016/ S0254-6272(15)30112-6

Qin, J. H., Ma, J. Z., Yang, X. W., Hu, Y. J., Zhou, J., Fu, L. C., et al. (2015). A triterpenoid inhibited hormone-induced adipocyte differentiation and alleviated dexamethasone-induced insulin resistance in 3T3-L1 adipocytes. Nat. Prod. Bioprospect. 5 (3), 159-166. doi: 10.1007/s13659-015-0063-5

Rabiei, K., Ebrahimzadeh, M. A., Saeedi, M., Bahar, A., Akha, O., and Kashi, Z. (2018). Effects of a hydroalcoholic extract of Juglans regia (walnut) leaves on blood glucose and major cardiovascular risk factors in type 2 diabetic patients: a double-blind, placebo-controlled clinical trial. BMC Complement. Altern. Med. 18 (1), 206. doi: 10.1186/s12906-018-2268-8

Rafraf, M., Zemestani, M., and Asghari-Jafarabadi, M. (2015). Effectiveness of chamomile tea on glycemic control and serum lipid profile in patients 
with type 2 diabetes. J. Endocrinol. Invest. 38 (2), 163-170. doi: 10.1007/ s40618-014-0170-x

Reeds, D. N., Patterson, B. W., Okunade, A., Holloszy, J. O., Polonsky, K. S., and Klein, S. (2011). Ginseng and ginsenoside Re do not improve beta-cell functionor insulin sensitivity in overweight and obese subjects with impaired glucosetolerance or diabetes. Diabetes Care 34, 1071-1076. doi: 10.2337/dc10-2299

Richard, A. J., Burris, T. P., Sanchez-Infantes, D., Wang, Y., Ribnicky, D. M., and Stephens, J. M. (2014). Artemisia extracts activate PPARgamma, promote adipogenesis, and enhance insulin sensitivity in adipose tissue of obese mice. Nutrition 30 (7-8 Suppl), S31-36. doi: 10.1016/j.nut.2014.02.013

Richter, E., and Hargreaves, M. (2013). Exercise, GLUT4, and skeletal muscle glucose uptake. Physiol. Rev. 93 (3), 993-1017. doi: 10.1152/physrev.00038.2012

Riehle, C., and Abel, E. D. (2016). Insulin signaling and heart failure. Circ. Res. 118 (7), 1151-1169. doi: 10.1161/CIRCRESAHA.116.306206

Rinella, M. E. (2015). Nonalcoholic fatty liver disease: a systematic review. JAMA 313 (22), 2263-2273. doi: 10.1001/jama.2015.5370

Roshan, H., Nikpayam, O., Sedaghat, M., and Sohrab, G. (2018). Effects of green coffee extract supplementation on anthropometric indices, glycaemic control, blood pressure, lipid profile, insulin resistance and appetite in patients with the metabolic syndrome: a randomised clinical trial. Br. J. Nutr. 119 (3), 250-258. doi: $10.1017 /$ S0007114517003439

Rui, L., Aguirre, V., Kim, J., Shulman, G., Lee, A., Corbould, A., et al. (2001). Insulin/IGF- 1 and TNF-alpha stimulate phosphorylation of IRS-1 at inhibitory Ser307 via distinct pathways. J. Clin. Invest. 107 (2), 181-189. doi: 10.1172/ JCI10934

Saad, M., Araki, E., Miralpeix, M., Rothenberg, P., White, M., and Kahn, C. (1992). Regulation of insulin receptor substrate-1 in liver and muscle of animal models of insulin resistance. J. Clin. Invest. 90 (5), 1839-1849. doi: 10.1172/JCI116060

Sabio, G., Cavanagh-Kyros, J., Ko, H., Jung, D., Gray, S., Jun, J., et al. (2009). Prevention of steatosis by hepatic JNK1. Cell Metab. 10 (6), 491-498. doi: 10.1016/j.cmet.2009.09.007

Saito, T., Nishida, M., Saito, M., Tanabe, A., Eitsuka, T., Yuan, S. H., et al. (2016). The fruit of Acanthopanax senticosus (Rupr. et Maxim). Harms improves insulin resistance and hepatic lipid accumulation by modulation of liver adenosine monophosphate-activated protein kinase activity and lipogenic gene expression in high-fat diet-fed obese mice. Nutr. Res. 36 (10), 1090-1097. doi: 10.1016/j.nutres.2016.09.004

Saltiel, A., and Kahn, C. (2001). Insulin signalling and the regulation of glucose and lipid metabolism. Nature 414 (6865), 799-806. doi: 10.1038/414799a

Samadi, N., Mozaffari-Khosravi, H., Rahmanian, M., and Askarishahi, M. (2017). Effects of bee propolis supplementation on glycemic control, lipid profile and insulin resistance indices in patients with type 2 diabetes: a randomized, double-blind clinical trial. J. Integr. Med. 15 (2), 124-134. doi: 10.1016/ S2095-4964(17)60315-7

Samuel, V. T., and Shulman, G. I. (2016). The pathogenesis of insulin resistance: integrating signaling pathways and substrate flux. J. Clin. Invest. 126 (1), 12-22. doi: 10.1172/JCI77812

Sano, H., Eguez, L., Teruel, M. N., Fukuda, M., Chuang, T. D., Chavez, J. A., et al. (2007). Rab10, a target of the AS160 Rab GAP, is required for insulinstimulated translocation of GLUT4 to the adipocyte plasma membrane. Cell Metab. 5 (4), 293-303. doi: 10.1016/j.cmet.2007.03.001

Sasaki, H., Asanuma, H., Fujita, M., Takahama, H., Wakeno, M., Ito, S., et al. (2009). Metformin prevents progression of heart failure in dogs: role of AMP-activated protein kinase. Circulation 119 (19), 2568-2577. doi: 10.1161/ CIRCULATIONAHA.108.798561

Sathiyabama, R. G., Rajiv Gandhi, G., Denadai, M., Sridharan, G., Jothi, G., Sasikumar, P., et al. (2018). Evidence of insulin-dependent signalling mechanisms produced by Citrus sinensis (L). Osbeck fruit peel in an insulin resistant diabetic animal model. Food Chem. Toxicol. 116 (Pt B), 86-99. doi: 10.1016/j.fct.2018.03.050

Seki, E., Brenner, D. A., and Karin, M. (2012). A liver full of JNK: signaling in regulation of cell function and disease pathogenesis, and clinical approaches. Gastroenterology 143 (2), 307-320. doi: 10.1053/j.gastro.2012.06.004

Seo, E., Kim, S., Lee, S. J., Oh, B. C., and Jun, H. S. (2015). Ginseng berry extract supplementation improves age-related decline of insulin signaling in mice. Nutrients 7 (4), 3038-3053. doi: 10.3390/nu7043038

Seo, H. A., and Lee, I. K. (2013). The role of Nrf2: adipocyte differentiation, obesity, and insulin resistance. Oxid. Med. Cell Longev. 2013, 184598. doi: $10.1155 / 2013 / 184598$
Shen, Y., Honma, N., Kobayashi, K., Jia, L. N., Hosono, T., Shindo, K., et al. (2014). Cinnamon extract enhances glucose uptake in 3T3-L1 adipocytes and $\mathrm{C} 2 \mathrm{C} 12$ myocytes by inducing LKB1-AMP-activated protein kinase signaling. PLoS One 9 (2), e87894. doi: 10.1371/journal.pone.0087894

Shi, X., Zhou, F., Li, X., Chang, B., Li, D., Wang, Y., et al. (2013). Central GLP-2 enhances hepatic insulin sensitivity via activating PI3K signaling in POMC neurons. Cell Metab. 18 (1), 86-98. doi: 10.1016/j.cmet.2013.06.014

Shi, Y. L., Liu, W. J., Zhang, X. F., Su, W. J., Chen, N. N., Lu, S. H., et al. (2016). Effect of Chinese herbal medicine Jinlida granule in treatment of patients with impaired glucose tolerance. Chin. Med. J. (Engl) 129 (19), 2281-2286. doi: 10.4103/0366-6999.190676

Shimomura, I., Matsuda, M., Hammer, R., Bashmakov, Y., Brown, M., and Goldstein, J. (2000). Decreased IRS-2 and increased SREBP-1c lead to mixed insulin resistance and sensitivity in livers of lipodystrophic and ob/ob mice. Mol. Cell 6 (1), 77-86. doi: 10.1016/S1097-2765(05)00010-9

Singh, J., and Kakkar, P. (2013). Modulation of liver function, antioxidant responses, insulin resistance and glucose transport by Oroxylum indicum stem bark in STZ induced diabetic rats. Food Chem. Toxicol. 62, 722-731. doi: 10.1016/j.fct.2013.09.035

Siwicki, M., Engblom, C., and Pittet, M. J. (2016). Gal3 links inflammation and insulin resistance. Cell Metab. 24 (5), 655-656. doi: 10.1016/j.cmet.2016.10.014

Stenbit, A., Tsao, T., Li, J., Burcelin, R., Geenen, D., Factor, S., et al. (1997). GLUT4 heterozygous knockout mice develop muscle insulin resistance and diabetes. Nat. Med. 3 (10), 1096-1101. doi: 10.1038/nm1097-1096

Sun, X., Sun, H., Zhang, J., and Ji, X. (2016). Artemisia extract improves insulin sensitivity in women with gestational diabetes mellitus by up-regulating adiponectin. J. Clin. Pharmacol. 56 (12), 1550-1554. doi: 10.1002/jcph.755

Sun, Z., Zhan, L., Liang, L., Sui, H., Zheng, L., Sun, X., et al. (2016). ZiBu PiYin recipe prevents diabetes-associated cognitive decline in rats: possible involvement of ameliorating mitochondrial dysfunction, insulin resistance pathway and histopathological changes. BMC Complement. Altern. Med. 16, 200. doi: 10.1186/s12906-016-1177-y

Szendroedi, J., Phielix, E., and Roden, M. (2011). The role of mitochondria in insulin resistance and type 2 diabetes mellitus. Nat. Rev. Endocrinol: 8 (2), 92-103. doi: $10.1038 /$ nrendo.2011.138

Talbot, K., and Wang, H. Y. (2014). The nature, significance, and glucagon-like peptide-1 analog treatment of brain insulin resistance in Alzheimer's disease. Alzheimers Dement. 10 (1 Suppl), S12-25. doi: 10.1016/j.jalz.2013.12.007

Tamemoto, H., Kadowaki, T., Tobe, K., Yagi, T., Sakura, H., Hayakawa, T., et al. (1994). Insulin resistance and growth retardation in mice lacking insulin receptor substrate-1. Nature 372 (6502), 182-186. doi: 10.1038/372182a0

Tang, M., Gao, G., Rueda, C. B., Yu, H., Thibodeaux, D. N., Awano, T., et al. (2017). Brain microvasculature defects and Glutl deficiency syndrome averted by early repletion of the glucose transporter-1 protein. Nat. Commun. 8, 14152. doi: $10.1038 /$ ncomms 14152

Taniguchi, C., Ueki, K., and Kahn, R. (2005). Complementary roles of IRS-1 and IRS-2 in the hepatic regulation of metabolism. J. Clin. Invest. 115 (3), 718-727. doi: 10.1172/JCI23187

Thorens, B., Wu, Y., Leahy, J., and Weir, G. (1992). The loss of GLUT2 expression by glucose-unresponsive beta cells of $\mathrm{db} / \mathrm{db}$ mice is reversible and is induced by the diabetic environment. J. Clin. Invest. 90 (1), 77-85. doi: 10.1172/JCI115858

Tiganis, T. (2013). PTP1B and TCPTP - nonredundant phosphatases in insulin signaling and glucose homeostasis. FEBS J. 280 (2), 445-458. doi: 10.1111/j.1742-4658.2012.08563.x

Tuttle, R., Gill, N., Pugh, W., Lee, J., Koeberlein, B., Furth, E., et al. (2001). Regulation of pancreatic beta-cell growth and survival by the serine/threonine protein kinase Akt1/PKBalpha. Nat. Med. 7 (10), 1133-1137. doi: 10.1038/ nm1001-1133

Vallerie, S., and Hotamisligil, G. (2010). The role of JNK proteins in metabolism. Sci. Transl. Med. 2 (60), 60rv65. doi: 10.1126/scitranslmed.3001007

Wang, C., Li, Y., Hao, M., and Li, W. (2018). Astragaloside IV inhibits triglyceride accumulation in insulin-resistant HepG2 cells via AMPK-induced SREBP-1c phosphorylation. Front. Pharmacol. 9, 345. doi: 10.3389/fphar.2018.00345

Wang, L. H., Wang, X., Yu, X. Z., and Xu, W. T. (2016). Potent therapeutic effects of shouwu jiangqi decoction on polycystic ovary syndrome with insulin resistance in rats. Chin. J. Integr. Med. 22 (2), 116-123. doi: 10.1007/s11655-015-2147-9

Wang, L., Ye, X., Hua, Y., and Song, Y. (2018). Berberine alleviates adipose tissue fibrosis by inducing AMP-activated kinase signaling in high-fat 
diet-induced obese mice. Biomed. Pharmacother. 105, 121-129. doi: 10.1016/j. biopha.2018.05.110

Wang, X. A., Zhang, R., She, Z. G., Zhang, X. F., Jiang, D. S., Wang, T., et al. (2014). Interferon regulatory factor 3 constrains IKKbeta/NF-kappaB signaling to alleviate hepatic steatosis and insulin resistance. Hepatology 59 (3), 870-885. doi: 10.1002/hep.26751

Wang, Z. Q., Zhang, X. H., Yu, Y., Tipton, R. C., Raskin, I., Ribnicky, D., et al. (2013). Artemisia scoparia extract attenuates non-alcoholic fatty liver disease in diet-induced obesity mice by enhancing hepatic insulin and AMPK signaling independently of FGF21 pathway. Metabolism 62 (9), 1239-1249. doi: 10.1016/j.metabol.2013.03.004

Watt, M. J., Dzamko, N., Thomas, W. G., Rose-John, S., Ernst, M., Carling, D., et al. (2006). CNTF reverses obesity-induced insulin resistance by activating skeletal muscle AMPK. Nat. Med. 12 (5), 541-548. doi: 10.1038/nm1383

Wen, H., Gris, D., Lei, Y., Jha, S., Zhang, L., Huang, M. T., et al. (2011). Fatty acid-induced NLRP3-ASC inflammasome activation interferes with insulin signaling. Nat. Immunol. 12 (5), 408-415. doi: 10.1038/ni.2022

Wensveen, F. M., Jelencic, V., Valentic, S., Sestan, M., Wensveen, T. T., Theurich, S., et al. (2015). NK cells link obesity-induced adipose stress to inflammation and insulin resistance. Nat. Immunol. 16 (4), 376-385. doi: 10.1038/ni.3120

White, M. (2003). Insulin signaling in health and disease. Science 302 (5651), 1710-1711. doi: 10.1126/science. 1092952

Willette, A. A., Johnson, S. C., Birdsill, A. C., Sager, M. A., Christian, B., Baker, L. D., et al. (2015). Insulin resistance predicts brain amyloid deposition in late middle-aged adults. Alzheimers Dement. 11 (5), 504-510 e501. doi: 10.1016/j. jalz.2014.03.011

Winer, D. A., Luck, H., Tsai, S., and Winer, S. (2016). The intestinal immune system in obesity and insulin resistance. Cell Metab. 23 (3), 413-426. doi: 10.1016/j. cmet.2016.01.003

Winnay, J., Solheim, M., Dirice, E., Sakaguchi, M., Noh, H., Kang, H., et al. (2016). PI3-kinase mutation linked to insulin and growth factor resistance in vivo. J. Clin. Invest. 126 (4), 1401-1412. doi: 10.1172/JCI84005

Woerdeman, J., Del Rio, D., Calani, L., Eringa, E. C., Smulders, Y. M., and Serne, E. H. (2018). Red wine polyphenols do not improve obesity-associated insulin resistance: a randomized controlled trial. Diabetes Obes. Metab. 20 (1), 206210. doi: $10.1111 /$ dom. 13044

Wood, I. S., and Trayhurn, P. (2003). Glucose transporters (GLUT and SGLT): expanded families of sugar transport proteins. Br. J. Nutr. 89 (1), 3-9. doi: 10.1079/BJN2002763

Xiao, B., Heath, R., Saiu, P., Leiper, F. C., Leone, P., Jing, C., et al. (2007). Structural basis for AMP binding to mammalian AMP-activated protein kinase. Nature 449 (7161), 496-500. doi: 10.1038/nature06161

Xiao, B., Sanders, M. J., Underwood, E., Heath, R., Mayer, F. V., Carmena, D., et al. (2011). Structure of mammalian AMPK and its regulation by ADP. Nature 472 (7342), 230-233. doi: 10.1038/nature09932

Xiao, N., Yang, L. L., Yang, Y. L., Liu, L. W., Li, J., Liu, B., et al. (2017). Ginsenoside Rg5 inhibits succinate-associated lipolysis in adipose tissue and prevents muscle insulin resistance. Front. Pharmacol. 8, 43. doi: 10.3389/fphar.2017.00043

Xing, Q., and Chen, Y. (2018). Antidiabetic effects of a Chinese herbal medicinal compound Sangguayin preparation via PI3K/Akt signaling pathway in $\mathrm{db} / \mathrm{db}$ mice. Evid. Based Complement. Alternat. Med. 2018, 2010423. doi: $10.1155 / 2018 / 2010423$

$\mathrm{Xu}$, J., Pan, F., and Xu, H. (2015). [Effect of Zhenggan Tang decoction on the serum levels of leptin, adiponectin and insulin resistance on HBV-induced cirrhotic patients]. Zhonghua Liu Xing Bing Xue Za Zhi. 36 (4), 399-401.

Yagishita, Y., Uruno, A., Fukutomi, T., Saito, R., Saigusa, D., Pi, J., et al. (2017). Nrf2 improves leptin and insulin resistance provoked by hypothalamic oxidative stress. Cell Rep. 18 (8), 2030-2044. doi: 10.1016/j.celrep.2017.01.064

Yan, F., Dai, G., and Zheng, X. (2016). Mulberry anthocyanin extract ameliorates insulin resistance by regulating PI3K/AKT pathway in HepG2 cells and db/db mice. J. Nutr. Biochem. 36, 68-80. doi: 10.1016/j.jnutbio.2016.07.004

Yan, J., Wang, C., Jin, Y., Meng, Q., Liu, Q., Liu, Z., et al. (2018). Catalpol ameliorates hepatic insulin resistance in type 2 diabetes through acting on AMPK/NOX4/PI3K/AKT pathway. Pharmacol. Res. 130, 466-480. doi: 10.1016/j.phrs.2017.12.026

Yang, J., Leng, J., Li, J. J., Tang, J. F., Li, Y., Liu, B. L., et al. (2016). Corosolic acid inhibits adipose tissue inflammation and ameliorates insulin resistance via
AMPK activation in high-fat fed mice. Phytomedicine 23 (2), 181-190. doi: 10.1016/j.phymed.2015.12.018

Yang, J.-L., Wang, J.-L., Huang, F., Liu, K., and Liu, B.-L. (2014). Modified Si-MiaoSan inhibits inflammation and promotes glucose disposal in adipocytes through regulation of AMP-kinase. Chin. J. Nat. Med. 12 (12), 911-919. doi: 10.1016/S1875-5364(14)60134-5

Yang, S. J., Choi, J. M., Park, S. E., Rhee, E. J., Lee, W. Y., Oh, K. W., et al. (2015). Preventive effects of bitter melon (Momordica charantia) against insulin resistance and diabetes are associated with the inhibition of NF-kappaB and JNK pathways in high-fat-fed OLETF rats. J. Nutr. Biochem. 26 (3), 234-240. doi: 10.1016/j.jnutbio.2014.10.010

Yang, X., Li, L., Fang, K., Dong, R., Li, J., Zhao, Y., et al. (2017). Wu-Mei-Wan reduces insulin resistance via inhibition of NLRP3 inflammasome activation in HepG2 cells. Evid. Based Complement. Alternat. Med. 2017, 7283241. doi: $10.1155 / 2017 / 7283241$

Yang, Y., Li, W., Li, Y., Wang, Q., Gao, L., and Zhao, J. (2014). Dietary Lycium barbarum polysaccharide induces Nrf2/ARE pathway and ameliorates insulin resistance induced by high-fat via activation of PI3K/AKT signaling. Oxid. Med. Cell Longev. 2014, 145641. doi: 10.1155/2014/145641

Yang, Z., Wu, F., He, Y., Zhang, Q., Zhang, Y., Zhou, G., et al. (2018). A novel PTP1B inhibitor extracted from Ganoderma lucidum ameliorates insulin resistance by regulating IRS1-GLUT4 cascades in the insulin signaling pathway. Food Funct. 9 (1), 397-406. doi: 10.1039/C7FO01489A

Yao, L., Wei, J., Shi, S., Guo, K., Wang, X., Wang, Q., et al. (2017). Modified lingguizhugan decoction incorporated with dietary restriction and exercise ameliorates hyperglycemia, hyperlipidemia and hypertension in a rat model of the metabolic syndrome. BMC Complement. Altern. Med. 17 (1), 132. doi: 10.1186/s12906-017-1557-y

You, H. N., Park, M. H., Hwang, S. Y., and Han, J. S. (2018). Nardostachys jatamansi DC extract alleviates insulin resistance and regulates glucose metabolism in $\mathrm{C} 57 \mathrm{BL} / \mathrm{KsJ}-\mathrm{db} / \mathrm{db}$ mice through the AMP-activated protein kinase signaling pathway. J. Med. Food. 21 (4), 324-331. doi: 10.1089/jmf.2017.4015

Yu, N., Fang, X., Zhao, D., Mu, Q., Zuo, J., Ma, Y., et al. (2017). Anti-diabetic effects of Jiang Tang Xiao Ke granule via PI3K/Akt signalling pathway in type 2 diabetes KKAy mice. PLoS One 12 (1), e0168980. doi: 10.1371/journal. pone. 0168980

Yu, S. H., Chen, S. Y., Li, W. S., Dubey, N. K., Chen, W. H., Chuu, J. J., et al. (2015). Hypoglycemic activity through a novel combination of fruiting body and mycelia of Cordyceps militaris in high-fat diet-induced type 2 diabetes mellitus mice. J. Diabetes Res. 2015, 723190. doi: 10.1155/2015/723190

Yu, X., Xu, L., Zhou, Q., Wu, S., Tian, J., Piao, C., et al. (2018). The efficacy and safety of the Chinese herbal formula, JTTZ, for the treatment of type 2 diabetes with obesity and hyperlipidemia: a multicenter randomized, positivecontrolled, open-label clinical trial. Int. J. Endocrinol. 2018, 9519231. doi: $10.1155 / 2018 / 9519231$

Yu, Y., Zhao, Y., Teng, F., Li, J., Guan, Y., Xu, J., et al. (2018). Berberine improves cognitive deficiency and muscular dysfunction via activation of the AMPK/ SIRT1/PGC-1a pathway in skeletal muscle from naturally aging rats. J. Nutr. Health Aging 22 (6), 710-717. doi: 10.1007/s12603-018-1015-7

Yuan, Y., Wang, X., Lu, X., Marunaka, Y., and Wang, X. (2014). Effect of Coptidis Rhizoma extracts in a water-based solution on insulin resistance in 3T3-L1 adipocytes. Biomed. Res. 35 (5), 321-327. doi: 10.2220/biomedres.35.321

Zanquetta, M., Seraphim, P., Sumida, D., Cipolla-Neto, J., and Machado, U. (2003). Calorie restriction reduces pinealectomy-induced insulin resistance by improving GLUT4 gene expression and its translocation to the plasma membrane. J. Pineal. Res. 35 (3), 141-148. doi: 10.1034/j.1600-079X.2003.00067.x

Zhang, L., Xu, J., Song, H., Yao Z., and Ji, G. (2014). Extracts from SalviaNelumbinis naturalis alleviate hepatosteatosis via improving hepatic insulin sensitivity. J. Transl. Med. 12 (1479-5876 (Electronic)), 236-247. doi: 10.1186/ s12967-014-0236-8

Zhang, H., Ta, N., Chen, P., and Wang, H. (2017). Erchen decoction and Linguizhugan decoction ameliorate hepatic insulin resistance by inhibiting IRS-1Ser307 phosphorylation in vivo and in vitro. Evid. Based Complement. Alternat. Med. 2017, 1589871. doi: 10.1155/2017/1589871

Zhang, P., Lu, J., Jing, Y., Tang, S., Zhu, D., and Bi, Y. (2017). Global epidemiology of diabetic foot ulceration: a systematic review and meta-analysis (dagger). Ann. Med. 49 (2), 106-116. doi: 10.1080/07853890.2016.1231932 
Zhang, T. (2015). Effect of Qingre Yangyin recipe on endocrine and metabolism of polycystic ovary syndrome patients. Zhongguo Zhong Xi Yi Jie He Za Zhi. 35 (10), 1175-1180

Zhang, Z., Zhou, S., Jiang, X., Wang, Y. H., Li, F., Wang, Y. G., et al. (2015). The role of the Nrf2/Keap1 pathway in obesity and metabolic syndrome. Rev. Endocr. Metab. Disord. 16 (1), 35-45. doi: 10.1007/s11154-014-9305-9

Zhao, H., Huang, X., Jiao, J., Zhang, H., Liu, J., Qin, W., et al. (2015). Protein phosphatase 4 (PP4) functions as a critical regulator in tumor necrosis factor (TNF)-alpha-induced hepatic insulin resistance. Sci. Rep. 5, 18093. doi: 10.1038/srep18093

Zhao, H., Zhou, D., Chen, Y., Liu, D., Chu, S., and Zhang, S. (2017). Beneficial effects of Heqi san on rat model of polycystic ovary syndrome through the PI3K/AKT pathway. Daru. 25 (1), 21. doi: 10.1186/s40199-017-0188-7

Zhao, L., Fu, Z., Wu, J., Aylor, K. W., Barrett, E. J., Cao, W., et al. (2015). Globular adiponectin ameliorates metabolic insulin resistance via AMPK-mediated restoration of microvascular insulin responses. J. Physiol. 593 (17), 4067-4079. doi: 10.1113/JP270371

Zhao, R., Qiu, B., Li, Q., Zhang, T., Zhao, H., Chen, Z., et al. (2014). LBP-4a improves insulin resistance via translocation and activation of GLUT4 in OLETF rats. Food Funct. 5 (4), 811-820. doi: 10.1039/C3FO60602C

Zhao, W., Wang, M., Shao, L., Liao, M., Liu, K., Huang, F., et al. (2014). The total phenolic fraction of Anemarrhena asphodeloides inhibits inflammation and reduces insulin resistance in adipocytes via regulation of AMP-kinase activity. Planta Med. 80 (2-3), 146-152. doi: 10.1055/s-0033-1360197

Zhen, Z., Chang, B., Li, M., Lian, F. M., Chen, L., Dong, L., et al. (2011). Antidiabetic effects of a Coptis chinensis containing new traditional Chinese medicine formula in type 2 diabetic rats. Am. J. Chin. Med. 39 (1), 53-63. doi: 10.1142/S0192415X11008646

Zheng, Y., Ley, S. H., and Hu, F. B. (2018). Global aetiology and epidemiology of type 2 diabetes mellitus and its complications. Nat. Rev. Endocrinol. 14 (2), 88-98. doi: 10.1038/nrendo.2017.151

Zhou, B., Lu, Y., Hajifathalian, K., Bentham, J., Di Cesare, M., Danaei, G., et al. (2016). Worldwide trends in diabetes since 1980: a pooled analysis of 751 population-based studies with 4.4 million participants. Lancet 387 (10027), 1513-1530. doi: 10.1016/S0140-6736(16)00618-8

Zhou, Q., Chang, B., Chen, X. Y., Zhou, S. P., Zhen, Z., Zhang, L. L., et al. (2014). Chinese herbal medicine for obesity: a randomized, double-blinded, multicenter, prospective trial. Am. J. Chin. Med. 42 (6), 1345-1356. doi: 10.1142/S0192415X14500840

Zhu, L., Zhu, X., Sun, G., Meng, X., Wang, M., Cui, H., et al. (2018). Dai-ZongFang, a traditional chinese herbal formula, ameliorates insulin resistance in $\mathrm{db} /$ db Mice. Front. Physiol. 9, 224. doi: 10.3389/fphys.2018.00224

Zhu, R., Zheng, J., Chen, L., Gu, B., and Huang, S. (2016). Astragaloside IV facilitates glucose transport in $\mathrm{C} 2 \mathrm{C} 12$ myotubes through the IRS1/AKT pathway and suppresses the palmitate-induced activation of the IKK/IkappaBalpha pathway. Int. J. Mol. Med. 37 (6), 1697-1705. doi: 10.3892/ijmm.2016.2555

Zisman, A., Peroni, O., Abel, E., Michael, M., Mauvais-Jarvis, F., Lowell, B., et al. (2000). Targeted disruption of the glucose transporter 4 selectively in muscle causes insulin resistance and glucose intolerance. Nat. Med. 6 (8), 924-928. doi: 10.1038/78693

Zou, X., Huang, W., Lu, F., Fang, K., Wang, D., Zhao, S., et al. (2017). The effects of Jiao-Tai-Wan on sleep, inflammation and insulin resistance in obesity-resistant rats with chronic partial sleep deprivation. BMC Complement. Altern. Med. 17 (1), 165. doi: 10.1186/s12906-017-1648-9

Zulet, M. A., Navas-Carretero, S., Lara y Sanchez, D., Abete, I., Flanagan, J., Issaly, N., et al. (2014). A Fraxinus excelsior L. seeds/fruits extract benefits glucose homeostasis and adiposity related markers in elderly overweight/ obese subjects: a longitudinal, randomized, crossover, double-blind, placebocontrolled nutritional intervention study. Phytomedicine 21 (10), 1162-1169. doi: 10.1016/j.phymed.2014.04.027

Zuniga, L. Y., Gonzalez-Ortiz, M., and Martinez-Abundis, E. (2017). Effect of Gymnema sylvestre administration on metabolic syndrome, insulin sensitivity, and insulin secretion. J. Med. Food. 20 (8), 750-754. doi: 10.1089/jmf.2017.0001

Conflict of Interest Statement: The authors declare that the research was conducted in the absence of any commercial or financial relationships that could be construed as a potential conflict of interest.

Copyright (C) 2019 Li, Bai, Wei, Zhao, Wang, Xiao, Yan and Wei. This is an open-access article distributed under the terms of the Creative Commons Attribution License (CC $B Y)$. The use, distribution or reproduction in other forums is permitted, provided the original author(s) and the copyright owner(s) are credited and that the original publication in this journal is cited, in accordance with accepted academic practice. No use, distribution or reproduction is permitted which does not comply with these terms. 